\title{
Peut-on se passer du cuivre en protection des cultures biologiques?
}

Expertise scientifique collective

Didier Andrivon, Isabelle Savini, coord.

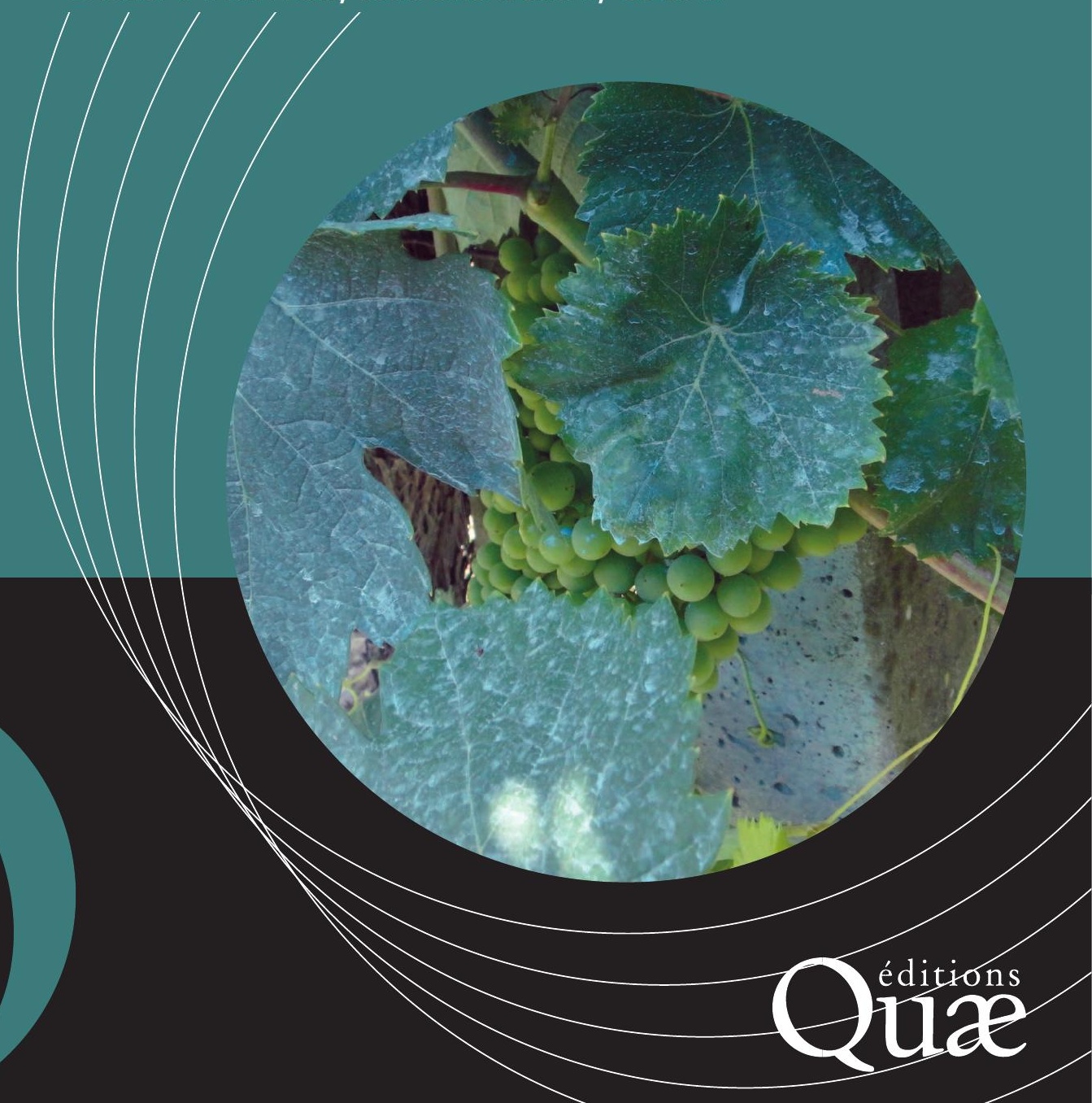





\section{Peut-on se passer}

du cuivre en protection

des cultures biologiques?

Expertise scientifique collective

Didier Andrivon, Isabelle Savini, coord.

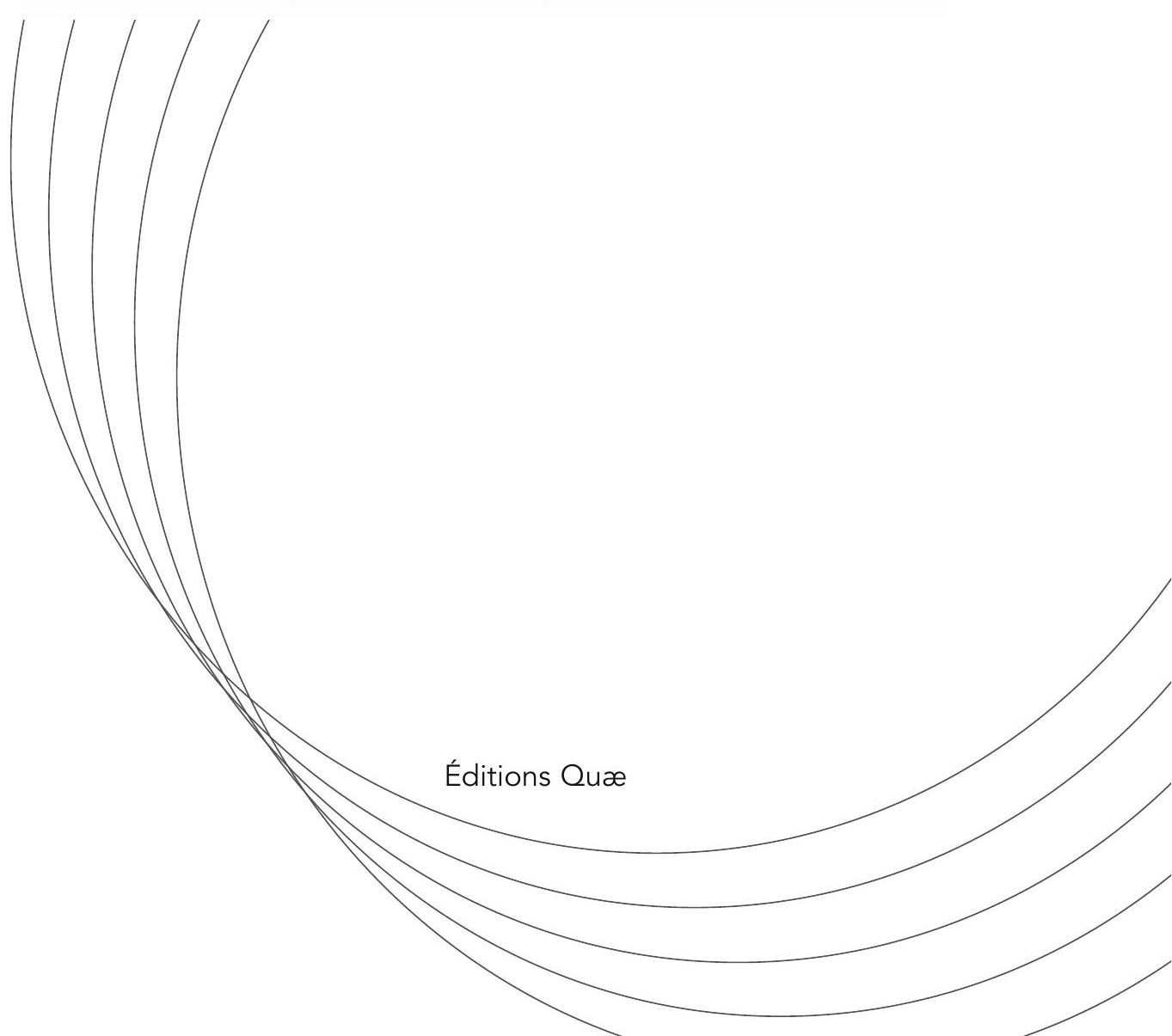


Expertise réalisée à la demande du métaprogramme « Gestion durable de la santé des cultures » de l'Inra et de l'Institut technique de l'agriculture biologique.

Le rapport d'expertise, source de cette synthèse, a été élaboré par les experts scientifiques sans condition d'approbation préalable par les commanditaires ou l'Inra. La synthèse a été validée par les auteurs du rapport.

Ces documents sont disponibles sur le site web institutionnel de l'Inra (www.inra.fr).

\title{
Responsable scientifique :
}

Didier Andrivon, Inra, département Santé des plantes et environnement, Rennes

Suivi du projet, rédaction et coordination éditoriale :

Isabelle Savini, Inra, Délégation à l'expertise, à la prospective et aux études (DEPE)

\section{Contacts :}

Didier Andrivon : didier.andrivon@inra.fr

Isabelle Savini : isabelle.savini@inra.fr

\section{Directeur de la publication :}

Guy Richard, Inra, Directeur de la Délégation à l'expertise, à la prospective et aux études (DEPE)

\section{Pour citer cet ouvrage :}

Andrivon D., Bardin M., Bertrand C., Brun L., Daire X., Fabre F., Gary C., Montarry J., Nicot P., Reignault P., Tamm L., Savini I., 2019. Peut-on se passer du cuivre en protection des cultures biologiques ?Éditions Quæ, 126 p.

En couverture : crédit photo wikimedia - Pg1945.

\author{
Éditions Quæ \\ RD 10, 78026 Versailles Cedex \\ www.quae.com \\ (C) Éditions Quæ, 2019
}

ISBN : 978-2-7592-2997-0 elSBN : 978-2-7592-2998-7 $\quad x I S B N ~: ~ 978-2-7592-2999-4$

Le Code de la propriété intellectuelle interdit la photocopie à usage collectif sans autorisation des ayants droit. Le non-respect de cette disposition met en danger l'édition, notamment scientifique, et est sanctionné pénalement. Toute reproduction, même partielle, du présent ouvrage est interdite sans autorisation du Centre français d'exploitation du droit de copie (CFC), 20 rue des GrandsAugustins, Paris $6^{\mathrm{e}}$. 


\section{Table des matières}

Introduction

1. Éléments de contexte

Le cuivre : propriétés et utilisations

Les alternatives au cuivre : nature et réglementation

2. Les méthodes alternatives à l'usage du cuivre 25

Les préparations naturelles biocides 25

Les agents microbiologiques de biocontrôle 33

Les résistances variétales $\quad 41$

Les stimulateurs des défenses naturelles des plantes 61

L'isothérapie, les préparations homéopathiques et biodynamiques 70

3. La gestion agronomique des risques phytosanitaires $\quad 75$

Les méthodes prophylactiques $\quad 75$

La protection physique contre les infections 80

La conduite des plantes et des couverts 82

Éléments de conclusion $\quad 84$

4. L'insertion des leviers alternatifs dans des systèmes intégrés de protection $\quad 87$

Les évaluations et comparaisons de systèmes de culture 88

Les stratégies d'acteurs, la mise à disposition et l'acceptabilité des innovations

Éléments de conclusion $\quad 98$

5. Conclusions générales 101

Une masse considérable d'information disponible... 101

...Mais très inégalement répartie entre les champs de recherche et de développement

Des solutions individuelles à effets partiels... 
...Mais encore insuffisamment insérées au sein de systèmes intégrés de protection des plantes

Sepasser du cuivre : des marges de manœuvre considérables

Plusieurs domaines insuffisamment explorés en recherche, mais cruciaux dans une perspective d'élimination complète du cuivre

Des enseignements à tirer depuis et vers les systèmes

dits " conventionnels"

Sélection bibliographique

Annexe. Le corpus bibliographique analysé 


\section{Introduction}

\section{Des utilisations importantes du cuivre, soumises à des restrictions croissantes}

DEPUIS LA FIN DU XIX ${ }^{E}$ SIÈCLE ET LA MISE AU POINT DE LA BOUILLIE BORDELAISE, le cuivre est un élément majeur des méthodes de protection des cultures contre diverses maladies (mildious, certaines mycoses et la plupart des bactérioses), en particulier sur vigne, productions fruitières et cultures légumières. S'il reste aujourd'hui largement employé dans diverses formes d'agriculture dites " conventionnelles ", aux côtés d'autres pesticides, le cuivre joue un rôle crucial dans les systèmes agrobiologiques, car c'est actuellement la seule substance active homologuée en agriculture biologique (AB) ayant à la fois un effet biocide fort et une large gamme d'action.

Si la plupart des utilisations du cuivre sont justifiées par son efficacité biologique, elles posent des problèmes écotoxicologiques (risques avérés pour les populations microbiennes du sol, les vers de terre, certains organismes aquatiques et des auxiliaires des cultures). La mise en évidence de ces impacts environnementaux du cuivre a motivé des restrictions réglementaires d'usage (plafonnement des doses applicables par hectare et par an), et même son interdiction comme pesticide dans certains pays européens (Pays-Bas, Danemark), ce qui génère des distorsions de concurrence entre pays.

\section{Les alternatives à l'emploi du cuivre : des travaux nombreux... nécessitant une synthèse critique des connaissances}

CES RESTRICTIONS CRoissantes des doses DE CUIVRe Autorisées ${ }^{1}$ ainsi que la menace persistante d'une interdiction totale à l'échelle européenne posent des difficultés aux producteurs, et plus particulièrement aux agriculteurs en $A B$, qui ne peuvent recourir à des pesticides de synthèse. En découle une demande récurrente d' " alternatives " au cuivre adressée à la recherche, qui a émergé il y a une vingtaine d'années mais reste inscrite dans les priorités de recherche récentes (par exemple celles figurant dans le plan français de développement de l'AB «Ambition Bio 2017 »).

Cette question des " alternatives » au cuivre a donc fait l'objet de nombreux travaux de recherche et de recherche-développement (R\&D), dont trois programmes européens majeurs depuis le début des années 2000, et de beaucoup d'actions de recherche d'envergure plus limitée partout dans le monde. Il existe également de nombreux essais de solutions alternatives, conduits par les centres techniques et les producteurs, pour

1. En novembre 2018 (après la parution de la présente expertise), la Commission européenne a voté la réautorisation pour sept ans des composés issus du cuivre en agriculture, en plafonnant cet usage, à comp-




évaluer la pertinence technique de telle ou telle molécule ou préparation. Des connaissances ont également été acquises sur les mécanismes biologiques sous-jacents (induction de défense des plantes contre les bioagresseurs, écologie des pathogènes et des agents de lutte biologique...).

Un grand nombre de références techniques a ainsi été accumulé, mais l'adoption en pratique de ces possibles innovations reste limitée. De fait, les résultats restent dispersés, souvent fragmentaires, et peu accessibles. Aucune synthèse complète et critique de ces travaux n'existe en effet à ce jour. Scientifiques et responsables techniques ne disposent donc d'aucun « état de l'art » consolidé, évaluant scientifiquement les efficacités et les limites de ces solutions, pour identifier les priorités de recherche et fonder des préconisations pour la mise en œuvre pratique de ces solutions.

\section{L'intérêt d'une expertise scientifique collective, et son cadrage}

Dans Ce contexte, le Comité interne en agriculture biologique (CIAB) de l'Inra, à l'occasion de rencontres avec les porteurs d'enjeux, a suggéré la conduite d'une analyse critique de l'ensemble des acquis disponibles et validés sur le sujet. Se saisissant de cette proposition, l'Institut technique de l'agriculture biologique (ITAB) et le métaprogramme «Gestion durable de la santé des cultures » (SMaCH, Sustainable Management of Crop Health) de l'Inra ont, conjointement, commandé une expertise scientifique collective (ESCo) visant à réaliser une synthèse pluridisciplinaire et critique des connaissances scientifiques et techniques disponibles sur ce sujet. Ce type d'exercice est conduit à l'Inra par la Délégation à l'expertise, à la prospective et aux études (DEPE), selon des règles et procédures de travail définies (encadré 1) : l'analyse de la bibliographie internationale (prioritairement académique) est réalisée par un collectif d'experts scientifiques (chercheurs des organismes publics de recherche et d'enseignement supérieur).

Le périmètre de l’ESCo couvre :

- les différentes solutions techniques possibles : traitements à base de substances d'origine naturelle à effet biocide et/ou stimulant les défenses naturelles des plantes, emploi d'agents microbiologiques de lutte, utilisation de variétés résistantes aux maladies, conduites des peuplements cultivés à visée prophylactique ;

- l'intégration de ces solutions individuelles au sein de systèmes de production/protection intégrée ;

- les freins et conditions nécessaires à l'adoption et à la diffusion des méthodes alternatives.

L'ESCo considère a priori tous les « usages » (couple culture $\times$ agent pathogène) homologués pour les traitements à base de cuivre, en mettant l'accent sur quelques usages « majeurs » (par l'importance économique des cultures concernées), qui ont fait l'objet du plus grand nombre de travaux.

L'objectif de l'ESCo est de produire une synthèse des connaissances publiées utilisable par les différents acteurs concernés, et donc susceptible d'orienter leurs choix, en matière 
d'actions de recherche ou de R\&D, d'incitations visant à favoriser l'émergence d'itinéraires techniques « zéro cuivre » ou « très bas cuivre ». L'ESCo apporte un éclairage, mais ne formule en revanche pas de recommandations.

L'analyse s'est focalisée sur le cas de l'AB, qui est à la fois le mode de production le plus dépendant de l'utilisation de cuivre et le cadre dans lequel ont été produites beaucoup des références disponibles. Cependant, ses résultats intéressent toutes les formes d'agriculture qui cherchent à réduire leur consommation de pesticides de synthèse.

\section{Statut et plan du document}

LE PRÉSENT DOCUMENT EST UNE SYNTHÈSE DU RAPPORT produit par le collectif d'experts (disponible sur le site de l'Inra). Il ne mentionne que quelques sources bibliographiques majeures, l'ensemble des références bibliographiques mobilisées figurant dans le rapport d'expertise.

Le premier chapitre rappelle des éléments de contexte - qui ne font pas l'objet du travail scientifique d'expertise. Ces données de cadrage concernent le cuivre (ses usages homologués, les restrictions réglementaires d'utilisation et leur motivation, les utilisations effectives en production) et les alternatives au cuivre (la gamme des techniques mobilisables, les règles générales d'homologation et d'autorisation d'emploi, les méthodes d'évaluation). Il précise les sources documentaires disponibles concernant ces alternatives.

Le deuxième chapitre passe en revue les différents leviers techniques disponibles pour lutter directement contre l'agent pathogène et/ou indirectement en augmentant la résistance de la culture : préparations naturelles biocides, agents microbiologiques de biocontrôle, résistance génétique des plantes, stimulateurs de défense naturelle des plantes, homéopathie et isothérapie...

Le troisième chapitre est consacré aux moyens agronomiques visant à limiter les risques phytosanitaires : mesures prophylactiques pour réduire les sources de contamination (élimination des plantes et résidus de culture infectés, par exemple), protection physique contre les infections (bâches anti-pluie et anti-grêle, par exemple), modes de conduite des plantes ou des couverts (taille des arbres fruitiers, couverts en mélanges, par exemple) visant à créer des conditions défavorables au développement ou à la propagation des épidémies.

Le quatrième chapitre examine les données disponibles à l'échelle des systèmes de culture, ainsi que la question des freins à la production et à l'adoption des innovations qui constituent ces systèmes.

Un dernier chapitre de conclusions tire les enseignements des analyses, en matière de disponibilité actuelle des méthodes alternatives au cuivre, de possibilités de mise en œuvre, et de besoins de recherche. Il propose en outre des prototypes (théoriques à ce stade) de systèmes intégrés de protection envisageables pour les trois principaux usages du cuivre. 


\section{Encadré 1. L'expertise scientifique collective (ESCo).}

L'ESCo est une activité d'expertise institutionnelle, régie par la charte nationale de l'expertise à laquelle l'Inra a adhéré en 2011. Elle se définit comme une activité d'analyse et d'assemblage de connaissances produites dans des champs très divers du savoir, et pertinentes pour éclairer l'action publique. Cet état des connaissances le plus complet possible, et son analyse, ne fournissent ni avis, ni recommandations, ni réponses directes aux questions qui se posent aux gestionnaires : il a pour seul objet de fournir un état critique des acquis scientifiquement avérés, mais aussi des questions controversées ou des champs mal couverts par l'activité scientifique, sur lequel les décideurs pourront s'appuyer pour établir leurs choix d'action.

L'analyse est conduite par un collectif pluridisciplinaire d'experts chercheurs d'origines institutionnelles diverses. Pour l'ESCo "Cuivre ", une dizaine d'experts issus de différents organismes ont été mobilisés. Leur travail s'est appuyé sur un corpus bibliographique de près de 900 références, composé essentiellement d'articles scientifiques, complétés par des documents plus techniques. Cet exercice se conclut par la production d'un rapport qui rassemble les contributions des experts, d'une synthèse à l'usage notamment des décideurs, et d'un résumé à diffusion large. 


\section{1. Éléments de contexte}

\section{Le cuivre: propriétés et utilisations}

\section{Propriétés biologiques et profils toxicologique et écotoxicologique du cuivre}

Le cuivre est un élément important pour les systèmes biologiques. Constituant vital impliqué dans le transport des électrons et donc dans le métabolisme énergétique, il est aussi doté de propriétés antimicrobiennes. Un consensus se dégage aujourd'hui pour penser que la gestion par l'hôte de l'homéostasie du cuivre, entre composant vital et poison cellulaire, est utilisée par de nombreux organismes pour réguler les infections microbiennes. Ces propriétés antimicrobiennes du cuivre génèrent diverses applications en santé humaine, animale et végétale.

\section{Les formulations à base de cuivre}

Pour ces utilisations sanitaires, le cuivre est principalement employé sous forme ionique, dans des formulations à base de sels de cuivre (sulfate ou hydroxyde) combinés à divers adjuvants. La bouillie bordelaise (sulfate de cuivre + chaux) est emblématique de ce type de formulation. Ces produits sont généralement utilisés en pulvérisation sur les parties aériennes de la culture ; ils peuvent aussi être employés en traitement des semences (pour les céréales) ou en application locale (badigeon sur les plaies des arbres). Les mécanismes précis d'action biocide du cuivre sur les micro-organismes restent à ce jour incomplètement élucidés, mais plusieurs hypothèses (fuites d'électrolytes via la membrane cellulaire, stress oxydant, perturbation de la balance ionique, voire chélations sur les sites actifs de protéines bloquant leur fonctionnement normal) ont pu être avancées.

Plus récemment, sont apparus des emplois du cuivre sous forme de nanoparticules à base d'oxydes de cuivre (nano-CuO et nano- $\mathrm{CuCO}_{3}$ ), qui peuvent être incorporées à différents supports (comme les textiles). Leur utilisation comme biocides pour le traitement des bois et des produits dérivés du bois, contre les champignons et insectes responsables de biodégradation, se développe.

\section{L'accumulation dans les sols}

La concentration en cuivre varie de 3 à $100 \mathrm{mg} / \mathrm{kg}$ dans les sols naturels, selon le substrat sous-jacent et le type de sol, et entre 5 et $30-45 \mathrm{mg} / \mathrm{kg}$ dans les sols agricoles non pollués. Dans ceux-ci, la teneur en cuivre de la solution du sol est généralement très basse (de l'ordre de 1 à $10 \mu \mathrm{m}$ selon les types de sols), une fraction importante du cuivre étant retenue sur les matrices argilo-humiques. 
Les activités humaines, et en particulier l'application répétée de pesticides à base de cuivre, sont la principale source de pollution cuivrique des sols agricoles, où elles causent une accumulation parfois massive de cet élément dans les horizons superficiels (figure 1.1). En Europe, l'application quasi ininterrompue de bouillie bordelaise pour lutter contre le mildiou a ainsi très fortement accru les teneurs en cuivre des sols viticoles, jusqu'à des valeurs pouvant atteindre 200 , voire $500 \mathrm{mg} / \mathrm{kg}$.

\section{Figure 1.1. Les teneurs en cuivre des horizons de surface $(0-30 \mathrm{~cm})$ des sols de France.}

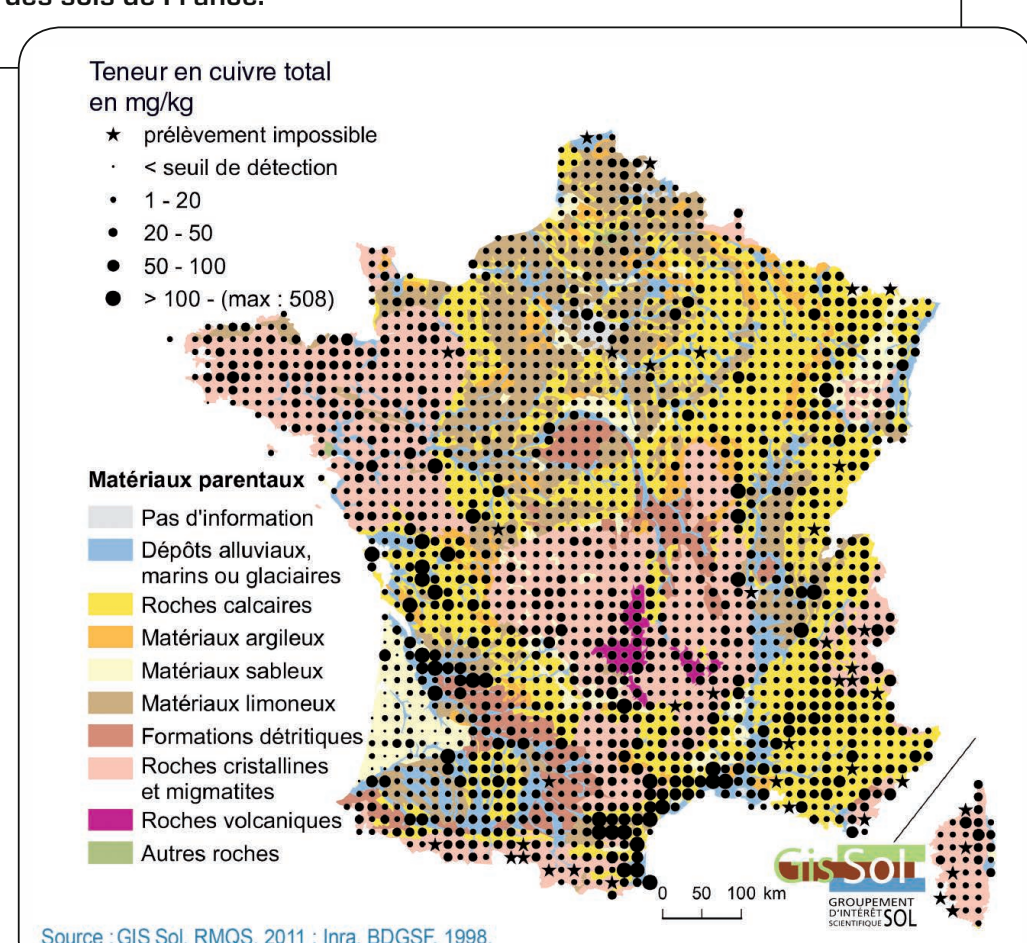

Source : GIS Sol, RMQS, 2011 ; Inra, BDGSF, 1998

Source : GIS Sol, 2011. L'état des sols de France, Groupement d'intérêt scientifique sur les sols, $188 \mathrm{p}$.

\section{La phytotoxicité pour les cultures}

Des concentrations excédentaires en cuivre ont des effets nocifs reconnus sur la croissance et le développement des systèmes aérien et racinaire de la plupart des plantes, dont elles réduisent la biomasse totale. Certaines espèces ou familles, en particulier les légumineuses, la vigne, le houblon ou les céréales, sont particulièrement affectées. 
La toxicité du cuivre est directement reliée à la biodisponibilité des ions cuivriques. Les concentrations médianes toxiques pour les plantes sont de seulement $2 \mu \mathrm{m}$ en solution nutritive. Une part importante de l'effet toxique provient de l'inhibition de la photosynthèse et de la dégradation des chloroplastes, se traduisant par une chlorose plus ou moins sévère. Perturbant le métabolisme oxydatif de la plante, le cuivre en excès induit également les défenses générales de la plante, qui ont un coût métabolique.

Les applications de cuivre ont aussi une incidence sur la composition et donc la qualité des produits récoltés. Ainsi, par exemple, elles réduisent la teneur en polyphénols et donc les propriétés antioxydantes des feuilles d'olivier, et modifient la concentration et l'équilibre en composés aromatiques des cônes de houblon.

Des travaux scientifiques conduits dans les années 1990 sur différentes espèces végétales occupant des sites miniers fortement contaminés ont établi qu'il existait chez ces espèces une base génétique exploitable pour accroître la tolérance des végétaux à des excès de métaux lourds, et exploitable en bioremédiation de sols pollués. À notre connaissance, cette capacité de tolérance au cuivre n'a toutefois pas fait l'objet de sélection par les obtenteurs de variétés chez les espèces d’intérêt agricole.

\section{L'écotoxicité}

Les effets délétères d'excès en cuivre sur les communautés microbiennes des sols semblent bien établis. C'est d'ailleurs du fait de ses effets antimicrobiens que le cuivre est employé en agriculture. Champignons et bactéries étant souvent impliqués dans les chaînes trophiques et le bouclage des cycles biogéochimiques, il n'est donc guère surprenant que la perturbation de ces communautés microbiennes dans les sols puisse conduire à un appauvrissement des ressources localement disponibles pour d'autres organismes consommateurs.

La toxicité du cuivre pour certaines composantes de la faune du sol, comme le collembole Folsomia candida, est également bien établie. Les impacts sont plus controversés pour d'autres espèces indicatrices, en particulier les vers de terre. Les estimations des concentrations de cuivre létales pour les vers adultes diffèrent : certains travaux montrent des surmortalités significatives pour des concentrations de $150 \mathrm{mg} / \mathrm{kg}$ de sol, alors que d'autres ne détectent aucun effet à ces teneurs. Le cuivre semble avoir une faible toxicité aiguë pour l'espèce-test de ver de terre Eisenia foetida, avec des concentrations létales $50 \%$ (CL 50) supérieures à $5500 \mathrm{mg} / \mathrm{kg}$ de sol sec en conditions de laboratoire. À des teneurs plus faibles, une toxicité chronique pour les vers de terre est souvent observée : retard à la maturité sexuelle, diminution du nombre de cocons et du taux d'éclosion. De plus, des doses même sans impact mesurable sur ces paramètres du cycle de vie ont des effets notables sur la physiologie des vers. Il est donc raisonnable de penser que les pollutions cupriques des sols ont des effets chroniques de long terme sur la dynamique des populations de vers de terre et d'autres composantes de la faune des sols importantes pour l'entretien des structures de ces sols et le bouclage des cycles biogéochimiques. Enfin, les applications de cuivre sont toxiques pour des espèces fongiques utilisées comme agents de biocontrôle (par exemple Beauveria bassiana, employé contre des insectes ravageurs). 


\section{Tableau 1.1. Usages actuels homologués du cuivre en France (sources : base de données E-Phy et Guide ITAB, 2017).}

\begin{tabular}{|c|c|c|c|}
\hline \multirow{2}{*}{\multicolumn{2}{|c|}{ Culture }} & \multicolumn{2}{|c|}{ Maladies/agents pathogènes } \\
\hline & & Bactérioses & Maladies fongiques \\
\hline \multirow{19}{*}{ 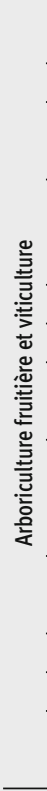 } & Agrumes & $\begin{array}{l}\text { Xanthomonas axonopodis pv. citri } \\
\text { et citrumelo, } X \text {. citri subsp. citri }\end{array}$ & \\
\hline & Arbres et arbustes & & Maladies diverses \\
\hline & Cerisier & Agrobacterium tumefaciens & Coryneum et Polystigma \\
\hline & & Pseudomonas & \\
\hline & $\begin{array}{l}\text { Fruits à coque (noyer, } \\
\text { noisetier, amandier) }\end{array}$ & $\begin{array}{l}\text { Pseudomonas avellanae et } P \text {. syringae } \\
\text { pv. coryli }\end{array}$ & \\
\hline & & Xanthomonas campestris pv. juglandis & \\
\hline & Kiwi & Pseudomonas syringae pv. actinidiae & \\
\hline & Olivier & Chancre (Pseudomonas savastanoi) & Maladie de l'œil de paon, Fusicoccum \\
\hline & Pêcher (+ abricotier) & Xanthomonas arboricola pv. pruni & Cloque(s) \\
\hline & & Pseudomonas & Coryneum et Polystigma \\
\hline & Pommier (+ poirier, & Pseudomonas & Chancre européen (Nectria galligena) \\
\hline & cognassier, nashı) & & Maladies du feuillage \\
\hline & & & Tavelure (Venturia inaequalis) \\
\hline & Prunier & Bactérioses & Tavelure(s) \\
\hline & & & Cloque \\
\hline & Cassissier & & Maladies du feuillage \\
\hline & Framboisier & & Maladies du feuillage \\
\hline & Vigne & Broussins (Agrobacterium vitis) & Excoriose (Phomopsis viticola) \\
\hline & & & Mildiou (Plasmopara viticola) \\
\hline \multirow{3}{*}{ 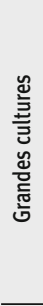 } & Blé & & $\begin{array}{l}\text { Champignons autres que pythiacées } \\
\text { [traitement des semences] : pourriture } \\
\text { (Bipolaris sorokiniana), piétin-échaudage } \\
\text { (Gaeumannomyces graminis), fusarioses } \\
\text { (Fusarium graminearum, F. culmorum, } \\
\text { Microdochium nivale) }\end{array}$ \\
\hline & Seigle & & $\begin{array}{l}\text { Champignons autres que pythiacées [traitement } \\
\text { des semences]: fusarioses (Microdochium } \\
\text { nivale, Fusarium sp.) }\end{array}$ \\
\hline & Pomme de terre & & Mildiou(s) : Phytophthora infestans \\
\hline \multirow{7}{*}{ 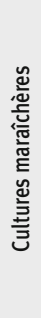 } & Artichaut & Bactérioses & Mildiou(s) \\
\hline & Carotte & & Champignons (pythiacées) \\
\hline & Céleris & Bactérioses & \\
\hline & $\begin{array}{l}\text { Chicorées - } \\
\text { production de racines }\end{array}$ & Bactérioses & \\
\hline & $\begin{array}{l}\text { Chicorées - } \\
\text { production de chicons }\end{array}$ & $\begin{array}{l}\text { Bactérioses [traitement des semences } \\
\text { et plants] }\end{array}$ & \\
\hline & Choux & Pseudomonas fluorescens (brocoli) & Mildiou(s) \\
\hline & & Xanthomonas campestris pv. campestris & \\
\hline
\end{tabular}


Tableau 1.1. Suite.

\begin{tabular}{|c|c|c|c|}
\hline \multicolumn{2}{|c|}{ Culture } & \multicolumn{2}{|c|}{ Maladies/agents pathogènes } \\
\hline & & Bactérioses & Maladies fongiques \\
\hline \multirow{14}{*}{ 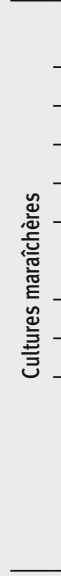 } & $\begin{array}{l}\text { Concombre } \\
\text { (+ cornichon, courgette) }\end{array}$ & & Mildiou \\
\hline & Fraisier & Bactérioses & Maladies des taches brunes \\
\hline & Haricots & Bactérioses & \\
\hline & Houblon & & Mildiou(s) \\
\hline & Laitue & Bactérioses & Mildiou(s) \\
\hline & Melon & Acidovorax citruli & Mildiou \\
\hline & & Xanthomonas campestris pv. cucurbitae & \\
\hline & Oignon & Xanthomonas axonopodis pv. allii & Mildiou(s) \\
\hline & Poireau & Pseudomonas syringae pv. porri & Mildiou(s) \\
\hline & Tomate & Pseudomonas syringae & Mildiou(s) : Phytophthora infestans \\
\hline & & Clavibacter michiganensis & \\
\hline & & Erwinia chrysanthemi & \\
\hline & & Ralstonia & \\
\hline & & Nombreuses Xanthomonas & \\
\hline \multirow{8}{*}{ 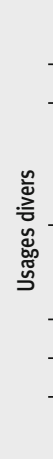 } & $\begin{array}{l}\text { Plantes d'intérieur } \\
\text { et de balcon }\end{array}$ & & Maladies diverses \\
\hline & Porte-graine & & Maladies diverses \\
\hline & $\begin{array}{l}\text { Porte-graine } \\
\text { - Betteraves } \\
\text { industrielle et } \\
\text { fourragère } \\
\end{array}$ & & Mildiou(s) \\
\hline & Porte-graine - & & Mildiou et rouille blanche \\
\hline & $\begin{array}{l}\text { PPAMC*, florales } \\
\text { et potagères }\end{array}$ & & Rouille(s) \\
\hline & PPAMC & Bactérioses & Maladies fongiques (mildiou) \\
\hline & Rosier & & Chancres à champignons \\
\hline & Traitements généraux & & $\begin{array}{l}\text { Protection des plaies [traitement des troncs } \\
\text { et branches] }\end{array}$ \\
\hline
\end{tabular}

* PPAMC : plantes à parfum, aromatiques, médicinales et condimentaires.

Entre crochets : les modes d'application autres que le traitement des parties aériennes.

Les nanoparticules contenant du cuivre s'avèrent également toxiques pour le système plante-sol, sans qu'il soit encore clair si cette toxicité est liée aux nanoparticules elles-mêmes ou au relargage d'ions cuivriques. Les effets sur les plantes sont similaires à ceux d'une hyperaccumulation d'ions dans le sol : forte réduction de croissance des plantes exposées et modification de la balance ionique des tissus végétaux. Les effets sur le compartiment microbien des sols (généralement attribués à la libération d’ions cuivriques) restent encore 
peu caractérisés, mais ils sont avérés : réductions de la diversité microbienne, de composantes des communautés bactériennes telluriques favorables à la croissance des plantes, ou de l'assimilation du fer par les végétaux et les microbes. Par ailleurs, il semble que ces nanoparticules affectent fortement d'autres compartiments environnementaux, en particulier les milieux aquatiques : poissons, crustacés et algues paraissent en effet plus sensibles que les bactéries du sol à la toxicité des nanoparticules à base d'oxydes de cuivre.

\section{Les utilisations du cuivre en protection des cultures}

\section{Les usages homologués}

Le cuivre est homologué en protection des plantes contre diverses maladies, en particulier les mildious, différentes mycoses, mais aussi diverses bactérioses, en particulier sur vigne, productions fruitières et cultures légumières (tableau 1.1 et encadré 1.1).

- En cultures pérennes, les usages homologués du cuivre concernent des maladies fongiques et des bactérioses qui affectent la vigne et des cultures de fruits à pépins, à noyau ou à coque. Des applications de cuivre sont parfois également réalisées contre des maladies sur lesquelles ces produits ne sont pas homologués, notamment la moniliose des fleurs de l'abricotier ou le black rot de la vigne.

- En cultures maraîchères, le cuivre est également homologué contre des maladies fongiques et des bactérioses, pour une douzaine de cultures appartenant à diverses familles botaniques.

- En grandes cultures, les usages homologués du cuivre sont limités à la lutte contre le mildiou de la pomme de terre, et contre quelques maladies fongiques du blé et du seigle transmises par les semences.

- Enfin, le cuivre est homologué contre diverses maladies fongiques qui affectent des plantes à parfum, aromatiques et médicinales (PPAM), des espèces ornementales et des cultures porte-graine, ou qui se développent sur les plaies du bois.

La dose maximale d'homologation des préparations à base de cuivre est actuellement de $6 \mathrm{~kg}$ de cuivre métal/ha/an. Les doses préconisées par le conseil technique aux producteurs peuvent être sensiblement inférieures à cette limite maximale.

\section{Les agents pathogènes ciblés}

Les micro-organismes pathogènes ciblés par les usages phytosanitaires du cuivre appartiennent à trois grands groupes, dont la biologie détermine les conditions de développement de la maladie et les moyens de lutte applicables. Ce sont :

- des ascomycètes (tavelure du pommier, par exemple), champignons qui présentent à la fois une reproduction sexuée (produisant des périthèces qui se conservent en hiver dans les feuilles mortes infectées, et d'où sortiront des ascospores responsables de l'infection primaire au printemps) et une reproduction asexuée (produisant sur les organes aériens de la plante des conidies, dont la dissémination assure les infections secondaires jusqu'à l'automne) ; 
- des oomycètes (mildious), longtemps classés comme groupe proche des champignons, dont ils se distinguent par des hyphes non cloisonnés, un génome diploïde et la présence de spores nageuses (zoospores), mais qui présentent un cycle biologique similaire ;

- des bactéries, organismes procaryotes et à multiplication très majoritairement asexuée, et pénétrant dans la plante le plus souvent par des ouvertures naturelles (stomates, lenticelles, blessures) et non via des structures spécialisées.

\section{Encadré 1.1. Quelques usages majeurs du cuivre.}

Certains usages du cuivre, notamment en $A B$, peuvent être considérés comme majeurs, par les surfaces et le poids économique de la culture concernée, les pertes de récolte occasionnées par les maladies visées et/ou les quantités de cuivre épandues. Ils font de ce fait l'objet du plus grand nombre de recherches et d'essais techniques. - Le mildiou de la vigne, dû à l'oomycète Plasmopara viticola, est l'une des deux principales maladies (avec l'oïdium) de cette culture. Très dommageable, en particulier dans les régions à climat océanique, son fort potentiel épidémique impose une protection de très haute efficacité, faute de quoi la récolte peut être sévèrement affectée, voire entièrement détruite. La lutte contre le mildiou nécessite donc, en cas d'utilisation de produits de contact comme le cuivre et compte tenu de la forte sensibilité de la plupart des cépages, des applications nombreuses (jusqu'à une quinzaine par an). Les vignobles représentent de l'ordre de 782700 ha en France (Agreste, 2016).

- La tavelure du pommier, causée par le champignon ascomycète Venturia inaequalis, est une maladie économiquement importante lles fruits tavelés ne sont pas commercialisables). Les vergers de pommiers reçoivent en moyenne 23 traitements fongicides/ bactéricides par an (de 15 à 29 selon les régions), dont près des trois quarts ciblent la tavelure (Agreste). Le cuivre pouvant provoquer de la rugosité sur fruits, la protection des pommiers bio contre la tavelure utilise du cuivre (très efficace), du soufre et de la bouillie sulfo-calcique (sous réserve d'autorisation). Les traitements à base de cuivre servent également à contrôler le chancre européen (dû à Nectria galligena). La production de pommes de table couvre environ 36500 hectares en France.

- Le mildiou de la pomme de terre, causé par l'oomycète Phytophthora infestans, est la maladie la plus grave de cette culture. Elle se manifeste par des symptômes de nécrose évolutive sur tous les organes (feuilles, tiges et tubercules). Elle est à l'origine de pertes de rendement pouvant aller jusqu'à la destruction totale de la parcelle, mais aussi, en cas d'attaques tardives, de pertes de qualité du fait des pourritures sur tubercules atteints. La maladie est importante dans toutes les régions de production, mais plus régulièrement sévère en zones océaniques. Elle motive l'application de 10 à 12 traitements en moyenne, jusqu'à 15 ou 20 en zone à fort risque de mildiou. En France, la pomme de terre occupe environ 180000 ha.

$P$. infestans occasionne également d'importants dégâts sur la tomate (qui appartient à la même famille botanique que la pomme de terre), en particulier en cultures de plein champ. 
Ces agents pathogènes ont en commun de générer des infections polycycliques (figure 1.2) et de dépendre de la présence d'eau liquide (ou au moins d'une humidité saturante), nécessaire à la dissémination et à la germination des spores de champignons (sensu lato), et à la dissémination des bactéries.

Figure 1.2. Cycle biologique schématique de maladies fongiques polycycliques.

Les pesticides peuvent inhiber la croissance des tissus végétatifs (hyphes) et/ou la germination des spores issues de la reproduction sexuée ou asexuée. La lutte contre ces maladies polycycliques nécessite un traitement dès que les conditions climatiques (pluviométrie, température) sont favorables à l'infection primaire au printemps, puis aux infections secondaires tout au long de la saison. Les outils d'aide à la décision (OAD) existants, qui visent essentiellement à améliorer le positionnement des traitements (et à en limiter si possible le nombre), évaluent le risque d'infection grâce à des modèles simulant le développement de l'agent pathogène en fonction des conditions météorologiques.

\section{Les restrictions réglementaires d'usage}

La mise en évidence d'effets environnementaux négatifs des produits à base de cuivre a motivé des restrictions réglementaires d'usage. L'emploi du cuivre à des fins phytosanitaires est actuellement autorisé en France et dans la plupart des autres pays de l'Union européenne, en agriculture conventionnelle comme en agriculture biologique, à une dose maximale de $6 \mathrm{~kg} / \mathrm{ha} / \mathrm{an}$ de Cu métal. Certains pays ont toutefois décidé de limiter plus encore ces doses autorisées. C'est le cas de la Suisse, qui restreint cet emploi à $4 \mathrm{~kg} \mathrm{Cu} / \mathrm{ha} / \mathrm{an}$ sur la plupart des cultures (moyenne lissée sur 5 ans, avec des pics 
possibles jusqu'à $6 \mathrm{~kg}$ en cas de forte pression phytosanitaire une année donnée), voire même à $2 \mathrm{~kg} / \mathrm{ha} /$ an pour les petits fruits et à $1,5 \mathrm{~kg}$ pour les fruits à noyaux. D'autres pays (Pays-Bas, Scandinavie) ou certifications (Demeter en Allemagne par exemple) ont choisi d'interdire totalement les utilisations phytosanitaires du cuivre, tout en lui conservant un usage fertilisant, sans contingentement de dose. Cette brèche réglementaire a pu conduire à des utilisations phytosanitaires « dissimulées » du cuivre dans certains contextes.

L'usage du cuivre est contesté au sein même de l'AB. Les formulations de produits à base de cuivre utilisées en agriculture sont toutes issues de la chimie minérale de synthèse. Leur autorisation d'emploi en $A B$ apparaît donc comme contraire aux principes fondateurs de ce mode d'agriculture. Elle résulte simplement du fait que l'usage ancien des préparations à base de cuivre (la bouillie bordelaise date des années 1880) en faisait un élément de la pharmacopée phytosanitaire avant l'explosion, essentiellement après la Seconde Guerre mondiale, de l'usage de pesticides issus de la recherche chimique et pharmaceutique. Ce hiatus entre les principes fondateurs de l'AB et la nature synthétique des préparations à base de cuivre est une des motivations fortes de certains producteurs et organismes certificateurs, en particulier ceux du mouvement biodynamique, pour en refuser l'emploi.

Le différentiel réglementaire entre pays et productions, voire entre cahiers des charges, génère des impasses techniques dans les pays ayant aboli l'usage du cuivre et donc une diminution sensible de certaines productions biologiques, comme c'est le cas aux Pays-Bas pour la pomme de terre. Il crée aussi une distorsion de concurrence entre producteurs des différents pays, et motive donc une sollicitation insistante des pays ayant banni l'emploi phytosanitaire du cuivre pour généraliser cette interdiction au niveau européen.

\section{La consommation effective de cuivre en agriculture biologique}

Le cuivre constitue la seule matière active à effet fongicide fort et gamme d'action large homologuée en $\mathrm{AB}$. Son remplacement dans ce mode de production est donc bien plus problématique qu'en agriculture conventionnelle, qui dispose le plus souvent de solutions alternatives sous forme de pesticides de synthèse, au moins contre les maladies majeures.

$E n A B$, trois enquêtes récentes, réalisées d'une part en France par l'ITAB (Jonis, 2009) puis conjointement par l'ITAB et l'Institut français de la vigne et du vin (IFV) (Berthier et Chovelon, 2013), et d'autre part par l'Institut de recherche de l'agriculture biologique (FiBL) suisse (Speiser et al., 2015), montrent que la consommation effective de cuivre, si elle est généralement inférieure aux doses maximales autorisées, reste néanmoins élevée. En Suisse, elle avoisine $3 \mathrm{~kg} / \mathrm{ha} / \mathrm{an}$ en cultures de pomme de terre, de céleris ou de cépages européens (sensibles au mildiou) de vigne, $2,5 \mathrm{~kg} / \mathrm{ha} /$ an pour la production de cerises, et $1 \mathrm{~kg} / \mathrm{ha} /$ an en vergers de pommiers et de poiriers ; ces doses se situent entre 60 et $80 \%$ des doses maximales autorisées.

En France, la consommation de cuivre en viticulture biologique avoisine en moyenne $5 \mathrm{~kg} / \mathrm{ha} / \mathrm{an}$ en année à forte pression de mildiou (soit environ un an sur deux durant la 
première décennie duxxle siècle), avec de très fortes disparités entre régions : $1,6 \mathrm{kgCu} / \mathrm{ha} / \mathrm{an}$ en Alsace, 5,6 kg en Val de Loire, et jusqu'à plus de 6 kg en Champagne, Midi-Pyrénées, Aquitaine ou Languedoc-Roussillon. Les variations interannuelles sont également marquées : la consommation moyenne française est ainsi de $3 \mathrm{~kg} \mathrm{Cu} / \mathrm{ha} / \mathrm{an}$ en année de faible pression de maladie, contre 5 en année de forte pression. La même enquête relève des tendances très similaires en arboriculture fruitière et en productions légumières. Les valeurs françaises sont en général sensiblement plus élevées que celles relevées dans l'enquête suisse ; ces différences proviennent sans doute pour partie de la plus grande diversité des terroirs, mais aussi du fait que les données françaises sont plus anciennes. Il convient de noter que l'enquête de 2009 rapporte des valeurs plus élevées, en viticulture et en arboriculture, que les préconisations de certains guides récents destinés aux producteurs. Ainsi, en culture de pommier, les prescripteurs recommandent actuellement 7 à 8 traitements, échelonnés du débourrement à la récolte, mais apportant chacun des doses faibles de cuivre (100 à $300 \mathrm{~g} /$ ha par application) pour la lutte contre la tavelure, soit une dose totale inférieure à la dose unitaire homologuée de $2500 \mathrm{~g} / \mathrm{ha}$. Cependant, cette enquête, comme celle de 2013 en viticulture, montre aussi l'existence de situations d'impasses techniques ou d'usages multiples du cuivre, amenant une fraction des producteurs à excéder les préconisations, voire le seuil homologué. Ainsi, en production de pêches bio, la recommandation est de $5 \mathrm{~kg}$ environ de Cu métal par ha et par an pour la seule lutte contre la cloque, essentiellement en traitement de début de saison; s'y ajoutent une à trois applications à raison de $1250 \mathrm{~g} / \mathrm{ha}$ à la chute des feuilles contre les bactérioses, pour une consommation totale supérieure au seuil de $6 \mathrm{~kg} / \mathrm{ha} / \mathrm{an}$. Enfin, les enquêtes ne comptabilisent que les applications explicitement phytosanitaires; or les prescriptions en pratique incluent fréquemment l'emploi d'engrais foliaires cupriques, à des doses faibles mais répétées. Ainsi, des apports en saison, à 100-200 g de cuivre par apport, non comptabilisés dans les usages phytosanitaires, sont conseillés en production d'abricots bio pour contenir la rouille des feuilles et les attaques de tavelure sur fruits. Il est donc vraisemblable que la consommation effective de cuivre, au moins pour certaines productions majeures comme la vigne ou les arbres fruitiers, reste dans bien des cas proche ou supérieure aux $6 \mathrm{~kg} / \mathrm{ha} /$ an autorisés.

\section{L'efficacité des traitements cupriques}

Il existe plusieurs manières d'évaluer l'efficacité d'un traitement. L'une consiste à mesurer les réductions d'incidence ou de sévérité de maladies dans des parcelles traitées par rapport à des témoins non traités. L'autre approche considère les différences de rendement entre parcelles traitées et témoins. La plupart des références sont issues de parcelles expérimentales, donc pas forcément représentatives des conditions en production commerciale. Toutefois, des gains de rendements grâce aux traitements cupriques ont été généralement observés. D'après une synthèse allemande, l'emploi de cuivre éviterait des pertes moyennes évaluées à 10 à $15 \%$ en productions légumières et ornementales, 15 à $20 \%$ en culture de pomme de terre, et 50 à $100 \%$ en arboriculture fruitière. 
Si la plupart des utilisations du cuivre sont justifiées par son efficacité biologique, certaines sont inutiles mais néanmoins réalisées, voire préconisées. C'est par exemple le cas des applications contre la moniliose des fleurs de l'abricotier, qui « bénéficie » des traitements de printemps homologués contre la bactériose. Alors même qu'une synthèse des résultats d'essais et d'observations au champ montre que ces applications printanières sont sans effet, voire néfastes, sur le contrôle de la maladie, et que les produits cupriques ne disposent pas d'homologation pour cet usage, ces applications restent souvent recommandées aux producteurs « par précaution ».

Il existe peu de cas identifiés d'évolution des populations parasites en réponse aux traitements à base de cuivre. Le principal est l'apparition, sur tomates, de souches de Xanthomonas résistantes au cuivre, qui motive la recherche active de résistances génétiques contre cette bactériose.

\section{Les alternatives au cuivre : nature et réglementation}

\section{Les types de méthodes et de modes d'action mobilisables}

Les méthodes alternatives peuvent être regroupées en trois grands types, selon les principes d'action qui les sous-tendent :

- les méthodes à action directe sur le pathogène lui-même. Elles regroupent l'application de substances biocides (extraits de plantes à action antimicrobienne en particulier), mais aussi l'emploi d'organismes en lutte biologique directe, agissant vis-à-vis de l'agent pathogène par antagonisme, hyperparasitisme ou compétition écologique ;

- l'utilisation des capacités de résistance des plantes elles-mêmes, que ces résistances soient constitutives ou induites après infection ou stimulation exogène : création de variétés résistantes, exploitant les ressources génétiques de l'espèce cultivée ou d'espèces apparentées ; application de stimulateurs de défense des plantes ;

- la mise en œuvre de pratiques agronomiques pour lutter contre les infections primaires (prophylaxie) ou secondaires (évitement). Au nombre des premières, figure en premier lieu la gestion des résidus de récoltes potentiellement infectés (ramassage, broyage, enfouissement des litières ; sélection sanitaire des semences et plants ; élimination des repousses et tas de déchets dans et à proximité des parcelles). Parmi les secondes, citons le bâchage des cultures pour éviter la contamination du feuillage par des spores présentes dans l'air ou dispersées par les éclaboussures de pluie, diminuer les durées d’humectation des organes végétaux, limitant ainsi la germination des spores et les infections, mais aussi réduire les blessures du végétal, qui constituent des portes d'entrée pour les parasites.

Le « biocontrôle » englobe à la fois les méthodes à effets directs utilisant des substances ou produits « naturels » (à l'exclusion donc des préparations de synthèse minérale ou organique), la lutte biologique, et la stimulation des défenses des plantes par des produits également d'origine naturelle. Il intègre par ailleurs l'emploi de molécules à effets 
sémiochimiques (phéromones attractives ou répulsives, odeurs de plantes...), qui ne concernent pas les micro-organismes cibles du cuivre. Il est important de noter que toutes les méthodes de biocontrôle ne sont pas ipso facto éligibles à l'utilisation en $A B$, et que certaines méthodes utilisées en $A B$ (comme l'emploi de doses plus ou moins fortes de cuivre) sont logiquement exclues du champ du biocontrôle.

\section{Les obligations réglementaires pour l'homologation et la commercialisation}

La mise sur le marché de substances, préparations ou variétés est soumise à un cadre réglementaire destiné en premier lieu à assurer l'utilisateur de la nature et de la qualité de ce qu'il achète, le consommateur de l'innocuité des produits, et l'industriel de ses droits. Ces exigences réglementaires sont en France majoritairement celles en vigueur à l'échelle communautaire, la réglementation nationale pouvant toutefois aller plus loin que les règles adoptées par l’Union européenne.

\section{L'homologation des substances biocides et agents de biocontrôle}

La procédure d'homologation des produits phytopharmaceutiques (encadré 1.2) s'applique aux préparations naturelles biocides, aux stimulateurs de défense des plantes, mais aussi aux agents de lutte biologique.

Le Règlement (CE) n 1107/2009 concernant la mise sur le marché des produits phytopharmaceutiques définit la notion de substance active (art. 22). Il introduit les notions de substance de base (art. 23) et de produit phytopharmaceutique à faibles risques (art. 47), catégories de produits qui bénéficient de procédures d’homologation allégées. Les substances de base correspondent à des substances non initialement élaborées pour être utilisées en protection des plantes, mais qui peuvent avoir un intérêt pour celle-ci (denrées alimentaires...) et sont sans impact négatif répertorié sur la santé humaine ou l'environnement. Ces substances sont une catégorie de produits utilisables en vue de renforcer la santé des cultures, mais distincte des produits phytosanitaires.

En France, la réglementation utilise la notion de préparations naturelles peu préoccupantes (PNPP) - qui n'existe pas dans la législation européenne. La loi d'avenir pour l'agriculture, l'alimentation et la forêt (2014) définit les PNPP (art. 50) comme composées exclusivement de substances de base (au sens du Règlement (CE) n 1107/2009) et de substances naturelles à usage « biostimulant ». L'activité de ces dernières n'est pas phytopharmaceutique (toute allégation d'une autre activité que celle de biostimulant est interdite). L'allègement de la procédure d'homologation pour les substances de base et les PNPP, destinée à favoriser l'arrivée rapide de ce type de produits sur le marché, n'est pas sans conséquence. Il peut conduire certains dépositaires à entretenir un certain flou entre l'usage déclaré et celui véritablement recherché, le cas typique étant celui de produits de biocontrôle commercialisés comme biostimulants pour éviter une homologation lourde et coûteuse. 
Les conditions requises dans ces procédures allégées d'autorisation pour les substances jugées peu préoccupantes concernent l'absence d'effet nocif sur la santé humaine (innocuité acquise pour les substances de base alimentaires, examinée pour les autres), sur la santé animale et sur l'environnement. La substance doit être d'origine végétale, animale ou minérale, à l'exclusion des micro-organismes, et obtenue par un procédé accessible à tout utilisateur final. Les demandes sont examinées en France par l'Agence nationale de sécurité sanitaire de l'alimentation, de l'environnement et du travail (Anses).

\section{Encadré 1.2. La procédure d'homologation des produits phytopharmaceutiques.}

La procédure, identique pour tous les produits phytosanitaires, comporte deux étapes :

- au niveau européen, une étape d'homologation de la substance active. La demande est évaluée par l'EFSA (European Food Safety Authority), selon trois critères : les propriétés physico-chimiques de la substance et ses profils de risque pour la santé humaine (toxicologie et résidus) et pour l'environnement (persistance et comportement dans l'environnement, et écotoxicologie). Lorsqu'elle est homologuée, la substance active est inscrite à l'annexe 1 du règlement UE/540/2011. La liste européenne Pesticide Database (http://ec.europa.eu/sanco_pesticides/ public/index.cfm) répertorie toutes les substances autorisées ;

- au niveau national, une étape d'autorisation de mise sur le marché (AMM) du produit commercial formulé (substance active + adjuvants). Le dossier soumis comprend, outre les éléments fournis pour l'évaluation européenne, des données sur l'efficacité du produit et sur ses usages autorisés (culture, dose d'application). En France, les AMM sont délivrées par l'Anses. La liste des produits homologués en France est disponible sur le site internet de l'agence (https://ephy.anses.fr/).

Fin 2017, 18 substances de base ont reçu une approbation communautaire (dont une, l'eau oxygénée, est interdite en $A B$ ). La plupart des demandes déposées jusqu'à présent pour des préparations à base de plantes n'ont pas été acceptées, les données fournies ayant été jugées insuffisantes par l'EFSA ; seules les préparations à base d'ortie, de prêle et d'écorce de saule ont à ce jour été approuvées. La liste des biostimulants (catégorie relativement mal définie) autorisés en France ne comprend pour l'instant que des plantes médicinales vendues librement (arrêté du 27/04/16).

Pour les produits commerciaux homologués en Europe, l'efficacité du produit pour les usages revendiqués dans l'homologation doit être démontrée. Ce n'est pas toujours le cas hors de l'Union européenne : dans certains pays, notamment aux États-Unis, la démonstration de l'efficacité d'un produit n'est pas requise pour son homologation.

Les produits destinés au biocontrôle sont recensés dans une liste spécifique après homologation. L'inscription d'un produit sur cette liste n'impliquant pas une autorisation 
automatique en $\mathrm{AB}$, tout nouveau produit homologué et disposant d'une AMM fait l'objet d'une instruction complémentaire quant à son éligibilité au cahier des charges de l'AB (annexe II du règlement $889 / 2008$ ). La seule exception notable à cette règle est celle des macro-organismes utilisables en lutte biologique, qui ne font pas l'objet d'AMM.

\section{L'inscription des variétés}

Pour que ses semences soient autorisées à la vente et à la culture, une variété doit être inscrite au Catalogue officiel des espèces et variétés végétales (géré en France par le Comité technique permanent de la sélection, CTPS), pour les espèces disposant d'un tel catalogue. Pour cela, la variété doit satisfaire à des critères dits DHS, pour « distinction » (par rapport aux variétés déjà inscrites), " homogénéité » (entre les individus de la variété) et « stabilité » (dans le temps, de ses caractéristiques). Pour les espèces de grande culture, la nouvelle variété doit également passer les épreuves dites « de VATE » (pour valeur agronomique, technologique et environnementale), visant à évaluer le progrès génétique qu'elle apporte dans ces trois domaines.

Afin de favoriser l'obtention de variétés adaptées à l'AB et plus généralement à une agriculture " bas intrants ", les épreuves VATE comportent une évaluation de la tolérance/résistance aux principales maladies de la variété, qui est donc testée sans protection pesticide.

Pour les variétés anciennes ou locales, souvent moins homogènes, les règles d'inscription au Catalogue officiel ont été assouplies. Les variétés dites « de conservation » (adaptées à des conditions locales et menacées d'érosion génétique), pour les espèces de grandes cultures et potagères, et les variétés « sans valeur intrinsèque », pour les espèces potagères, bénéficient ainsi d'un dispositif particulier facilitant leur inscription et leur multiplication tout en encadrant leur commercialisation.

\section{Les évaluations d'efficacité des alternatives au cuivre}

Pour les substances non homologuées, faisant l'objet de recherches ou d'essais techniques, la bibliographie révèle une large gamme de pratiques d'évaluation : tests in vitro (application du produit à tester sur l'agent pathogène cultivé au laboratoire), essais sur des cultures en pot ou sous serre (après inoculation artificielle du pathogène), essais au champ (en station d'expérimentation ou, plus rarement, chez des producteurs).

Comme pour le cuivre, l'efficacité d'une méthode de lutte peut être mesurée par ses effets sur : la fréquence ou la sévérité des symptômes ou dégâts sur les feuilles et/ou les organes récoltés; les pertes de récolte occasionnées par l'agent pathogène ; la quantité de propagules de cet agent pathogène présentes dans le milieu.

Les évaluations portent sur des efficacités comparées, entre différentes modalités de protection, en agriculture biologique et/ou en agriculture conventionnelle. L'efficacité du produit alternatif ou de la pratique testée peut être comparée à celle des traitements standard à base de cuivre ou à celle d'un fongicide de synthèse de référence (par exemple 
le mancozèbe, utilisé sur de nombreuses cultures). Bon nombre d'essais évaluent aussi l'efficacité de la méthode alternative associée à une dose réduite de cuivre.

Une méthode alternative peut être jugée intéressante même si elle ne permet pas, seule, d'assurer une protection suffisante pour une production commerciale. La distinction entre des situations (années, sensibilité de la variété cultivée) de faible ou forte pression de la maladie considérée permet par exemple d’identifier les méthodes qui peuvent s'avérer suffisantes dans certaines conditions.

\section{Les travaux engagés sur les alternatives au cuivre}

La forte pression réglementaire pour limiter ou supprimer les usages phytosanitaires du cuivre et, plus largement (au-delà des maladies ciblées par les traitements cupriques), les incitations à développer des méthodes pour réduire l'emploi des pesticides de synthèse, ont suscité des travaux nombreux et très divers. Sont ainsi intervenus :

- trois programmes européens dédiés à la recherche et à la mise en œuvre d'alternatives au cuivre, lancés depuis le début des années 2000 (encadré 1.3) ;

\section{Encadré 1.3. Les trois programmes européens majeurs de recherche dédiés aux alternatives au cuivre.}

- Blight Mop (Development of a systems approach for the Management of potato late blight (caused by Phytophthora infestans) in EU Organic Potato production in the absence of copper-based fungicides ; 2000-2005) était exclusivement consacré au mildiou de la pomme de terre. Comme les deux autres, ce projet comportait l'évaluation de techniques innovantes de contrôle de la maladie (stimulation de défense des plantes, pratiques agronomiques, variétés résistantes...) et visait à leur intégration au sein de systèmes complets, évalués à la fois en stations expérimentales et dans des fermes pilotes.

- RepCo (Replacement of copper fungicide in organic production of grapevine and apple in Europe ; 2005-2009) impliquait 6 pays, et a testé, sur vigne et pommier, de nombreux produits alternatifs (fongicides, éliciteurs, antagonistes, biostimulants) ainsi que la réduction des doses de cuivre. Ce projet a notamment produit l'étude la plus complète sur vigne (plus d'une centaine de substances testées sur plantes en pot ; Dagostin et al., 2011).

- Co-Free (Innovative strategies for copper-free low input and organic farming systems ; 2012-2017), qui couvrait les cultures fruitières, la vigne, la pomme de terre et la tomate, visait le développement de stratégies intégrées, mais a dû consacrer une part importante de ses efforts à l'évaluation de solutions individuelles nouvelles lextraits de plantes, micro-organismes utilisables en lutte biologique) sur lesquelles les références nécessaires n'avaient pu être acquises en amont du lancement du projet. Le projet s'étant achevé récemment, ses résultats ne sont encore que très partiellement publiés. 
- des recherches plus fondamentales sur les mécanismes biologiques, notamment de défense des plantes contre les pathogènes ;

- en génétique, la recherche systématique, permise par le développement des méthodes d'analyse moléculaire des génomes, de gènes ou de quantitative trait loci (QTL) de résistance, chez les espèces majeures (comme la vigne et le pommier) et leurs espèces apparentées ;

- des essais plus techniques visant à tester ou renforcer l'efficacité de diverses préparations, à base de plantes notamment, utilisées en $A B$;

- des travaux de recherche ou de R\&D menés par les entreprises privées, mais qui, couverts par le secret industriel, sont peu ou pas accessibles.

\section{La constitution du corpus bibliographique analysé et ses caractéristiques}

La constitution du corpus documentaire de l'ESCo se fonde sur la recherche dans la base de données bibliographiques internationale Web of Science (WoS). La requête a été construite en croisant deux équations de recherche : l'une listant des méthodes de lutte (techniques génériques, substances particulières...), l'autre les agents pathogènes ciblés (ceux contre lesquels des produits à base de cuivre sont homologués).

Les références issues de cette extraction ont été réparties entre les experts, selon leur domaine de compétence. Chaque expert a procédé à une amélioration de ce corpus initial : liste nettoyée du « bruit » inévitable ; requêtes affinées ou enrichies sur des points particuliers ; corpus complété par sa propre base bibliographique, avec des ouvrages ou articles plus généraux (sur les modes d'action des substances, par exemple), ou des références plus techniques (articles de revues professionnelles, comptes rendus d'essais, par exemple). Pour ces références non académiques (non validées par les pairs scientifiques), c'est à l'expert de retenir, ou non, chaque référence, en fonction de sa qualité (informations suffisantes sur les conditions d'expérimentation, par exemple). Enfin, des bases de données en ligne ont été consultées pour recenser les usages homologués du cuivre ou les produits autorisés en $A B$, par exemple.

Le corpus total examiné par l'ESCo comprend environ 880 références, très majoritairement issues de revues scientifiques à comité de lecture, et publiées après 2000 (voir annexe Le corpus bibliographique analysé). Les corpus sont de tailles très variables selon les sujets.

Pour les alternatives au cuivre ayant donné lieu à de (très) nombreux essais, ces résultats ont fait l'objet d'un dépouillement systématique (sous forme de tableaux présentés dans le rapport). 


\section{Les méthodes alternatives à l'usage du cuivre}

\section{Les préparations naturelles biocides}

SUR LES PRÉPARATIONS OU SUBSTANCES NATURELLES BIOCIDES potentiellement utilisables comme alternatives au cuivre, un corpus de 466 références a été constitué et exploité. En ce qui concerne les substances en développement, la diversité des protocoles expérimentaux in vitro et les différences d'activité observées lors du transfert au champ ne permettent pas d'évaluer le réel potentiel biocides des produits naturels. L'analyse a donc été focalisée sur les substances ayant fait l'objet d'essais au champ ou sous serre, et sur les produits déjà disponibles. Elle a privilégié une soixantaine d'articles de revues à comité de lecture. Une publication issue d'un programme de recherche européen (Dagostin et al., 2011) se distingue, car elle permet de comparer des produits testés (sur plantes en pot) dans les mêmes conditions expérimentales.

\section{Origine et mode d'action}

Les substances actives et préparations organiques biocides sont issues d'extraits végétaux ou de métabolites microbiens. Elles sont constituées soit d'extraits comprenant un mélange de composés, soit de molécules purifiées. Les modes d'action antimicrobiens de ces préparations sont rarement connus, mais la plupart de ces substances biologiquement actives inhibent soit la croissance des colonies ou des hyphes, soit la formation ou la germination des propagules (spores, cellules bactériennes...). Leurs modes d'action physiologiques et moléculaires, notamment ceux des composés antifongiques, restent souvent mal élucidés : seuls quelques composés actifs contre des souches pathogènes pour l'homme ont été étudiés.

\section{Les préparations naturelles " biocides " approuvées en France et en Europe}

Sur les 18 substances ou préparations qui bénéficient, fin 2017, d’une reconnaissance communautaire en tant que substance de base, et sont donc inscrites à l'annexe 1 du Règlement (CE) n 1107/2009, 11 affichent une activité fongicide, dont 7 sur des usages ciblés par le cuivre (tableau 2.1). Cette liste s'allonge régulièrement au fil de l'examen des dossiers, dont beaucoup concernent des extraits végétaux. Les substances de base alimentaires sont toutes utilisables en $A B$; les autres sont examinées au cas par cas. 


\section{Tableau 2.1. Préparations naturelles « biocides " approuvées en 2017 en France et en Europe.}

\begin{tabular}{|c|c|c|c|}
\hline Substance & $\begin{array}{l}\text { Homologation } \\
\text { Catégorie* ; date }^{*}\end{array}$ & $\begin{array}{c}\text { Usage } \\
\text { (culture/pathogène) }\end{array}$ & Produits commerciaux \\
\hline Substances de base & & Usages** & \\
\hline Hydroxyde de calcium (chaux éteinte) & $F ; 07 / 2015$ & Pommier/chancre (Nectria) & \\
\hline Bicarbonate de sodium & $\mathrm{F} ; 12 / 2015$ & Pommier/tavelure & \\
\hline \multirow[t]{3}{*}{ Prêle (Equisetum arvense) } & $F ; 07 / 2014$ & Pommier/tavelure & \\
\hline & & Pêcher/cloque & \\
\hline & & Vigne/mildiou & \\
\hline \multirow[t]{3}{*}{ Extrait d'écorce de saule (Salix spp.) } & $F ; 07 / 2015$ & Pommier/tavelure & \\
\hline & & Pêcher/cloque & \\
\hline & & Vigne/mildiou & \\
\hline \multirow[t]{2}{*}{ Ortie (Urtica spp.) } & F; 2017 & Vigne/mildiou & \\
\hline & & Pomme de terre/mildiou & \\
\hline Vinaigre (acide acétique) & $B, F ; 07 / 2015$ & $\begin{array}{l}\text { Blé (traitement des semences)/ } \\
\text { champignons autres que } \\
\text { pythiacées }\end{array}$ & \\
\hline \multirow[t]{2}{*}{ Lécithines } & $F ; 07 / 2015$ & Pêcher/cloque & \\
\hline & & Vigne/mildiou & \\
\hline Substances actives & & Usages homologués & \\
\hline Soufre & & Pommier/tavelure & Nombreux produits \\
\hline Bicarbonate de potassium & & Pommier/tavelure & Armicarb, K-BLOC \\
\hline \multirow{2}{*}{$\begin{array}{l}\text { Préparations à base d'huile } \\
\text { essentielle d'agrumes }\end{array}$} & & Vigne/mildiou & \multirow{2}{*}{$\begin{array}{l}\text { Essen'Ciel, Limocide, } \\
\text { Prev-Am }\end{array}$} \\
\hline & & Laitue/mildiou & \\
\hline
\end{tabular}

${ }^{*} \mathrm{~B}=$ bactéricide $; \mathrm{F}=$ fongicide.

** D’après les « Fiches d'usage » disponibles sur http://www.itab.asso.fr/activites/pp-dossiers-sb.php.

Les sels de calcium et de potassium. Le bicarbonate de potassium, dont deux préparations sont autorisées en $A B$, réduit de manière significative la tavelure du pommier et le mildiou de la vigne. L'efficacité est plus élevée lorsque l'application est proche de la période d'inoculation, et elle est améliorée si le bicarbonate de potassium est mélangé à des huiles minérales. L'hydroxyde de calcium (en verger) et le bicarbonate de sodium (sous serre) ont également montré une activité contre la tavelure du pommier. Contre la cloque du pêcher, l'hydroxyde de calcium vient de montrer des efficacités comparables (voire supérieures) à celle du cuivre dans un essai réalisé en 2017 en verger. 
Le soufre, principalement utilisé contre les oïdiums, est homologué pour un seul usage du cuivre : la tavelure du pommier. Le soufre et le polysulfure de calcium sont des biocides complémentaires du cuivre pour la protection des pommiers biologiques contre la tavelure : ils sont employés en verger pendant les périodes de sensibilité des fruits à la rugosité (provoquée par le cuivre).

Les substances de base d'origine végétale ou animale. Sont aussi approuvés en Europe comme substances de base fongicides la prêle, la lécithine, l'écorce de saule, le vinaigre et l'ortie. Parmi ces substances, seules la prêle, l'ortie et l'écorce de saule ont fait l'objet de publications décrivant leurs effets phytosanitaires, en particulier contre le mildiou de la vigne.

À notre connaissance, seules les préparations hydroalcooliques à base de prêle montrent une activité en cas de faible pression de mildiou et en combinaison avec une dose réduite de cuivre. Les effets du purin (macération) d'ortie pour lutter contre les maladies des plantes sont vantés par de nombreux ouvrages et sites populaires de jardinage. En France, l'arrêté du 18 avril 2011 autorise la mise sur le marché de purin d'ortie (préparation), notamment en pulvérisation foliaire ou sur le sol contre le mildiou ; cet arrêté a été complété par une liste de plantes utilisables pour fabriquer des purins. Sur le plan réglementaire, l'ortie n'est approuvée comme substance de base au niveau européen que depuis 2017.

Depuis 1990, un seul essai, réalisé dans le Gard sur mildiou de la vigne et black rot, a mis en évidence une " efficacité moyenne des purins (prêle et ortie) dans un contexte de mildiou normal », permettant d'envisager d'associer le purin au cuivre en dose réduite. Aucun autre des nombreux essais réalisés sur divers pathosystèmes n'a pu montrer de différence par rapport au témoin non traité ; c'est notamment le cas de l'étude de Dagostin et al. (2011) sur mildiou de la vigne en pot.

Préparations à base d'huiles essentielles d'agrumes. Trois préparations commerciales à base d'huiles essentielles d'agrumes, en particulier d'orange douce, sont autorisées en $A B$ pour des applications sur mildiou de la vigne et de la laitue. Elles présentent aussi, in vitro, une activité contre l'Alternaria de la carotte, et inhibent la germination des conidies de tavelure. Elles sont également développées en viticulture et en arboriculture par leur fabricant.

\section{Les préparations naturelles biocides à fort potentiel}

Ne sont reprises ici que les préparations naturelles ayant fait l'objet d'études en conditions de culture, et affichant des propriétés antimicrobiennes significatives vis-à-vis des agents phytopathogènes, mais non homologuées en France ou en Europe à ce jour. Les données sont récapitulées dans le tableau 2.2.

\section{Les huiles essentielles}

Les huiles essentielles (HE) sont des extraits naturels de plantes contenant des principes volatils, extraits par distillation dans la vapeur d'eau ou par pression. Plusieurs HE sont commercialisées aux États-Unis comme fongicides pour l'AB. Peu d'articles scientifiques traitent de l'identification des composants actifs et des modes d'action de ces produits. 


\section{Tableau 2.2. Extraits ou produits naturels à activité antimicrobienne, mais actuellement non homologués en Europe pour des usages phytosanitaires.}

\begin{tabular}{|c|c|c|c|c|}
\hline & Produit & Principe(s) actif(s) & Usages (culture/cible) testés & Produit commercial \\
\hline \multirow{9}{*}{ 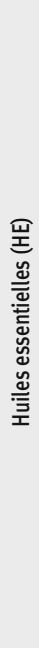 } & $\begin{array}{l}\text { HE de thym } \\
\text { (Thymus vulgaris) }\end{array}$ & $\begin{array}{l}\text { Thymol ( } 90 \%) \\
\text { et carvacrol ( } 8 \%)\end{array}$ & $\begin{array}{l}\text { Pommier/tavelure (et feu } \\
\text { bactérien) }\end{array}$ & Promax $^{T M}$ \\
\hline & & & Vigne/mildiou & \\
\hline & $\begin{array}{l}\text { HE de sariette } \\
\text { (Satureja hortensis) }\end{array}$ & Carvacrol (99\%) & $\begin{array}{l}\text { Pommier/tavelure (et feu } \\
\text { bactérien) }\end{array}$ & \\
\hline & $\begin{array}{l}\text { HE d'origan } \\
\text { (Origanum acutidens) }\end{array}$ & Carvacrol et thymol & & \\
\hline & $\begin{array}{l}\text { HE de clou de girofle } \\
\text { (Syzygium aromaticum) }\end{array}$ & Eugénol & $\begin{array}{l}\text { Tomate/flétrissement } \\
\text { bactérien }\end{array}$ & \\
\hline & & & Cacahuète/11 champignons & \\
\hline & $\begin{array}{l}\text { Mélange d'HE de romarin } \\
(18 \%) \text {, de clou de girofle } \\
(15 \%) \text { et de thym }(5 \%)\end{array}$ & & & Sporatec \\
\hline & $\begin{array}{l}\text { HE d'arbre à thé, Tea tree } \\
\text { (Melaleuca alternifolia) }\end{array}$ & Terpine-4-ol & & BM-608 \\
\hline & $\begin{array}{l}\text { HE de sapin d'eau } \\
\text { (Metasequoia } \\
\text { glyptostroboides) }\end{array}$ & & $\begin{array}{l}\text { Melon/bactériose à } \\
\text { Xanthomonas (sous serre) }\end{array}$ & \\
\hline \multirow{8}{*}{ 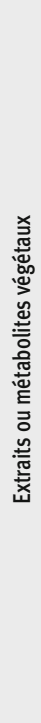 } & Extrait de yucca & Saponines & Vigne/mildiou & \\
\hline & & & $\begin{array}{l}\text { Sorgho/maladies du sol; } \\
\text { traitement des semences }\end{array}$ & \\
\hline & $\begin{array}{l}\text { Extrait de pavot plume } \\
\text { (Macleaya cordata) }\end{array}$ & $\begin{array}{l}\text { Sanguinarine } \\
\text { et chélérythine } \\
\text { (alcaloïdes) }\end{array}$ & $\begin{array}{l}\text { Agrumes/anthracnose, oïdium } \\
\text { Concombre/mildiou }\end{array}$ & Kimura SC \\
\hline & $\begin{array}{l}\text { Extrait d'ail } \\
\text { (Allium sativum) }\end{array}$ & Allicine & $\begin{array}{l}\text { Tomate/Alternaria solani } \\
\text { Carotte, sorgho/A. alternata } \\
\text { Vigne/mildiou }\end{array}$ & \\
\hline & $\begin{array}{l}\text { Pommier de Sodome } \\
\text { (Calotropis procera): } \\
\text { extrait de feuilles }\end{array}$ & & & \\
\hline & Extrait purifié de latex & Protéine CpOsm & & \\
\hline & $\begin{array}{l}\text { Extrait de renouée de } \\
\text { Sakhaline (Reynoutria } \\
\text { sachalinensis) }\end{array}$ & $\begin{array}{l}\text { Physcion et émodine } \\
\text { (action de stimulation } \\
\text { de défense des plantes) }\end{array}$ & $\begin{array}{l}\text { Plantes sous serre et } \\
\text { ornementales/oïdium }\end{array}$ & 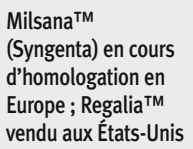 \\
\hline & $\begin{array}{l}\text { Extrait de sauge officinale } \\
\text { (Salvia officinalis) }\end{array}$ & $\begin{array}{l}\text { Dérivés de lutéoline } \\
\text { et d'acide rosmarinique } \\
\text { (phénols) }\end{array}$ & $\begin{array}{l}\text { In vitro/Alternaria solani } \\
\text { Vigne/mildiou }\end{array}$ & \\
\hline
\end{tabular}


Tableau 2.2. Suite.

\begin{tabular}{|c|c|c|c|c|}
\hline & Produit & Principe(s) actif(s) & Usages (culture/cible) testés & Produit commercial \\
\hline \multirow{5}{*}{ 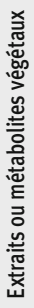 } & $\begin{array}{l}\text { Extrait de peuplier noir } \\
\text { (Populus nigra) }\end{array}$ & $\begin{array}{l}\text { Populin (polyphénol) } \\
\text { à confirmer }\end{array}$ & Pommier/tavelure & \\
\hline & \multirow{2}{*}{$\begin{array}{l}\text { Extrait de réglisse } \\
\text { (Glycyrrhiza glabra) }\end{array}$} & \multirow[t]{2}{*}{ Flavonoïdes } & Concombre/mildiou & \\
\hline & & & Vigne/mildiou & \\
\hline & \multicolumn{2}{|l|}{$\begin{array}{l}\text { Extrait de margousier } \\
\text { (Melia azedarach) }\end{array}$} & Vigne/mildiou & \\
\hline & \multicolumn{2}{|l|}{ Huile végétale } & Vigne/mildiou & $\begin{array}{l}\text { Natur'l óleo }{ }^{\circledR} \text { (huile } \\
\text { vendue au Brésil) }\end{array}$ \\
\hline \multirow{4}{*}{ 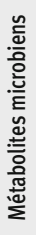 } & $\begin{array}{l}\text { Antibiotiques produits } \\
\text { par des actinomycètes } \\
\text { (Streptomyces spp.) }\end{array}$ & \multicolumn{2}{|l|}{$\begin{array}{l}\text { Streptomycine, } \\
\text { validamycine }\end{array}$} & $\begin{array}{l}\text { Nombreux produits } \\
\text { commerciaux dans le } \\
\text { monde. Interdits en } \\
\text { Europe }\end{array}$ \\
\hline & \multirow[t]{3}{*}{ Lipopeptides bactériens } & \multirow{3}{*}{$\begin{array}{l}\text { Surfactines, iturines } \\
\text { et fengycines }\end{array}$} & Tomate/Alternaria alternata & \\
\hline & & & Vigne/mildiou & \\
\hline & & & Laitue/mildiou & \\
\hline
\end{tabular}

L'essentiel des publications rapporte des évaluations d'activité - plus de 140 publications démontrant des activités antifongiques surtout en traitement post-récolte contre des maladies de conservation (hors périmètre de l'expertise).

L'efficacité antibactérienne d'HE de plantes constitue un enjeu important, compte tenu du manque de moyens de lutte contre les bactérioses des cultures. Une synthèse recense les HE (issues d'une trentaine d'espèces) actives contre Xanthomonas, et montre une efficacité intéressante sous serre.

Les huiles essentielles à thymol et carvacrol. L'HE de thym aurait un effet significatif, utilisée avec de la bouillie bordelaise, contre Erwinia amylovora, au laboratoire et en verger. Elle présente, in vitro, la capacité de réduire la germination des ascospores et des conidies de Venturia inaequalis. Une formulation d'HE de thym est préconisée pour la fumigation des sols contre un large spectre de parasites telluriques. Une préparation à base d'huile de thym a été testée par Dagostin et al. (2011) en conditions contrôlées contre le mildiou de la vigne, sans donner de résultat satisfaisant. L'HE de sariette est active, in vitro, contre la tavelure et le feu bactérien. Les HE de thym et de sariette présentent un large spectre d'activité contre des champignons de post-récolte. Enfin, l'HE d'origan a montré un large spectre d'activité contre plus de 17 espèces de champignons et d'oomycètes pathogènes des plantes, dont Alternaria alternata, $A$. solani, Botrytis sp., plusieurs Fusarium, Monilinia sp., Pythium ultimum, Phytophthora capsici, Rhizoctonia solani, Sclerotinia minor et Verticillium dahliae. 
L'huile essentielle de clou de girofle a montré un intérêt contre le flétrissement bactérien de la tomate (Ralstonia solanacearum) in vitro et en conditions de culture. L'huile et son composé majoritaire, l'eugénol, ont également une activité importante in vitro sur 11 espèces de champignons pathogènes de la cacahuète. L'eugénol affiche un large spectre d'activité contre des souches d'Alternaria; il serait aussi actif, in vitro, pour contrôler d'autres espèces affectant la conservation des pommes. En vignoble, une préparation commerciale à base d'HE de clou de girofle, de romarin et de thym a montré une certaine efficacité contre le mildiou en conditions de pression faible.

L'huile essentielle d'arbre à thé (Tea Tree), riche en terpènes, perturberait l'intégrité des membranes des bactéries et des champignons. Une étude met en évidence, au champ, une certaine efficacité contre le mildiou de la vigne dans des conditions de pression faible. Par ailleurs, cette HE a montré une activité potentielle significative (inhibition de la croissance des hyphes in vitro) en protection des semences contre 7 espèces de champignons pathogènes (Ascochyta rabiei, Colletotrichum lindemuthianum, Fusarium graminearum, F. culmorum, Drechslera avenae, Alternaria radicina et $A$. dauci).

\section{Les extraits ou métabolites végétaux}

L'extrait de yucca. Il figure parmi les traitements les plus efficaces de l'étude de Dagostin et al. (2011) : une préparation à base de saponines issue d'extraits de yucca est en effet citée comme prometteuse, car elle affiche plus de $95 \%$ d'activité dans certains essais au champ contre le mildiou de la vigne. L'extrait de yucca permettrait également, en traitement des semences, de réduire significativement certaines maladies du sol du sorgho. Il aurait aussi une activité contre la tavelure du pommier, par inhibition de la germination des conidies et/ou par effet stimulateur de défense des plantes (SDP).

L'extrait de pavot plume. Les extraits de racine de Macleya cordata (plante utilisée en médecine chinoise) contiennent des alcaloïdes qui ont des activités fongicides et insecticides. Même si le mode d'action n'a pas été confirmé, un extrait de $M$. cordata est vendu comme fongicide, et certains produits commerciaux basés sur cette plante sont connus pour induire une résistance systémique acquise. Ces extraits contiennent de nombreux alcaloïdes, dont la sanguinarine. Son efficacité est comparable aux effets en serre des fongicides de synthèse, et s'exerce contre divers agents pathogènes microbiens des plantes. Ainsi, les extraits de $M$. cordata réduisent la libération et la survie de zoospores des oomycètes in vitro, et inhibent la croissance de mycélium de $P$. infestans. Contre le mildiou du concombre, l'extrait induit à des concentrations très faibles une réduction de $90 \%$ de l'infestation. La sanguinarine afficherait également une activité antifongique significative contre Rhizoctonia solani. Par ailleurs, l'extrait de pavot plume ne serait pas considéré comme toxique vis-à-vis des espèces non-cibles.

Les extraits d'ail. Selon les formulations de jus d'ail évaluées en protection des semences, le facteur de protection varie considérablement. Un essai avec un extrait aqueux de feuilles a mis en évidence une réduction significative de l'impact d'Alternaria solani sur tomate (en plein champ et en serre), avec une réduction de la sévérité des 
symptômes de plus de $71 \%$ et 57 \% respectivement sous serre et en plein champ, et une augmentation de $66 \%$ des rendements en fruits au champ. Un extrait aqueux de gousses a montré une capacité à inhiber la croissance de $A$. alternata et $A$. dauci sur graines de carotte. Une huile végétale additionnée d'extrait d'ail a montré sur vigne une réduction significative de la sévérité des symptômes du mildiou. Un extrait de zimmu (Allium cepa $\times$ A. sativum) a été testé au champ contre Alternaria alternata sur sorgho, avec une réduction de la croissance fongique de $74 \%$ et une augmentation significative du rendement. L'huile essentielle d'ail serait aussi active in vitro contre le chancre suintant du noyer.

L'extrait de pommier de Sodome. Les extraits de feuilles de cet arbuste originaire des régions arides d'Afrique et du Moyen-Orient ont montré, contre Alternaria solani sur tomate au champ, une efficacité qui peut être équivalente à celle du mancozèbe en matière de réduction de la sévérité de la maladie et d'augmentation du rendement en fruits. Par ailleurs, une protéine (osmotine) purifiée à partir du latex affiche une activité antifongique (inhibition de germination des spores et de croissance des hyphes) contre Fusarium solani, Neurospora sp. et Colletotrichum gloeosporioides; elle est relativement thermostable et conserve son activité sur une large gamme de $\mathrm{pH}$, ce qui en fait un bon candidat pour le développement de produits.

Les extraits riches en polyphénols. Un extrait de renouée de Sakhaline, déjà vendu aux États-Unis, est en cours d'homologation (dossier déposé par Syngenta en 2012) en Europe pour le contrôle d'un large éventail de maladies fongiques et bactériennes, en agriculture biologique et conventionnelle. Il serait particulièrement efficace contre l'oïdium, et il est utilisé principalement sur les plantes sous serre et ornementales. Il agit apparemment indirectement, par l'induction des défenses de la plante. Pour leur part, les extraits de sauge officinale ont une activité antifongique mise en évidence par de nombreuses publications. Ils inhibent fortement la croissance in vitro d'Alternaria solani. Des évaluations sur vigne d'un produit à base d'extrait de sauge développé par JKI/Safecrop ont donné des résultats prometteurs : contre le mildiou, son activité est équivalente à celle du cuivre en conditions contrôlées et en plein champ sur grappe (sur deux saisons de récolte). L'extrait de peuplier noir montre une efficacité intéressante contre la tavelure du pommier, in vitro et en verger, où son effet serait équivalent à celui des fongicides conventionnels (mancozèbe, hydroxyde de cuivre, penconazole), pour un coût de traitement qui serait inférieur ; ces travaux restent à confirmer, mais ébauchent une piste de travail intéressante. Des extraits de réglisse montrent des activités antifongiques contre les mildious du concombre, de la vigne et (en serre seulement) de la laitue.

Plusieurs travaux mettent aussi en évidence le potentiel des lignanes extraits de Myristica fragrans, in vitro et in vivo, sur tomate et riz, et de la berbérine extraite de Coptis chinensi pour lutter contre Monilia fructicola.

L'extrait de margousier. Sur mildiou de la vigne, l'extrait de fruits et graines inhibe in vitro la germination des sporanges, et s'avère au champ aussi efficace que la bouillie 
bordelaise. Toutefois, certains extraits de fruits montrent aussi une activité insecticide à large spectre ; c'est pourquoi des études d'impact sur les auxiliaires et pollinisateurs seraient une étape préalable à tout projet éventuel d'homologation.

Les acides gras et l'huile végétale. Des essais au champ sur deux années, montrant que l'utilisation d'huile végétale seule ou en combinaison avec de la bouillie bordelaise permet de réduire les symptômes causés par le mildiou de la vigne de plus de 66 \%, suggèrent un avenir prometteur pour ces préparations en protection de la vigne.

\section{Les métabolites microbiens}

Les antibiotiques produits par des actinomycètes. D’assez nombreux produits, issus principalement de Streptomyces spp., ont été commercialisés et utilisés intensivement comme fongicides au Japon, et dans une moindre mesure dans d'autres pays. La streptomycine, utilisée contre plusieurs bactérioses et mycoses des plantes, et la validamycine, employée contre les Rhizoctonia, sont ainsi vendues sous de nombreux noms commerciaux. Étant considérés comme des antibiotiques (produits à usage pharmaceutique), ces composés ne sont pas autorisés en Europe en protection des cultures. Aux États-Unis, ils ne sont pas acceptés en $A B$, sauf la streptomycine contre le feu bactérien du pommier et du poirier.

Les lipopeptides bactériens. Le potentiel de biosurfactants d'origine naturelle comme antimicrobiens utilisables en protection des cultures a fait l'objet de nombreuses recherches. Parmi ces biosurfactants figurent des lipopeptides produits par certaines souches de Bacillus subtilis ou de Pseudomonas sp., dont les activités biocides ont été largement démontrées. Ces souches de Bacillus produisent trois familles de biocides lipopeptidiques (surfactines, iturines et fengycines), qui agissent en favorisant le développement de fractions bénéfiques du microbiote racinaire ou foliaire des plantes, en inhibant la croissance des hyphes de champignons pathogènes et/ou en induisant des réactions de résistance systémique. Ces substances seraient responsables des effets mis en évidence contre Alternaria sur tomate, contre le mildiou de la vigne et celui de la laitue, et d'un large spectre d'activités antagonistes contre notamment Botrytis cinerea, Rhizoctonia solani, Pythium aphanidermatum et Podosphaera. Ces composés présentent une faible toxicité (tests microtox et daphnie) par rapport aux produits conventionnels.

\section{I Éléments de conclusion}

\section{Peu de spécialités aujourd'hui homologuées et efficaces}

Parmi les substances actives déjà autorisées en Europe, et en $A B$, certaines peuvent aider à réduire les doses de cuivre, comme le bicarbonate de potassium. Les substances de base aujourd'hui homologuées (extraits d'ortie et de prèle, vinaigre, bicarbonate de sodium...) sont aisément disponibles, mais leur efficacité contre les parasites ciblés par le cuivre semble très limitée, voire nulle. 


\section{De nombreuses pistes prometteuses}

De nombreuses huiles essentielles ont été testées in vitro, mais peu ont fait l'objet d'études au champ. Les huiles essentielles riches en thymol et carvacrol affichent de fortes activités in vitro sur un large spectre de phytopathogènes, et certaines études montrent leur potentiel au champ, tout comme les huiles essentielles de clou de girofle et d'arbre à thé.

Parmi les extraits de plantes, ceux de sauge officinale et de réglisse contre le mildiou de la vigne, ou encore de yucca et de peuplier noir contre la tavelure du pommier, montrent des résultats particulièrement intéressants.

L'utilisation de métabolites bactériens de type surfactant, combinant activité antifongique et stimulation des défenses, mérite aussi d'être explorée.

Finalement, il existe de nombreuses substances biocides qui ont fait preuve d'une efficacité intéressante en conditions de culture ; elles devront cependant passer le crible des études écotoxicologiques et toxicologiques avant d'être autorisées comme substances actives ou substances de base. Certaines de ces substances, par leur nature et leur activité vis-à-vis de certains pathogènes de l'homme, sont considérées comme des antibiotiques, et ne seront donc pas autorisées en protection des cultures, ni $a$ fortiori en $\mathrm{AB}$.

\section{Des freins souvent importants à l'innovation}

Les probabilités de voir arriver sur le marché des produits ayant comme substances actives l'un des biocides examinés dépendent du niveau de protection de la propriété intellectuelle, et de la nature du consortium de recherche ayant effectué les travaux. Ainsi, les substances pouvant être autorisées comme substances de base auront plus de chances d'être disponibles pour les agriculteurs et les jardiniers, professionnels ou amateurs.

\section{Les agents microbiologiques de biocontrôle}

LA PROTECTION BIOLOGIQUE A ÉTÉ INTENSIVEMENT ÉTUdIÉE au cours des dernières décennies. Si de nombreux micro-organismes ont été identifiés comme agents de biocontrôle potentiels contre les maladies des plantes, seul un nombre restreint est actuellement commercialisé. Rappelons que l'utilisation d'un agent microbien comme agent de protection nécessite une homologation en tant que produit phytosanitaire.

Le corpus bibliographique analysé est constitué de 181 publications, essentiellement issues de revues scientifiques. Les articles concernent des études réalisées dans 34 pays couvrant tous les continents (majoritairement Europe, Amériques et Asie). Ces études portent principalement sur l'effet protecteur de micro-organismes contre des agents pathogènes bactériens et fongiques importants des cultures fruitières (en particulier abricotier, pêcher et pommier) et de diverses cultures maraîchères. Les mildious sont également 
abordés, notamment sur la vigne, la pomme de terre et la tomate. En complément, des ouvrages de référence et des sites Web ont été consultés pour répertorier les produits de biocontrôle à base de micro-organismes homologués en France et à l'étranger sur des usages qui correspondent à l'utilisation actuelle du cuivre en France.

\section{Les types d'agents biologiques, leurs modes d'action et conditions d'utilisation}

\section{Types d'organismes}

Les micro-organismes utilisables pour le biocontrôle contre les agents pathogènes cibles des traitements cupriques appartiennent à trois grands groupes biologiques : les champignons, levures ou oomycètes, organismes eucaryotes généralement multicellulaires et produisant un thalle porteur des organes de reproduction sexuée ou asexuée ; les bactéries et actinomycètes, organismes procaryotes unicellulaires se multipliant essentiellement par division cellulaire asexuée ; les virus, qui utilisent la machinerie cellulaire de l'hôte infecté pour se multiplier.

Les propriétés biologiques spécifiques de ces groupes influent sur leurs modalités d'emploi (formulation, mode d'application, capacité de conservation, possibilité de les associer entre eux ou avec d'autres moyens de lutte...) et conditionnent en partie leurs possibilités de développement opérationnel en conditions de culture. Elles sont donc prises en compte par les entreprises, mais celles-ci diffusent très peu d’informations sur la composition effective de leurs produits (la nature des formulants, par exemple), qui relève de la propriété intellectuelle.

\section{Modes d'action}

Trois modes d'action principaux, mettant en jeu divers mécanismes biologiques, ont été identifiés : la destruction ou l'inhibition directe du pathogène, la compétition avec l'agent pathogène, et l'interaction avec le processus de pathogenèse. Pour certains agents de protection biologique, leur mode d'action n'est pas précisément défini.

\section{L'inhibition directe ou la destruction de l'agent pathogène}

Ce mode d'action peut mobiliser deux mécanismes :

- l'antibiose, dans laquelle l'organisme antagoniste produit des métabolites secondaires toxiques pour l'agent pathogène, dont ils peuvent inhiber la germination, la croissance mycélienne et/ou la sporulation. L'antibiose est le mode d'action le plus étudié, car il est aisément révélé au laboratoire. La production de composés antibiotiques dépend cependant de nombreux facteurs environnementaux (potentiel hydrique, $\mathrm{pH}$ du milieu, température...). Il existe beaucoup d'exemples de bactéries et de champignons producteurs de composés à effet antibiotique, notamment Bacillus subtilis, Pseudomonas fluorescens, Streptomyces sp. ou Trichoderma sp. Des substances responsables de l'antibiose ont pu être caractérisées chez diverses espèces, et les gènes impliqués dans la production de certaines de ces substances ont été identifiés. 
Ce mode d'action est le plus proche de celui de la lutte chimique ; il peut donc s'avérer très efficace pour inhiber le développement d'un microbe pathogène, mais aussi présenter les mêmes risques de toxicité des molécules produites pour l'environnement, les utilisateurs et les consommateurs, et d'apparition de souches résistantes chez l'agent pathogène cible ;

- l'hyperparasitisme, dans lequel l'antagoniste pénètre dans les tissus de l'agent pathogène, et entraîne sa destruction via la colonisation de ses organes. Le champignon Ampelomyces quisqualis parasite ainsi les champignons responsables de l'oïdium. L'utilisation d'hyperparasites présente des contraintes, comme la nécessité d'un contact direct avec l'agent pathogène lui-même et d'une action rapide pour assurer sa destruction.

\section{La compétition pour les nutriments ou l'espace}

Certains micro-organismes (bactéries, levures, champignons filamenteux) peuvent inhiber la germination des conidies du pathogène via la compétition pour des éléments nutritifs comme l'azote, le carbone ou des macro- ou micro-éléments présents dans le milieu. Ce mode d'action est particulièrement efficace contre les champignons pathogènes dont les spores ont besoin d'une source de nutriments pour initier leur germination. La réduction du taux de spores germées et le ralentissement de la croissance mycélienne de l'agent pathogène limitent le nombre d'infections et l'expansion des lésions. La compétition pour les nutriments a par exemple été établie pour le champignon antagoniste Trichoderma harzianum $\mathrm{T} 39$.

\section{L'interaction avec le processus de pathogenèse}

Ce mode d'action peut mobiliser trois mécanismes distincts :

- une interférence avec le pouvoir pathogène de la cible, notamment les enzymes hydrolytiques que synthétisent les champignons pathogènes pour dégrader les tissus de la plante lors du processus d'infection. Les agents de protection biologique peuvent affecter le pouvoir pathogène de champignons en dégradant certaines enzymes hydrolytiques, ou en réduisant leur efficacité (via par exemple une modification du pH du milieu) ;

- une modification des propriétés de surface des organes de la culture hôte. Certaines bactéries ont la capacité, en synthétisant des composés à effet tensioactif qui modifient la mouillabilité des feuilles, de gêner le processus d'adhésion et de croissance des pathogènes, et de réduire les périodes d’humidité favorable à leur développement ;

- une induction de la résistance de la plante hôte. De nombreux micro-organismes ont une action de SDP (voir section « Les stimulateurs des défenses naturelles des plantes»), induite par la production d'éliciteurs de natures chimiques diverses. C'est le cas par exemple de Bacillus subtilis, la bactérie active du produit Serenade ${ }^{\circledR}$. Cette thématique fait l'objet de nombreux travaux de recherche actuellement.

Dans certains cas, le contrôle biologique semble résulter de la combinaison de plusieurs mécanismes d'action. Chez le champignon Trichoderma, différents modes d'action, en 
particulier hyperparasitisme et antibiose, ont ainsi été mis en évidence chez une même souche. Dans ces cas de combinaison d'effets, le rôle et l'importance relative de chacun des modes d'action dans le contrôle de la maladie ne sont généralement pas quantifiés précisément.

\section{Facteurs d'efficacité et contraintes d'utilisation}

L'efficacité des agents de biocontrôle est régie par des facteurs complexes liés à leurs modes d'action et au fait qu'il s'agit d'organismes vivants. En conditions de cultures commerciales, leur survie, leur installation et leur activité vont ainsi dépendre :

- du contexte environnemental rencontré. La fluctuation des conditions microclimatiques (température et humidité notamment) est généralement identifiée comme l'un des facteurs clés du manque de stabilité de l'efficacité des agents de protection biologique. À la surface des plantes, ces agents sont aussi soumis à des variations de la disponibilité en nutriments et des caractéristiques des feuilles (morphologie, exsudats chimiques...) ; - des pratiques culturales. L'efficacité d'un agent de protection biologique peut différer en fonction de la variété cultivée, de la fertilisation de la plante ou des autres traitements phytosanitaires appliqués. Des informations sur la compatibilité avec les produits pesticides et entre agents de biocontrôle sont donc nécessaires ;

- de la qualité du produit de biocontrôle et de son mode d'application. L'efficacité de la protection et sa stabilité dans le temps dépendent des caractéristiques de l'agent microbien, mais aussi de la formulation du produit, de ses conditions de transport et de stockage et de l'homogénéité de son application, qui vont influer sur la quantité de propagules vivantes appliquées au champ, sur leur capacité de reprise d'activité et de multiplication, sur leur contact avec leur cible. Les contraintes d'utilisation varient selon le mode d'action : l'application d'un micro-organisme actif par contact est plus délicate que s'il agit à distance, la mise en place d'une résistance induite chez la plante requiert un certain délai, par exemple ;

- des caractéristiques des agents pathogènes ciblés. Les maladies à évolution rapide sont plus difficiles à contenir que les maladies monocycliques à évolution lente. L'efficacité d'un agent de protection biologique va ensuite dépendre de la quantité d'inoculum pathogène présente, et de la variabilité génétique des souches pathogènes.

\section{Produits homologués en France sur les usages actuels du cuivre}

En France, onze produits à base de micro-organismes bénéficient d'une autorisation de mise en marché (AMM) pour lutter contre des maladies faisant l'objet d'un usage homologué du cuivre (tableau 2.3-A). Ces produits couvrent :

- partiellement deux des 21 usages du cuivre en arboriculture et viticulture : la lutte contre la tavelure du pommier (Serenade ${ }^{\circledR}$ ) et les maladies du bois de la vigne (Esquive ${ }^{\circledR}$ ). Serenade bénéficie également d'une AMM pour la lutte contre les monilioses sur fruits à noyaux ; 
- partiellement deux usages du cuivre en grandes cultures : la lutte contre les champignons (fusarioses) sur blé et sur seigle, avec application en traitement de semences. Le produit concerné est le Cerall ${ }^{\circledR}$; deux autres produits, Prestop ${ }^{\circledR}$ et Polyversum ${ }^{\circledR}$, pourraient également être utilisés contre ce type de cibles. Un usage majeur du cuivre, le mildiou de la pomme de terre, n'est pas couvert ;

- partiellement deux des 20 usages du cuivre en cultures maraîchères. Deux produits (Trianum ${ }^{\circledR}$ et Tusal ${ }^{\circledR}$ ) peuvent être utilisés pour protéger la carotte contre des pythiacées (Pythium et Phytophthora), et Serenade ${ }^{\circledR}$ est homologué contre la « bactériose » de la tomate (il n'est cependant pas clair si toutes les bactéries qui affectent la tomate sont efficacement contrôlées par le produit) ;

- très partiellement, divers usages sur les plantes d'intérieur et balcon et les PPAMC (plantes à parfum, aromatiques, médicinales et condimentaires). Il s'agit de six produits (Asperello T34 Biocontrol, Mycostop ${ }^{\circledR}$, Prestop ${ }^{\circledR}$, Serenade ${ }^{\circledR}$, Trianum ${ }^{\circledR}$ et Tusal ${ }^{\circledR}$ ), avec des modes d'application différents de celui du cuivre. Enfin, un produit homologué contre les maladies du bois de la vigne (Esquive ${ }^{\circledR}$ ) pourrait couvrir partiellement un usage du cuivre en protection des plaies.

La bibliographie scientifique disponible ne permet pas de préciser l'efficacité de ces produits dans les conditions de production françaises.

\section{Produits homologués à l'étranger}

Au niveau de l'Union européenne (UE), 27 souches de micro-organismes sont actuellement inscrites dans la base de données EU Pesticide Database pour la lutte contre des agents de maladies des plantes : 17 souches de champignons, levures ou oomycètes, 8 souches de bactéries ou actinomycètes, et 2 virus (consultation le 31/01/2017). Parmi ces souches, 9 non homologuées en France actuellement se positionnent sur des usages du cuivre en France (tableau 2.3-B ; souches notées en bleu). Certains de ces microorganismes complètent ainsi, ailleurs dans l'UE, des usages non encore couverts en France. Une souche supplémentaire est homologuée dans l'UE contre la moniliose du pêcher. De plus, Serenade ${ }^{\circledR}$ bénéficie dans d'autres pays européens d'une homologation sur des usages majeurs supplémentaires, notamment l'oïdium de la vigne et le mildiou de la laitue.

Au niveau mondial, 44 micro-organismes sont développés commercialement comme agents de biocontrôle contre les maladies des plantes : 25 souches de champignons, levures ou oomycètes, 14 souches de bactéries ou actinomycètes, et 5 virus. Parmi eux, 19 souches (plus des bactériophages commercialisés aux États-Unis) sont utilisées dans des produits homologués en dehors de l'UE sur des usages correspondant à ceux du cuivre en France (tableau 2.3-C). S’ils s'avéraient efficaces dans les conditions de production française, ces produits permettraient potentiellement de couvrir, au moins partiellement, 19 usages du cuivre non pourvus par des produits actuellement autorisés en France, et de renforcer les 11 usages déjà pourvus. Sept de ces souches (en bleu dans le tableau 2.3-C) sont déjà homologuées dans l'UE sur des usages différents, ce qui pourrait faciliter leur homologation en France. 


\section{Tableau 2.3. Produits phytopharmaceutiques à base de micro-organismes homologués pour le contrôle des maladies faisant l'objet d'un usage autorisé du cuivre en France.}

\begin{tabular}{|c|c|c|c|c|}
\hline & $\begin{array}{c}\text { Nom du produit } \\
\text { (fabricant/distributeur) }\end{array}$ & $\begin{array}{l}\text { Micro-organisme } \\
\text { Espèce et souche(s) }\end{array}$ & Usage (culture/cible) & $\begin{array}{l}\text { Type de } \\
\text { traitement }\end{array}$ \\
\hline \multirow{11}{*}{  } & $\begin{array}{l}\text { Asperello T34 Biocontrol } \\
\text { (Bio Control } \\
\text { Technologies) }\end{array}$ & Trichoderma asperellum $\mathrm{T}_{34}$ & $\begin{array}{l}\text { Cultures ornementales/ } \\
\text { trachéomycoses }\end{array}$ & Sol \\
\hline & $\begin{array}{l}\text { Blossom Protect } \\
\text { (Bio Ferm GMBH) }\end{array}$ & $\begin{array}{l}\text { Aureobasidium pullulans } \\
\text { DSM } 14940 \text { et DSM } 14941\end{array}$ & Pommier/feu bactérien & Parties aériennes \\
\hline & Cerall (Belchim) & $\begin{array}{l}\text { Pseudomonas } \\
\text { chlororaphis MA342 }\end{array}$ & $\begin{array}{l}\text { Blé, seigle/champignons } \\
\text { autres que pythiacées }\end{array}$ & Semences \\
\hline & Esquive (Agrauxine) & Trichoderma atroviride I-1237 & $\begin{array}{l}\text { Vigne/esca, black dead arm, } \\
\text { eutypiose }\end{array}$ & $\begin{array}{l}\text { Parties aériennes } \\
\text { (dont badigeon) }\end{array}$ \\
\hline & $\begin{array}{l}\text { Mycostop Verdera Oy } \\
\text { (Lallemand Plant Care) }\end{array}$ & Streptomyces K61 & $\begin{array}{l}\text { Traitements généraux (limité } \\
\text { aux légumes fruits sans } \\
\text { contact avec le sol et plantes } \\
\text { non alimentaires) }\end{array}$ & Sol \\
\hline & $\begin{array}{l}\text { Polyversum } \\
\text { (De Sangosse) }\end{array}$ & $\begin{array}{l}\text { Pythium oligandrum M1 } \\
\text { et ATCC } 38472\end{array}$ & Blé/fusarioses & Parties aériennes \\
\hline & $\begin{array}{l}\text { Prestop Verdera 0y } \\
\text { (Lallemand Plant Care) }\end{array}$ & Gliocladium catenulatum J1446 & $\begin{array}{l}\text { Blé, seigle/champignons } \\
\text { autres que pythiacées } \\
\text { Traitements généraux/ } \\
\text { champignons autres que } \\
\text { pythiacées; pythiacées }\end{array}$ & Sol \\
\hline & $\begin{array}{l}\text { Rotstop Verdera 0y } \\
\text { (Lallemand Plant Care) }\end{array}$ & Phlebiopsis gigantea & Forêts/pourridié & $\begin{array}{l}\text { Souches } \\
\text { des arbres }\end{array}$ \\
\hline & Serenade (Bayer) & Bacillus subtilis QST 713 & $\begin{array}{l}\text { Cultures ornementales, } \\
\text { fruits à coque, tomate, } \\
\text { PPAMC/bactérioses } \\
\text { Pommier/feu bactérien, } \\
\text { tavelure } \\
\text { Fruits à noyau/moniliose }\end{array}$ & Parties aériennes \\
\hline & $\begin{array}{l}\text { Trianum } \\
\text { (Koppert) }\end{array}$ & $\begin{array}{l}\text { Trichoderma harzianum Rifai T-22 } \\
\text { et ITEM-908 }\end{array}$ & $\begin{array}{l}\text { Cultures légumières/ } \\
\text { pythiacées } \\
\text { Cultures ornementales, } \\
\text { PPAMC/maladies fongiques }\end{array}$ & Sol \\
\hline & $\begin{array}{l}\text { Tusal } \\
\text { (Newbiotechnic SA) }\end{array}$ & Trichoderma atroviride T11 & $\begin{array}{l}\text { Cultures légumières, } \\
\text { florales et ornementales, } \\
\text { plantes vertes/champignons } \\
\text { et pythiacées }\end{array}$ & Irrigation \\
\hline
\end{tabular}


Tableau 2.3. Suite.

\begin{tabular}{|c|c|c|c|c|}
\hline & $\begin{array}{l}\text { Nom du produit } \\
\text { (fabricant/distributeur) }\end{array}$ & $\begin{array}{l}\text { Micro-organisme } \\
\text { Espèce et souche(s) }\end{array}$ & Usage (culture/cible) & $\begin{array}{l}\text { Type de } \\
\text { traitement }\end{array}$ \\
\hline \multirow{10}{*}{ 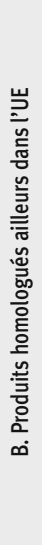 } & & Ampelomyces quisqualis $\mathrm{AQ}_{10}$ & Vigne/oïdium & \\
\hline & & Bacillus pumilus QST 2808 & & \\
\hline & $\begin{array}{l}\text { Serenade } \\
\text { (usages suppl.) }\end{array}$ & Bacillus subtilis QST 713 & $\begin{array}{l}\text { Vigne/oïdium } \\
\text { Laitue/mildiou }\end{array}$ & \\
\hline & & Pseudomonas sp. DSMZ 13134 & Champignons telluriques & Sol \\
\hline & & Saccharomyces cerevisiae LAS02 & Pêcher/moniliose & \\
\hline & & Streptomyces K61 & Plantes aromatiques & Sol \\
\hline & & Streptomyces lydicus WYEC 108 & Champignons telluriques & Sol \\
\hline & & Trichoderma atroviride $\mathrm{SC}_{1}$ & Vigne/maladies du bois & \\
\hline & & $\begin{array}{l}\text { Trichoderma atroviride } \\
\text { IMI } 206040 \text { et T. polysporum } \\
\text { IMI } 206039\end{array}$ & Chondrostereum purpureum & \\
\hline & & Verticillium albo-atrum WCS850 & Orme/verticilliose & \\
\hline \multirow{12}{*}{ 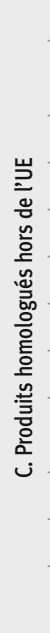 } & AgriPhage & & & \\
\hline & Bio-Tam, Tenet & $\begin{array}{l}\text { Trichoderma asperellum ICCO12 + } \\
\text { T. gamsii ICC080 }\end{array}$ & & \\
\hline & BlightBan A506 & Pseudomonas fluorescens & & \\
\hline & Bloomtime Biological & Pantoea agglomerans $\mathrm{E}_{325}$ & & \\
\hline & Double Nickel 55 & Bacillus amyloliquefaciens D747 & & \\
\hline & Ecosom-TV & Trichoderma viride TNAU & & \\
\hline & Galltroll & Agrobacterium radiobacter $\mathrm{K} 84$ & & \\
\hline & Nogall & Agrobacterium radiobacter $\mathrm{K}_{1026}$ & & \\
\hline & $\begin{array}{l}\text { Polyversum } \\
\text { (usages suppl.) }\end{array}$ & $\begin{array}{l}\text { Pythium oligandrum M1 } \\
\text { et ATCC } 38472\end{array}$ & & \\
\hline & Serenade (usages suppl.) & Bacillus subtilis QST 713 & & \\
\hline & Sonata & Bacillus pumilus QST 2808 & & \\
\hline & Taegro & $\begin{array}{l}\text { Bacillus subtilis } \\
\text { amyloliquefaciens FZB24 }\end{array}$ & & \\
\hline
\end{tabular}

PPAMC : plantes à parfum, alimentaires, médicinales et condimentaires.

En bleu : produit, souche ou usage homologués ailleurs qu'en France dans l'UE (éventuellement sur d'autres usages que ceux ciblés par le cuivre en France). En violet : produit, souche ou usage homologués uniquement hors de l'UE (éventuellement sur d'autres usages que ceux ciblés par le cuivre en France) (source : https://ephy.anses.fr/, site consulté le 31 janvier 2017). 


\section{Autres agents microbiens présentant un potentiel de biocontrôle}

Sur la cinquantaine d'usages du cuivre répertoriés en France, 24 ne sont pas couverts par des produits commerciaux à base de micro-organismes autorisés en France ou dans d'autres pays. Pour 4 de ces usages « orphelins », des publications scientifiques montrent l'existence de micro-organismes testés pour leur effet contre l'agent pathogène concerné. Les agents pathogènes concernés sont uniquement des bactéries, sur olivier, vigne, oignon et poireau. Pour l'usage oignon $\times$ bactérioses, les travaux (réalisés aux États-Unis) portent

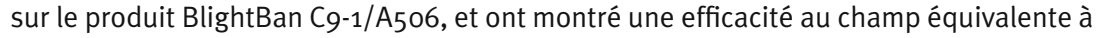
celle du cuivre. Pour les trois autres usages, les recherches concernent des souches « de laboratoire », et ne permettent pas d'évaluer de manière précise l'efficacité de la protection ou révèlent des efficacités variables au champ.

Certaines des publications scientifiques examinées portent sur des micro-organismes ayant déjà fait l'objet d'un développement industriel (Actinovate ${ }^{\circledR}$, AgriPhage ${ }^{\mathrm{TM}}, \mathrm{AQ}_{10}{ }^{\circledR}$, BlightBan ${ }^{\circledR}$, Bloomtime Biological'TM, Bmj WP, Mycostop ${ }^{\circledR}$, Serenade ${ }^{\circledR}$ et Sonata ${ }^{\circledR}$ ), mais utilisés pour des indications différentes. Il s'agit donc là d'une tentative d'extension d'usage, en amont d'une demande potentielle de reconnaissance officielle de cet effet. Les données d'efficacité disponibles suggèrent l'intérêt de Serenade ${ }^{\circledR}$ en remplacement du cuivre sur plusieurs usages importants : vigne $\times$ mildiou, pomme de terre $\times$ mildiou, et tomate $\times$ bactériose (du moins celle causée par Pseudomonas syringae). Pour BlightBan ${ }^{\circledR}$, ces données d'efficacité, excepté pour la bactériose de l'oignon, amènent un constat plus mitigé sur les pathosystèmes étudiés (tomate $\times$ bactérioses causées par Pseudomonas syringae ou Xanthomonas sp.).

L'analyse bibliographique montre que de nouvelles souches de micro-organismes pourraient potentiellement compléter les usages déjà couverts par des produits autorisés en France ou ailleurs. Cependant, le développement futur de ces nouveaux micro-organismes en produits commerciaux nécessite de nombreuses étapes au-delà de la " simple » démonstration d'une efficacité à l'échelle d'un projet de recherche. Ces étapes incluent notamment des études de faisabilité technique et de coûts de production industrielle, et des démarches réglementaires liées à l’homologation.

\section{Conclusion et perspectives}

\section{Une couverture très partielle des usages du cuivre}

Parmi la cinquantaine d'usages du cuivre en France, onze sont couverts partiellement par des produits à base de micro-organismes actuellement autorisés en France. Cette couverture est " partielle ", car beaucoup de ces usages sont très vastes (ils correspondent chacun à plusieurs, voire de nombreux, pathogènes), alors que l'efficacité des agents de protection biologique est souvent très spécifique d'un ou quelques pathogènes. De plus, cinq des onze usages sont couverts par un seul produit, ce qui pourrait poser à terme des problèmes de durabilité de l'efficacité de la protection. 
Potentiellement, 19 usages supplémentaires pourraient être partiellement couverts en cas d'autorisation en France de produits déjà commercialisés dans l'UE ou dans d'autres pays. Cependant, leur intérêt réel en remplacement du cuivre en France dépendra de l'efficacité qu'ils pourront avoir dans les cultures françaises. Dans certains pays, notamment en Amérique du Nord, la démonstration de l'efficacité d'un produit n'est pas requise pour son homologation, à la différence des règles applicables en Europe. Il est donc possible que certains produits homologués à l'étranger ne puissent bénéficier d'une autorisation de mise sur le marché en Europe.

D'après l'analyse bibliographique, des micro-organismes permettraient éventuellement de couvrir quatre usages supplémentaires à plus long terme, en fonction de contingences d'ordres technique, industriel, réglementaire et commercial, et de la volonté des firmes d'effectuer les démarches d'autorisation de mise sur le marché.

Enfin, 20 usages n'ont pas même fait l'objet de travaux de recherche publiés.

\section{D'importants besoins complémentaires de recherche}

Des investissements scientifiques et industriels conséquents sont nécessaires pour la mise au point et la commercialisation des agents microbiens de biocontrôle. Cela explique sans doute en partie pourquoi une part importante des travaux porte sur des extensions d'emploi de produits commerciaux déjà disponibles. Le flux de préparations utilisant de nouvelles souches ou espèces à des fins de biocontrôle reste pour sa part limité, y compris dans des indications majeures du cuivre.

Par ailleurs, la nature même des produits de lutte biologique pose de nombreuses questions sur la compatibilité entre efficacité de ces produits et emploi d'autres techniques culturales mises en œuvre sur la culture. Un essor des travaux d'écologie microbienne pour mieux positionner et insérer la lutte microbiologique est donc un élément clé du développement de ce type de solution.

\section{Les résistances variétales}

LA CRÉATION ET LE dÉPLOIEMENT DE VARIÉTÉS RÉSISTANTES constituent une méthode de protection des plantes très intéressante pour limiter l'emploi des produits phytosanitaires en général. L'amélioration des connaissances en génétique des plantes a permis aux sélectionneurs d'introduire des facteurs de résistance dans les variétés cultivées, notamment grâce à des croisements avec des espèces sauvages apparentées. Mais la culture à grande échelle de ces variétés a rapidement mis en évidence la capacité des bioagresseurs à contourner ces résistances.

Les mécanismes de résistance des plantes aux bioagresseurs, mobilisés par l'amélioration génétique mais aussi par l'emploi de stimulateurs de défense des plantes (voir section « Les stimulateurs des défenses naturelles des plantes »), sont présentés en encadré 2.1. 


\section{Encadré 2.1. Les résistances végétales.}

Comme tous les êtres vivants, les plantes ne survivent que parce qu'elles sont capables de s'opposer, via un système immunitaire qui leur est propre, à une vaste gamme d'agresseurs, principalement des micro-organismes pathogènes (virus, bactéries et champignons) et des arthropodes phytophages (insectes et acariens). Cette capacité des plantes à empêcher l'exploitation de leurs propres tissus comme source de nutriments pour des parasites constitue la résistance aux parasites. Cette résistance peut être caractérisée d'un point de vue génétique (hérédité du caractère), pathologique (expression et évolution des symptômes au cours de l'interaction), moléculaire (mécanismes physiologiques sous-jacents) et écologique (gamme d'hôte et spécialisation parasitaire).

\section{Typologie des résistances végétales}

Trois types principaux de résistance des plantes peuvent être distingués sur la base des niveaux d'interaction établis entre la plante et le micro-organisme agresseur : les résistances non-hôte, les résistances qualitatives et les résistances quantitatives.

- Les résistances non-hôte se caractérisent par une exclusion totale de l'agresseur potentiel, qui ne parvient donc pas à établir une relation parasitaire avec la plante. C'est une caractéristique des espèces : l'ensemble des génotypes d'une espèce végétale est alors résistant à tous les génotypes d'un agent microbien donné. Elle se traduit par une absence complète d'infection, et donc de symptômes (immunité totale). Elle repose essentiellement sur des défenses constitutives préformées, mises en place avant même le contact avec l'agresseur potentiel, et constituant des barrières physiques à l'infection : par exemple cuticule externe, composition des parois cellulaires végétales. La résistance non-hôte, qui correspond au cas le plus fréquent de résistance des plantes, en est également la forme la plus durable. C'est pourquoi la compréhension de ses mécanismes et de son déterminisme génétique, actuellement très partielle, pourrait à l'avenir permettre de sélectionner des cultivars durablement résistants aux principaux agents pathogènes.

Lorsque l'agresseur parvient à éviter ces barrières initiales, il peut établir une interaction parasitaire plus ou moins efficace avec son hôte. Les capacités de la plante à restreindre plus ou moins complètement les conséquences de cette interaction constituent les deux types de résistance hôte : qualitative ou quantitative.

- Les résistances qualitatives se traduisent le plus souvent, sur le plan des symptômes, par une réaction dite " hypersensible ", c'est-à-dire une nécrose cellulaire limitée au site d'infection, sans extension au-delà et sans reproduction de l'agent pathogène. Ce sont donc des résistances totales, au sens où elles empêchent complètement le développement de la maladie sur les hôtes résistants.

D’un point de vue génétique, ces résistances sont généralement mono- ou oligogéniques, c'est-à-dire héritées via un ou quelques gènes de la plante. Les interactions hôteparasite correspondantes suivent très généralement le modèle "gène-pour-gène " : 
c'est l'interaction (directe ou indirecte) entre le produit du gène de résistance de la plante et le produit d'un gène d'avirulence du pathogène qui aboutit à la résistance. Cela explique que ces résistances ne soient actives que chez certains génotypes de la plante (ceux porteurs du gène de résistance) et contre certains génotypes du parasite (ceux porteurs du gène d'avirulence). Ces résistances sont donc spécifiques de ces configurations génétiques, et non pas générales comme le sont les résistances non-hôte.

Du fait de leurs très forts effets génétique (hérédité simple) et phénotypique (blocage complet des infections), les gènes de résistance qualitative sont très souvent qualifiés de "gènes majeurs de résistance", et notés $R^{*}$.

- Les résistances quantitatives se traduisent par une réduction de la sévérité des symptômes (taille des lésions, vitesse d'extension) par rapport aux témoins sensibles. Elles peuvent réduire également la reproduction du parasite, mais ne l'empêchent généralement pas entièrement. Ce sont donc des résistances partielles, car elles ne permettent pas de bloquer entièrement le cycle de développement du parasite.

Ces résistances sont le plus souvent actives vis-à-vis de l'ensemble des génotypes de l'agent pathogène, et donc qualifiées de résistances non spécifiques. Elles sont généralement polygéniques, c'est-à-dire déterminées par un nombre parfois élevé de QTL à effet individuel faible ou modéré. Ce déterminisme génétique complexe rend ardue la sélection de ces résistances, mais leur confère une durabilité supposée plus grande. De fait, les cas rapportés d'érosion de résistances partielles sont en nombre limité, bien inférieur à ceux de contournement de résistances totales.

Le temps nécessaire pour observer en conditions de culture des évènements de contournement (chute brutale d'efficacité) ou d'érosion (diminution progressive d'efficacité) des résistances se révèle très variable. Alors que certains gènes de résistance demeurent efficaces après plusieurs décennies d'utilisation intensive, d'autres ont été contournés en quelques années, voire en quelques mois. La durée nécessaire aux sélectionneurs pour créer et commercialiser une variété porteuse d'un nouveau gène de résistance reste, elle, longue. L'introgression de gènes $R$ dans des cultivars "élite " prend jusqu'à 15-20 ans via la sélection traditionnelle. La sélection assistée par marqueurs (SAM) a réduit de moitié le temps nécessaire à la création de nouvelles variétés. Cette technique permet de tester rapidement le statut (résistant ou sensible) d'un grand nombre d'individus en recherchant la présence de marqueurs moléculaires liés au gène d'intérêt, plutôt que par une évaluation phénotypique (tests d'inoculation en conditions contrôlées ou au champ).

\section{Mécanismes physiologiques sous-jacents : résistance et défense des plantes}

La première ligne de défense des plantes contre les agressions microbiennes, dite "constitutive", repose sur la cuticule (couche hydrophobe à la surface des organes aériens) et la paroi cellulaire. C'est elle qui est pour l'essentiel à l'origine de la résistance non-hôte. Toutefois, ce type de résistance pourrait également impliquer d'autres mécanismes, encore mal élucidés, et dont l'exploitation pourrait permettre à terme l'obtention de plantes durablement résistantes. 
Une seconde ligne de défense, inductible, repose sur la perception de l'agresseur puis sur les réactions de défense qui s'ensuivent (figure 2.1). C'est elle qui est mobilisée dans les différents types de résistance hôte, selon le modèle aujourd'hui couramment adopté dit « en zigzag ».

Figure 2.1. Les réactions de défense des plantes contre un agent pathogène dans le cadre de la PTI (PAMP-triggered immunity).



ET : éthylène; FT : facteur de transcription; MAMP: Microbial Associated Molecular Pattern; MAPK : Mitogen-Activated Protein Kinase; IA : acide jasmonique; SA : acide salicylique; PR : PathogenesisRelated ; PRR : Pattern Recognition Receptor; SDP : stimulateurs de défense des plantes.

Ce modèle distingue deux grandes étapes d'induction des défenses par les attaques parasitaires. La première est activée en réponse à des molécules produites par le parasite lui-même lors de l'infection, ou éliciteurs. Ces molécules, sécrétées par l'agent pathogène, portées à sa surface ou issues de la dégradation des cellules hôtes infectées, sont désignées sous le terme générique de PAMP (Pathogen-Associated Molecular Pattern). Ce sont le plus souvent des composés structuraux (de paroi cellulaire, de flagelle bactérien...), que l'on retrouve dans de nombreux micro-organismes et qui peuvent être détectés par des récepteurs spécifiques situés dans la membrane cytoplasmique végétale. Ces molécules sont donc pour la plante autant de signatures d'une attaque en cours. La liaison PAMP-récepteur déclenche alors une cascade de signalisations cellulaires, qui aboutit à l'expression de gènes de défense codant pour des composés antimicrobiens (phytoalexines), mais également des protéines de défense limpliquées dans la gestion du stress oxydant, dans la dégradation de 
l'agent pathogène ou dans la reprogrammation du métabolisme de la plante vers les voies de défense) et des composés mobilisés pour renforcer la paroi végétale au point d'attaque (callose, lignine...). Ce système, appelé PTI (PAMP-triggered immunity) ou immunité basale, permet de mettre en échec un grand nombre d'agresseurs microbiens. C'est lui qui serait directement impliqué dans les résistances quantitatives.

Pour pouvoir continuer à exploiter la plante après la mise en place de la PTI, certains parasites ont su développer d'autres types de molécules, nommées " effecteurs ", et destinés à bloquer les réactions de défense induites lors de la PTI. En retour, les plantes se sont dotées de récepteurs spécifiques ciblant ces effecteurs, et les utilisent pour activer une seconde batterie de réactions de défense, regroupée sous le nom d'ETI (Effector-triggered immunity). C'est la base mécanistique des résistances qualitatives, les gènes majeurs étant vraisemblablement ceux gouvernant les récepteurs spécifiques des effecteurs. L'ETI comporte elle-même deux mécanismes de défense. L'un, local et appelé « réaction hypersensible », déclenche la mort des cellules au voisinage du point d'attaque du pathogène, ce qui a pour effet de bloquer la progression des parasites biotrophes. L'autre, appelé « résistance systémique acquise », consiste, par la diffusion de signaux hormonaux dans la plante à partir du point d'attaque, à préparer les cellules des organes distants à déclencher leurs défenses plus rapidement et intensément en cas d'attaque ultérieure. Ces mécanismes sont sous la dépendance de phytohormones, dont les plus connues sont l'acide salicylique, l'acide jasmonique et l'éthylène. Les voies de défense associées à ces différentes hormones ne sont pas actives contre les mêmes agents pathogènes. Les défenses liées à l'ETI complètent donc la PTI et sont très efficaces, mais seulement contre certaines souches des agents pathogènes.

* Les gènes R sont nommés par les initiales du nom de l'agent pathogène, éventuellement suivies de 3 (4) lettres indiquant l'espèce chez laquelle le gène a été identifié, puis d'un numéro (par exemple Rpi-ber1 pour une résistance à Phytophthora infestans provenant de Solanum berthaultii).

Deux interrogations du WoS ont été réalisées : la première, ciblant les articles de synthèse sans se restreindre aux cultures « utilisatrices » de cuivre, a fourni 66 références ; la seconde, ciblant les articles primaires en se limitant aux cultures et agents pathogènes contrôlés par des traitements à base de cuivre, a fourni 422 références. L'analyse a aussi retenu quelques références issues de la littérature grise. Sur les 422 articles primaires, 125 ont pour plante d'étude le pommier, 118 la pomme de terre, 42 la tomate, 20 la vigne et 14 la laitue. C'est pourquoi l'analyse porte principalement sur ces cinq cultures d'importance agronomique majeure. La partie sur la gestion durable des résistances ne concerne pas uniquement ces cinq cultures, les articles analysés étant issus des deux interrogations du WoS. 


\section{Les résistances chez les principales cultures utilisatrices de cuivre}

\section{Ressources génétiques et variétés disponibles chez le pommier}

\section{Les facteurs de résistance identifiés et utilisés}

Sur pommier, le cuivre est utilisé pour contrôler la tavelure (causée par Venturia inaequalis) et le chancre européen. La sélection génétique cible en priorité la résistance à $V$. inaequalis, espèce à fort potentiel évolutif.

Concernant la tavelure, 17 gènes majeurs de résistance (nommés Rvi1 à Rvi17) ont été décrits à ce jour. Tous fonctionnent selon le modèle gène-pour-gène. La majorité des variétés de pommier résistantes à la tavelure utilisées actuellement porte le gène de résistance Rvi6 (aussi appelé $V f$ ) : plus d'une centaine de ces variétés sont recensées dans les catalogues commerciaux. Toutefois, ces variétés résistantes n'occupent qu'une très faible part des surfaces cultivées ( $<1 \%$ en Europe), même si cette part est parfois bien supérieure dans les vergers en AB. Dès les années 1990, cette résistance a été contournée dans différents pays européens par des souches virulentes, qui s'avèrent issues de populations de pathogènes présentes sur un hôte sauvage géniteur de la résistance $V f$. Très peu de variétés intègrent d'autres gènes (Rvi5 dans les cultivars Murray et Rouville, Rvi 4 dans Regia et Rvirz dans Durello di Forli). Par ailleurs, au moins $13 \mathrm{QTL}^{2}$ de résistance partielle ont été décrits chez le pommier, avec des spectres d'action large (QTL efficaces vis-à-vis de la majorité des souches testées, comme F11 et F17) ou étroit (QTL spécifiques, efficaces seulement contre certaines souches ; cas de T1).

Des recherches ont aussi identifié des facteurs de résistance au feu bactérien (dû à Erwinia amylovora), et des programmes de sélection sont en cours pour obtenir des variétés cumulant des résistances au feu bactérien et à la tavelure, et, pour certaines, à l'oïdium (dû à Podosphaera leucotricha). Quelques cultivars ont été identifiés à l'issue de ces travaux.

Le poirier, espèce génétiquement proche du pommier, est également affecté par une tavelure (causée par Venturia pirina ou V. nashicola). La littérature disponible sur cette culture est bien moins abondante. Trois gènes majeurs de résistance ont cependant été décrits, ainsi que vraisemblablement au moins 11 QTL.

2. Un QTL (pour quantitative trait locus, locus de caractère quantitatif), est une région chromosomique plus ou moins grande qui est étroitement associée à un caractère quantitatif. Un QTL est donc une partie de chromosome qui contient un ou plusieurs gènes ségrégant en même temps que ce caractère. Les QTL étant identifiés via des méthodes de cartographie génétique, donc de corrélation entre présence/absence de certains marqueurs moléculaires et variation phénotypique constatée pour le caractère étudié (résistance à un parasite, rendement, qualité du produit récolté...), leur taille dépend beaucoup de la finesse de la mesure du caractère lui-même (qualité des données phénotypiques), du nombre et de la densité de marqueurs génomiques disponibles, et de la taille de la population en ségrégation utilisée pour la cartographie. L'identification de marqueurs génétiques situés à proximité des gènes, ou QTL d'intérêt, permet la sélection assistée par marqueurs (SAM). 


\section{Les sensibilités variétales au champ}

Plusieurs travaux ont évalué des sensibilités variétales en verger. Une des études les plus conséquentes (réalisée au Canada et publiée en 2005) a évalué pendant trois ans, dans un verger ne recevant aucun traitement fongicide, la sensibilité à la tavelure de 54 cultivars et 14 lignées en cours de sélection. Ce travail a permis de distinguer 16 cultivars pour leur très faible niveau (voire l'absence) de maladie : Regine, Rebella, Resi, Rewena, Akane, Anis Aily, Antonovka, Bramley's Seedling, Chehalis, Discovery, Generos, Golden Reinette, Golden Russett, Margil, Peypring Cerueuko et Wolf River.

Par ailleurs, des documents techniques nationaux recensent des données sur les sensibilités variétales observées. Ainsi, en France, le guide Inra-GRAB « Guide des sensibilités variétales aux bio-agresseurs », paru en 2016, rapporte les données de sensibilités à la tavelure relevées sur 19 variétés de pommiers dans un verger implanté dans le Sud-Est (Inra Gotheron), dont 8 variétés sont également suivies dans l'Ouest (Inra Angers), et sur 36 variétés « anciennes et nouvelles » suivies dans quatre vergers (Drôme, Nord, Lot-et-Garonne et Vaucluse). Ce guide signale que de nombreuses variétés anciennes sont peu sensibles à la tavelure sur feuille, telles Provençale rouge d'hiver, Pomme d'Adam, Pomme de Risoul, de l'Estre, Court Pendu, Gris du Limousin, Reinette Champagne, Reinette des Capucins ou Cabarette. Parmi les variétés plus récentes, Reine des Reinettes ou Honeycrisp sont également peu sensibles au niveau du feuillage, mais beaucoup plus attaquées sur fruits. Parmi les variétés avec le meilleur comportement à la fois sur feuille et sur fruit, figurent Belle de Boskoop, Akane ou Reinette des Capucins. Des travaux antérieurs ont montré la valeur de ces résistances pour réduire l'emploi de pesticides. Ainsi, il a été possible de réduire le nombre d'applications fongicides contre la tavelure de plus de $50 \%$ sur Melrose et de plus de $60 \%$ sur Reine des Reinettes par rapport à la référence Golden. Comme beaucoup des variétés étudiées dans le réseau servant de base au guide s'avèrent plus résistantes que ces deux génotypes, il est sans doute possible d'envisager des réductions de traitements sensiblement plus fortes en utilisant les cultivars les plus résistants.

Au Canada, le guide "Lutte intégrée contre les ennemis du pommier », publié par le ministère chargé de l'Agriculture de l'Ontario, dresse une liste partielle de cultivars résistants à la tavelure disponibles sur le marché ; il décrit 26 cultivars de pommier, tous notés résistants sauf un (Rouville). Aux États-Unis, l'université de Purdue a compilé en 2006 des données sur la sensibilité de 88 cultivars de pommier à la tavelure et au feu bactérien. Les données concernant la tavelure montrent le faible niveau de résistance de la majorité des variétés (figure 2.2), mais identifient 15 variétés présentant de hauts niveaux de résistance (CrimsonCrisp, Entreprise, Florina, Freedom, GoldRush, Liberty, Macfree, Nova Easygrow, Novamac, Nova Spy, Prima, Priscilla, Pristine, Sir Prize et William's Pride). Vis-à-vis du feu bactérien, 19 variétés sont notées " résistantes », et deux « très résistantes ». Il s'agit des variétés Freedom et Novamac, également « très résistantes » à la tavelure. 


\section{Figure 2.2. Sensibilités variétales du pommier à la tavelure : distribution de la note " tavelure " de 88 variétés de pommier.}



La note 1 indique une variété très sensible, la note 6 une variété très résistante. En rouge : la médiane des notes de sensibilité. L'ordonnée correspond au nombre de variétés dans chaque classe de résistance (source : Beckerman, J., 2006. Disease susceptibility of common apple cultivars. Purdue Extension publications, BP-132-W, 4 p.).

\section{Ressources génétiques et variétés disponibles chez la vigne}

En viticulture, les produits à base de cuivre ne sont homologués que contre le mildiou (causé par Plasmopara viticola) et les bactérioses. Les programmes d'amélioration génétique de la vigne ciblent en général ses deux principales maladies : le mildiou et l'oïdium (causé par Erysiphe necator, contrôlé en AB par des produits à base de soufre).

\section{Les facteurs de résistance identifiés et utilisés}

Concernant le mildiou, au moins 14 facteurs de résistance ont été décrits (synthèse de 2011), dont 6 sont utilisés dans les programmes de sélection européens (références de 2003 à 2012) (tableau 2.4B).

Pour l'oïdium, au moins 11 facteurs de résistance (nommés Run puis Ren) ont été décrits (revue de 2015), dont 4 sont utilisés dans les programmes de sélection européens : Run1, Run2.2, Ren1 et Ren3.

Les principaux acteurs de la création variétale en vigne sont européens (WBI en Allemagne, IGA en Italie, Agroscope en Suisse). En France, l'Inra développe depuis 1974, aux côtés de l'IFV, un programme visant à incorporer dans la vigne européenne (Vitis vinifera) des facteurs de résistance originaux, portés par Muscadinia rotundifolia, espèce très résistante à l'oïdium et au mildiou. Ce programme a abouti en 2000 à une série de génotypes (appelée "Bouquet ») qui ont ensuite été, dans un nouveau programme de sélection, 
croisés avec des espèces sauvages de vignes américaines et asiatiques. Le matériel généré, appelé « Resdur », doit conforter la durabilité des résistances en pyramidant plusieurs gènes de résistance. Parmi les cépages "Resdur », l'année 2017 a vu l'inscription de quatre cépages (Artaban, Vidoc, Floreal et Voltis) cumulant les gènes Rpv1 et $R p v 3$ (+ Run1 et Run3 pour l'oïdium) ; une seconde série de 19 variétés associant les gènes Rpv1 et Rpv10 (+ Run1 et Ren3.2) sera présentée en 2020.

Les populations d'oïdium et de mildiou de la vigne possèdent un fort potentiel évolutif, illustré par la vitesse à laquelle ces deux pathogènes ont déjà répondu à la pression exercée par les fongicides en développant des résistances à presque toutes les molécules. La crainte d'une adaptation aux cépages résistants semble donc justifiée. Plusieurs cas de contournements/érosion ont d'ailleurs déjà été décrits : concernant le mildiou, pour les QTL Rpv3, Rpv1 et Rpv1o pris isolément ; concernant l'oïdium, pour les QTL Renz et Run1.

\section{Les sensibilités variétales au champ}

Le guide technique publié par l'Institut coopératif du vin (ICV) en 2013, "Les cépages résistants aux maladies cryptogamiques - Panorama européen », présente un état de l'art sur la résistance des cépages et sur les programmes de sélection en cours, ainsi qu'une caractérisation des qualités agronomiques (en particulier les résistances aux mildiou, botrytis et oïdium) et technologiques de 200 cépages étudiés dans 6 pays d’Europe. Depuis 2017, l'Observatoire national du déploiement des cépages résistants 3 (OsCar) collecte et diffuse dans plusieurs bassins viticoles des données sur la sensibilité au champ d’une large gamme de cépages résistants.

Le catalogue international des variétés de vigne recense pour sa part les caractéristiques de plusieurs milliers de cépages avec, pour certains, des notations de sensibilité aux principales maladies. L'analyse des 847 cépages dédiés à la production viticole inclus dans ce catalogue montre que la résistance au mildiou est assez rare chez les cépages de l'espèce Vitis vinifera, mais assez répandue dans les cépages issus de croisements interspécifiques (figure 2.3, A et B).

\section{Ressources génétiques et variétés disponibles chez la pomme de terre}

Le mildiou (causé par Phytophthora infestans) peut toucher tous les organes de la pomme de terre (parties aériennes et tubercules). L'utilisation de variétés résistantes est considérée comme une bonne solution pour limiter les pertes de rendement dues au mildiou, mais $P$. infestans présente de fortes capacités d'adaptation aux résistances de ses hôtes. L'amélioration génétique de la pomme de terre (Solanum tuberosum) bénéficie de la richesse du genre Solanum, qui comprend 1500 à 2000 espèces, adaptées à des habitats, et donc à des stress biotiques et abiotiques, très variés. De nombreuses accessions du genre Solanum, qui contiennent des allèles intéressants pour différents objectifs de sélection, sont maintenues dans différentes banques de gènes internationales, accessibles

3. http://observatoire-cepages-resistants.fr/. 
Figure 2.3. Sensibilités au mildiou des variétés de vigne destinées à la production de vin : distribution de la note " mildiou du feuillage" de 108 cépages de Vitis vinifera (A) et de 739 cépages issus de croisements interspécifiques (B).

\section{A}

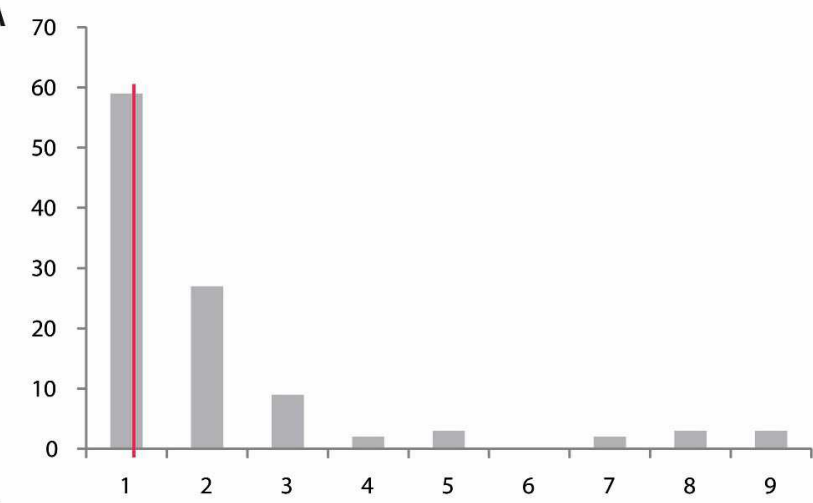

B

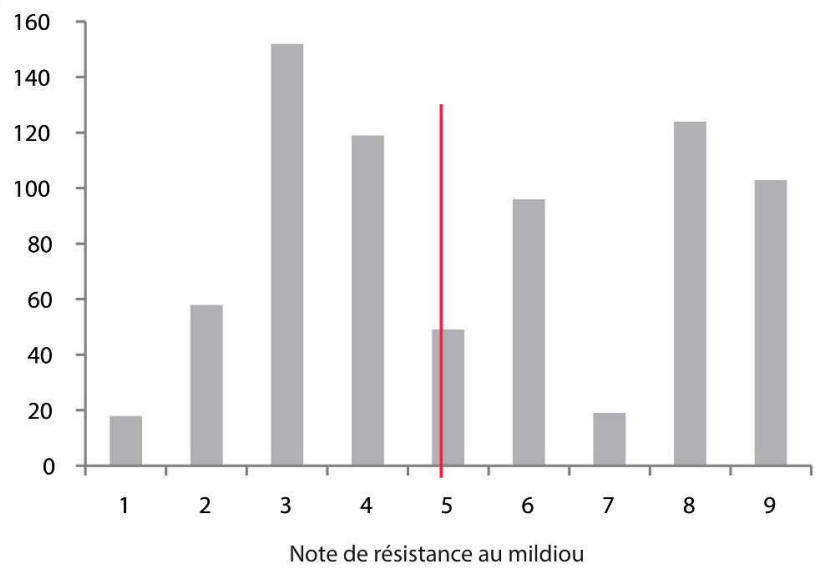

La note 1 indique une variété très sensible et la note 9 une variété très résistante. En rouge : la médiane des notes de sensibilité. L'ordonnée correspond au nombre de variétés dans chaque classe de résistance (source : Catalogue international des variétés de vigne ; www.vivc.de, consulté le 27/02/2017).

aux chercheurs et aux sélectionneurs. En France, l'Inra de Rennes conserve ainsi plus de 10000 accessions. L'amélioration génétique de la pomme de terre est un processus long et complexe, car l'espèce est polyploïde, fortement hétérozygote, ce qui cause des barrières à l’hybridation interspécifique pouvant obliger à recourir à la fusion de protoplastes 
pour croiser certains génotypes. Le temps nécessaire pour créer une variété, entre les premiers croisements et l'obtention, est de l'ordre de 15 à 30 ans.

La liste des gènes majeurs de résistance établie en 2013 comporte 63 gènes, issus de 27 espèces de Solanum. Les premiers gènes ( $R_{1}$ à $\left.R_{11}\right)$ ont été identifiés chez l'espèce sauvage mexicaine $S$. demissum. $R_{1}, R_{2}, R_{3}, R_{4}$ et $R_{10}$ ont été introgressés dans des variétés cultivées, mais ils ont été rapidement contournés au champ, dès les années 1950. D'autres gènes majeurs ont été identifiés. Les gènes privilégiés aujourd'hui présentent des spectres d'action larges, comme ceux identifiés chez S. bulbocastanum (Rpi-blb1, Rpi-blb2, Rpi-blb3 et Rpi-abpt) ou chez S. phureja (Rpi-phu1). La sélection assistée par marqueurs est possible pour de nombreux gènes majeurs de résistance à $P$. infestans. Le fait que plus de 1300 gènes de résistance candidats aient été identifiés dans le génome de S. phureja (espèce diploïde proche de la pomme de terre, qui sert de référence) et l'existence de très nombreuses espèces de Solanum suggèrent que de nombreux gènes n'ont pas encore été exploités.

Des résistances quantitatives, de niveaux d'efficacité très variés, ont aussi été identifiées chez diverses espèces de Solanum. Il existe une forte association entre les QTL de résistance partielle et le caractère tardif (défavorable) des variétés. Des gènes candidats associés à de la résistance partielle indépendante de la maturité ont toutefois été identifiés récemment. Des études au champ ont montré qu’il est possible de réduire les doses et le nombre de traitements fongicides en utilisant des variétés partiellement résistantes. Bien que les cas d'érosion de résistances partielles ne soient pas nombreux, il a été montré que les populations de $P$. infestans sont capables de s'adapter à des résistances partielles utilisées de manière prolongée et massive.

Contrairement à celle du mildiou du feuillage, la génétique de la résistance au mildiou du tubercule n'a été que peu étudiée. La résistance du tubercule apparaît héritable indépendamment de celle du feuillage, seul le gène de résistance $R 1$ agissant aux deux niveaux. La résistance des tubercules semble être sous le contrôle de plusieurs QTL de résistance partielle : quatre QTL ont été identifiés sur les chromosomes de la pomme de terre. Malgré le nombre important de facteurs de résistance ( $R$ et $Q T L$ ) disponibles, et des niveaux de résistance parfois très élevés au champ, des études notent que les variétés résistantes ne sont pas forcément bien adoptées et pas suffisamment cultivées, alors même que les OAD peuvent prendre en compte efficacement le niveau de résistance des variétés, et ainsi ajuster le nombre de traitements chimiques. L'analyse de 310 variétés de pomme de terre produites en France, et pour lesquelles la note de résistance au mildiou est disponible, montre que le niveau de résistance médian reste faible (figure 2.4).

\section{Ressources génétiques et variétés disponibles chez la tomate}

Sur tomate, le cuivre est utilisé pour contrôler le mildiou (causé par Phytophthora infestans) et les bactérioses foliaires causées par différentes espèces de Xanthomonas. Des résistances face à ces deux pathogènes ont été identifiées chez des espèces de tomate sauvages (Lycopersicum pennelli, Solanum pimpinellifolium, S. peruvianum et S. habrochaites). 


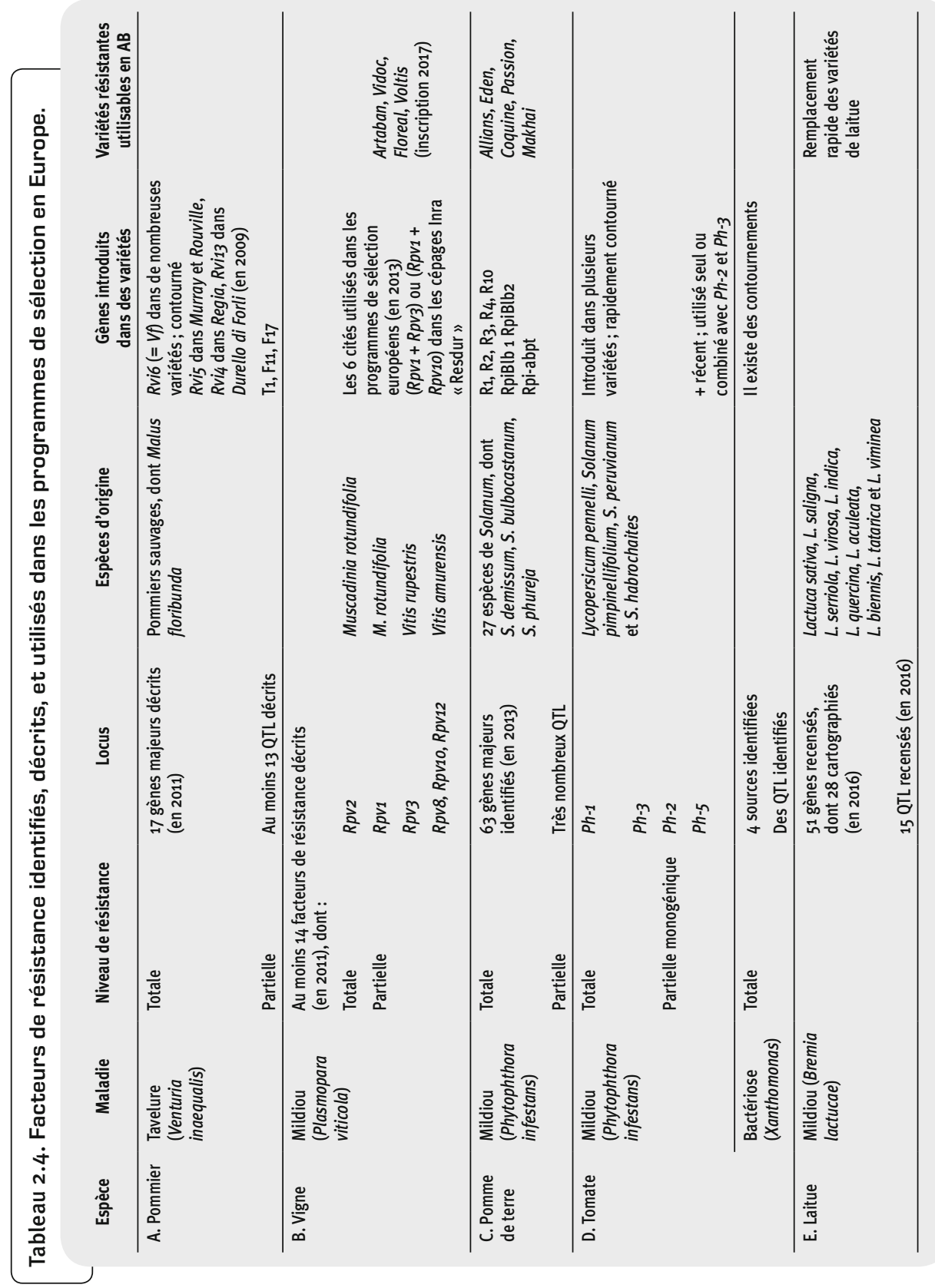


Figure 2.4. Sensibilités variétales de la pomme de terre au mildiou : distribution de la note " mildiou du feuillage " de $\mathbf{3 1 0}$ variétés de pomme de terre produites en France.

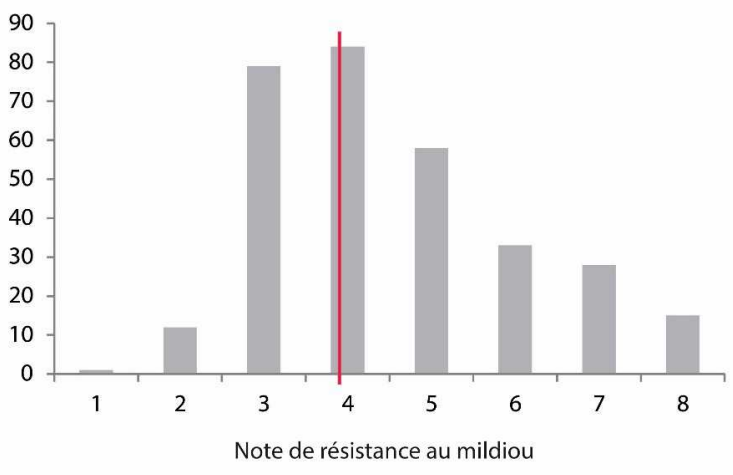

La note 1 indique une variété très sensible et la note 8 une variété très résistante. En rouge : la médiane des notes de sensibilité. L’ordonnée correspond au nombre de variétés dans chaque classe de résistance (source : Semences et Progrès, $n^{0}$ 173, décembre 2015-janvier 2016).

Plusieurs gènes de résistance (par exemple $P h-1, P h-2$ et $P h-3$ ) et QTL de résistance partielle ont un effet sur Phytophthora infestans. Le gène majeur de résistance $P h-1$ a été introduit dans une première variété (Rockingham, inscrite en 1962), puis dans plusieurs autres (Nova, New Yorker...), mais il a été rapidement contourné par de nouveaux génotypes de $P$. infestans. La résistance conférée par $P h-2$, cartographiée sur une unique région du génome de la tomate, ralentit le développement de la maladie : il s'agit donc d'un gène de résistance partielle. L'expression de cette résistance dépend des conditions environnementales (température), de l'âge de la plante, et bien sûr des souches de $P$. infestans présentes. $P h-2$ a cependant été introgressé dans de nombreuses variétés, comme Legend, Centennial, Macline, Pieraline, Herline et Fline. Le gène de résistance Ph-3 a un effet fort, et a été introduit dans différentes variétés cultivées, mais des souches de $P$. infestans virulentes face à ce gène ont été mises en évidence. Au Brésil, $P h-1, P h-2$ et $P h$-3 sont contournés, et certaines souches de $P$. infestans sont même virulentes face aux trois gènes. Plus récemment, le gène $P h-5$ a été identifié ; il contrôle de nombreux isolats dont ceux contournant $P h-3$. Ph-5 est utilisé seul ou en combinaison avec $P h-2$ et $P h-3$. Les bactérioses à Xanthomonas ont été initialement contrôlées par des applications de cuivre, mais des populations bactériennes résistantes sont rapidement apparues, rendant ce moyen de lutte inefficace. Aussi, depuis les années 1960, la recherche de gènes de résistance a fait l'objet d'efforts considérables. Quatre sources de résistance majeure ont été identifiées (l'une est une résistance totale conférée par trois gènes, alors que 
les trois autres sont monogéniques), ainsi que des marqueurs moléculaires permettant de la sélection assistée par marqueurs. Mais face à chacune de ces résistances, il existe des pathotypes virulents, ce qui limite la durabilité de ces résistances hypersensibles. L'étude récente des effecteurs bactériens a permis d'en identifier deux qui sont de bonnes cibles à exploiter pour identifier de nouvelles résistances par une approche d'effectoromique (voir section « Les stratégies de sélection génétique pour une plus grande durabilité des résistances »). Des résistances quantitatives polygéniques ont également été identifiées, et leur durabilité semble plus prometteuse.

\section{Ressources génétiques et variétés disponibles chez la laitue}

Parmi les nombreuses maladies qui affectent la laitue, deux sont contrôlées par le cuivre : le mildiou (causé par Bremia lactucae), l'une des maladies majeures de la laitue, et les bactérioses (dues par exemple à Pseudomonas cichorii ou Xanthomonas campestris). La résistance aux maladies, et en particulier au mildiou, est une priorité dans les programmes de sélection de la laitue.

Le genre Lactuca comprend une centaine d'espèces sauvages, majoritairement originaires d'Asie et d'Afrique. Des gènes de résistance au mildiou ont été identifiés chez Lactuca sativa et 9 espèces sauvages de Lactuca. En 2016, une synthèse sur les facteurs de résistance ciblant $B$. lactucae a recensé 51 gènes (dont 28, nommés $D m$, ont été cartographiés à un seul locus sur le génome de la laitue) et 15 QTL (nommés qDMR).

Les contournements de ces résistances de type gène-pour-gène par des souches virulentes de $B$. lactucae sont courants au champ, et conduisent à un remplacement rapide des variétés de laitue. Ils se traduisent par une évolution rapide de la fréquence des facteurs de virulence dans les populations de B. lactucae, dont le suivi permet d'identifier les gènes de résistance encore efficaces localement. Pour améliorer la durabilité de ces résistances, plusieurs stratégies ont été suggérées : l'introduction régulière de nouveaux gènes, la combinaison de plusieurs gènes dans un même génotype et l'introduction de résistances partielles, et l'association au champ de plusieurs variétés dotées de résistances complémentaires.

\section{La gestion durable des résistances}

Au cours des années 2000, la notion de « résistance durable » s'est progressivement effacée au profit de celle de " gestion durable des résistances ». Historiquement, ont été définies comme durables les résistances qui conservent leur efficacité suite à leur déploiement sur de grandes surfaces et sur une longue durée, dans un environnement favorable au développement de l'agent pathogène. Ainsi définie, la durabilité d'une résistance ne peut être identifiée qu'a posteriori, après son contournement. Elle apparaît en outre comme une propriété intrinsèque du gène de résistance, alors qu'elle résulte plutôt d'une combinaison d'effets opérant de l'échelle du gène à celle du bassin de production, et de l'interaction hôte-parasite plutôt que du seul gène de résistance. 
L'objectif de la gestion durable des résistances est de proposer des stratégies de déploiement des résistances qui permettent de réduire simultanément le développement des épidémies à court terme, et la probabilité d'adaptation des agents pathogènes sur le long terme. Il faut pour cela à la fois cibler des programmes de sélection, avec des gènes ou combinaisons de gènes de résistance potentiellement les plus durables (voir section « Des ressources génétiques abondantes pour la création variétale »), et raisonner le déploiement, dans le temps et l'espace, des variétés résistantes et sensibles disponibles (voir section "La sélection pour la résistance, priorité récente "). Dans certains cas, la gestion durable des résistances nécessite ainsi une coordination collective, et les gènes de résistances prennent alors valeur de bien « commun ».

\section{Les stratégies de sélection génétique pour une plus grande durabilité des résistances}

Pour augmenter la durabilité des résistances, plusieurs stratégies ont été testées ou peuvent être envisagées.

\section{Identifier des facteurs de résistance ou combinaison de facteurs potentiellement durables}

Un parasite devient virulent lorsque la molécule qu'il produit (dite « effecteur »), qui était détectée par la plante et déclenchait ses réactions de défense (ETI), n'est plus reconnue par elle. Cette modification de l'effecteur résulte d'une mutation (ou d'une délétion) du gène correspondant (dit "d'avirulence ») du pathogène. Cette mutation, qui permet de contourner la résistance de la plante hôte, peut aussi altérer la fonction initiale du gène : c'est le coût de la virulence, payé par le parasite " mutant " sur les hôtes sensibles (dépourvus du gène de résistance), où sa fitness est moindre que celle des individus avirulents.

Ces coûts de fitness associés à la virulence, difficiles à mesurer, ont été effectivement mis en évidence chez des virus, des bactéries ou des nématodes, mais aussi chez des espèces contrôlées par le cuivre comme le mildiou de la pomme de terre. Les coûts de virulence peuvent être compensés progressivement par d'autres mutations, qui restaurent la fonction du gène. Pour que la résistance soit durable, le coût de fitness associé à la virulence doit donc être élevé et difficile à compenser pour l'agent pathogène.

Les résistances majeures qui reconnaissent des effecteurs non essentiels à la fitness de l'agent pathogène peuvent donc être facilement contournées via la divergence rapide de la séquence ou même la perte de l'effecteur. De fait, au champ, n'ont été durables que les résistances ciblant des gènes d'avirulence essentiels à la fitness de l'agent pathogène.

Des approches nouvelles, combinant génie génétique et connaissance fine des mécanismes, sont actuellement développées en vue d'identifier les gènes de résistance possédant la plus grande durabilité potentielle. L'effectoromique est une stratégie de sélection de résistances qui repose sur une première étape d'identification chez l'agent pathogène d'une protéine d'avirulence (effecteur) indispensable à sa survie, puis sur une 
étape d'identification chez l'hôte du gène de résistance correspondant, qui devrait alors assurer une résistance durable. Cette approche est explorée notamment par plusieurs équipes de l'Inra travaillant sur Venturia inaequalis, Phytophthora infestans et $P$. capsici. Pour $P$. infestans, elle a permis d'identifier une nouvelle protéine de résistance et les gènes correspondant chez des Solanum.

Les résistances quantitatives partielles sont supposées intrinsèquement plus durables que les résistances qualitatives totales, puisque s'adapter aux résistances conférées par plusieurs QTL de résistance requiert un plus grand nombre de modifications génomiques (recombinaisons et/ou mutations). Toutefois, des cas (plutôt rares) d'adaptation à des résistances quantitatives ont été observés, notamment sur des maladies des céréales, mais aussi sur le mildiou de la vigne (adaptation aux résistances partielles portées par les cépages Regent, Prior et Bronner) ou de la pomme de terre (résistance partielle du cultivar Désirée). La largeur du spectre d'action des QTL est un facteur important : si les QTL à large spectre n'exercent qu'une faible pression de sélection sur les populations de pathogènes, les QTL à spectre étroit, plus spécifiques, sélectionnent des souches adaptées. Toutefois, dans le cas de la tavelure, des suivis en vergers sur huit années ont révélé une baisse d'efficacité de QTL à large spectre ( $F_{11}$ et $\left.F_{17}\right)$, mais une très faible érosion de l'efficacité d'un QTL spécifique (T1).

\section{Sélectionner des gènes à spectres larges ou complémentaires}

L'amélioration variétale exploite actuellement les mécanismes de la résistance hôte des plantes. Elle utilise en particulier, chaque fois qu'ils sont disponibles, les gènes de résistance interagissant avec les agents pathogènes selon le modèle gène-pour-gène, qui sont la plupart du temps spécifiques de certaines souches de l'agent pathogène.

À l'opposé, la résistance non-hôte désigne la résistance de l'ensemble des génotypes d'une espèce végétale envers tous les génotypes d'un agent pathogène donné. Ses mécanismes impliquent des défenses passives (barrières physiques à l'infection constituées par la cuticule, par exemple) et des réactions de défense actives induites par exemple par des éliciteurs généraux de l'agent pathogène (PAMP tels que la flagelline des bactéries ou la chitine des champignons), qui sont reconnus par des récepteurs (PRR) de la plante. La résistance non-hôte, qui correspond au cas le plus fréquent de résistance des plantes, est aussi supposée être plus durable que la résistance hôte. C'est pourquoi la compréhension de ses mécanismes et de son déterminisme génétique, actuellement très partielle, pourrait à l'avenir permettre de sélectionner des cultivars durablement résistants aux principaux agents pathogènes.

L'utilisation des biotechnologies, en particulier des méthodes d'édition des génomes, est évoquée dans la littérature, tout comme l'était la transgenèse au début des années 2000 , comme un moyen pour introduire des résistances non-hôtes dans les principales plantes cultivées. Plusieurs stratégies sont ainsi mentionnées dans des publications récentes : transférer des récepteurs PRR dans des espèces végétales qui en sont dépourvues (utilisé pour obtenir des tomates résistantes à plusieurs bactéries) ; faire produire par des 
plantes transgéniques de petits $A R N$ qui détruisent les transcrits de l'agent pathogène essentiels à la virulence (essais ciblant des virus, $P$. infestans et $B$. lactucae); ou inactiver des gènes de sensibilité aux agents pathogènes pour empêcher la colonisation de l'hôte.

\section{Cumuler différents gènes de résistance dans une même variété}

Le cumul (ou " pyramidage ») de gènes de résistance au sein d'une même variété peut permettre d'améliorer leur durabilité. Le pyramidage de gènes devrait être plus efficace face aux agents pathogènes à capacités de dispersion limitées (parasites telluriques) et à reproduction asexuée obligatoire (empêchant la recombinaison d'associer plusieurs facteurs de virulence dans un même génome). Il devrait également fonctionner plus efficacement si les coûts de virulence associés à chacun des gènes de résistance pyramidés sont élevés et additifs.

Pour que cette stratégie soit efficace, il est nécessaire (mais non suffisant) que les gènes pyramidés n'aient pas été au préalable utilisés individuellement, pour empêcher les agents pathogènes de les contourner un par un, les uns après les autres. Les programmes de sélection n'étant pas nécessairement concertés, cette condition est presque impossible à garantir.

Le pyramidage est actuellement la stratégie privilégiée pour la sélection de laitues et de vignes résistantes au mildiou. Il pourrait présenter également un intérêt pour contrôler le mildiou sur pomme de terre et sur tomate. Chez le pommier, le cumul des QTL T1, F11 et $F 17$ constitue une piste intéressante : en agissant à différentes étapes du cycle infectieux de $V$. inaequalis, cette association est plus efficace que les QTL seuls.

L'association d'un gène majeur et de QTL de résistance partielle s'avère en général plus durable que ce gène majeur introduit seul dans un fond génétique sensible. Le fond génétique partiellement résistant semble réduire suffisamment la taille de la population parasite pour empêcher, ou au moins ralentir fortement, l'adaptation au gène majeur de résistance. Les résistances durables à $P$. infestans des variétés de pomme de terre Sarpo Mira et Bzura seraient ainsi dues à une association de facteurs de résistances totales et partielles.

Certaines variétés (de tomate, de pomme de terre, de vigne...) cumulent des facteurs de résistance ciblant différents agents pathogènes et/ou ravageurs. Combiner plusieurs résistances dans une variété s'avère toutefois problématique, car les défenses des plantes face aux agents pathogènes biotrophes (qui se nourrissent de tissus vivants et ont souvent une gamme d'hôtes étroite) et nécrotrophes (qui tuent rapidement les tissus de l'hôte et ont souvent une gamme d'hôtes large) sont distinctes, et physiologiquement antagonistes les unes avec les autres. Il est ainsi très rare qu'une plante puisse mobiliser simultanément des voies de défense dépendant de l'acide salicylique et d'autres sous contrôle de l'acide jasmonique.

\section{Construire des variétés hétérogènes}

Accroître la diversité génétique des facteurs de résistance au sein des cultures améliore la durabilité des résistances majeures. Les programmes de création variétale peuvent 
favoriser la diversité génétique intraspécifique de deux façons. La première consiste à pratiquer la sélection massale de variétés-populations, c'est-à-dire de variétés constituées de mélanges d'individus ; la recherche peut y contribuer en mettant au point des méthodes de sélection participative permettant une gestion dynamique de la diversité.

La seconde voie est la création de variétés multi-lignées, c'est-à-dire constituées de génotypes phénotypiquement identiques qui présentent uniquement des gènes majeurs de résistance différents. Cette approche a été utilisée avec succès contre des rouilles des céréales. Sélectionner des variétés multi-lignées est toutefois long et difficile. Les approches d'édition de gènes (utilisant des systèmes comme CRISPR/Casg) permettent de construire de vraies lignées isogéniques, qui ne diffèrent que par leurs gènes de résistance, mais ces techniques de génie génétique sont contestées dans de nombreux pays, et (au moins pour le moment) interdites en $A B$ car assimilées à la transgenèse.

\section{Les stratégies d'utilisation au champ des variétés résistantes : organiser la diversification génétique}

La culture en mélange de variétés résistantes et sensibles peut limiter le développement des maladies de trois manières : la variété résistante constitue une barrière physique à la dispersion de l'inoculum entre plantes sensibles; elle réduit la multiplication de l'agent pathogène et donc la quantité d'inoculum disponible dans la parcelle ; enfin, la présence de génotypes avirulents du pathogène, capables d'infecter les composantes sensibles du mélange mais pas les fractions résistantes, peut déclencher les mécanismes de défense des plantes qui seront efficaces ensuite sur les souches virulentes. La spécialisation génétique qu'impose la diversité des hôtes au pathogène est à même de réduire le risque d'émergence de souches multi-virulentes.

Des travaux théoriques, utilisant des modèles mécanistes d'épidémies, prédisent que l'efficacité des mélanges dépend fortement de la surface développée occupée de manière contiguë par un même génotype : plus celle-ci est faible (mélange de très nombreux génotypes, plantes à faible surface foliaire, faible densité de plantation), plus l'efficacité attendue de l'association est forte. Cette efficacité sera donc plus faible pour une simple juxtaposition de champs sensibles et de champs résistants (mosaïques paysagères, par ailleurs assez difficiles à organiser en pratique) que pour des mélanges des mêmes variétés dans une même parcelle. Ce résultat théorique est conforté par les observations en verger : l'association en proportions égales de deux variétés de pommiers, l'une sensible à la tavelure (Smoothee ${ }^{\circledR}$, Melrouge) et l'autre résistante grâce au gène Vf (Baujade, Pitchounette), est plus efficace contre la tavelure sur la variété sensible en cas de mélange sur le rang que de rangs alternés.

Pour le mildiou de la pomme de terre, des résultats assez similaires ont été observés, mais soulignent le rôle déterminant de la pression d'inoculum présente localement sur l'efficacité des mélanges variétaux. Ainsi, des essais en conditions de pression de mildiou faible ou modérée montrent que les mélanges variétaux peuvent être efficaces (des mélanges en rangs alternés avec des cultivars partiellement résistants permettent de 
réduire le mildiou sur la variété sensible Bintje), alors que d'autres conduits en situation de fort risque de mildiou ne révèlent pas d'efficacité mesurable des mélanges. Cette augmentation de l'efficacité des mélanges variétaux lorsque la pression de la maladie est moins forte, ou abaissée artificiellement via des traitements pesticides, permet d'envisager des stratégies de cultures de mélanges sous protection fongicide réduite dans les environnements très favorables climatiquement au parasite à contrôler. C'est ainsi qu'une protection fongicide allégée a permis une très forte réduction d'incidence de la tavelure (jusqu'à $75 \%$ sur feuilles et $70 \%$ sur fruits) sur la variété sensible cultivée en mélange sur le rang avec une variété résistante. Des résultats très voisins ont été obtenus sur mildiou de la pomme de terre en situation de très forte pression de maladie.

Le mélange variétal n'a en revanche plus d'effet dès que des souches virulentes sur la variété résistante sont bien établies dans la parcelle. Ainsi, le mélange de variétés sensibles et résistantes de pommier n'avait plus d'avantage mesurable lorsque des souches de $V$. inaequalis virulentes vis-à-vis de la variété résistante étaient présentes dans le verger ; malheureusement, ce contournement du gène $V f$ est aujourd'hui fréquent en France. C'est pourquoi la mise en place de plans de surveillance de l'évolution de la virulence permet d'améliorer les stratégies de sélection de variétés résistantes et d'orienter les choix variétaux des agriculteurs. Une initiative "Suivi des virulences de Venturia inaequalis », lancée en 2009 en Suisse, surveille ainsi, dans un réseau de vergers implantés principalement en Europe, l'incidence et la sévérité de la tavelure sur une gamme de cultivars de pommier.

\section{I Éléments de conclusion}

\section{Des ressources génétiques abondantes pour la création variétale}

Pour la plupart des pathosystèmes d'intérêt, en particulier les mildious et la tavelure, il existe des ressources génétiques assez nombreuses utilisables en sélection végétale. Ces ressources, souvent issues d'espèces apparentées aux plantes cultivées, contiennent fréquemment des gènes de résistance spécifiques, dont la durabilité s'avère en pratique faible au champ (une à quelques années maximum), et parfois des QTL de résistance quantitative. Les résistances vis-à-vis d'autres agents pathogènes ciblés par le cuivre (bactérioses en particulier) sont en revanche plutôt de type quantitatif.

\section{La sélection pour la résistance, priorité récente}

La sélection pour la résistance n'est devenue prioritaire que depuis peu en création variétale, soit pour des questions de concentration des efforts sur d'autres cibles (rendement, qualité agronomique ou d'utilisation), soit du fait de l'association de certains gènes de résistance avec des caractères agronomiquement défavorables (tardivité par exemple), soit du fait de difficultés liées à la génétique du caractère (trait polygénique difficile à introgresser, fertilité faible des croisements imposant un recours aux techniques de biologie cellulaire). 
Les efforts de création variétale reposent prioritairement, dès que ceux-ci sont disponibles, sur un ou quelques gènes majeurs de résistance spécifique. Le pyramidage est souvent privilégié (mildious de la vigne et de la laitue, par exemple), y compris parfois avec des QTL de résistance partielle destinés à renforcer la durabilité de ces pyramides génétiques.

Le recours aux outils modernes issus de la génomique et de la connaissance des mécanismes biologiques sous-jacents (identification des effecteurs impliqués, débouchant sur les techniques d'effectoromique pour l'évaluation rapide de grandes populations ; édition de génomes) pourrait fortement raccourcir les délais d'obtention de nouvelles variétés ou combinaisons génétiques intéressantes. Néanmoins, la question de leur acceptabilité (en particulier en $\mathrm{AB}$ ) et le besoin de sélectionner pour des caractères différents selon les systèmes de production (pondération relative des critères, introduction de caractères nouveaux dans des idéotypes spécifiques) restent posés.

\section{Peu de sélection spécifique pour l’agriculture biologique}

La sélection de variétés spécifiques de l'AB reste marginale : $95 \%$ des variétés utilisées actuellement en $A B$ ont été sélectionnées pour des itinéraires techniques utilisés en agriculture conventionnelle, avec des niveaux élevés d'intrants. Or les traits pertinents à sélectionner diffèrent entre ces deux modes de conduite.

En Europe, quelques programmes de sélection variétale sont conduits avec une évaluation en itinéraires de culture $A B$ durant les phases finales de la sélection. Il s'agit notamment de programmes de sélection de céréales, conduits en Autriche, en Allemagne, et en France par l'Inra. Très peu de programmes appliquent des itinéraires $A B$ dès leurs débuts. C'est cependant le cas d'un programme mené en Suisse sur blé depuis 25 ans, qui prend notamment en compte la résistance à des maladies particulièrement problématiques en AB (septoriose, fusarium, rouille).

La sélection participative, qui implique directement les utilisateurs futurs des variétés dans le processus de sélection lui-même, est bien adaptée aux valeurs et besoins d'une création variétale dédiée à l'AB. Il existe deux exemples de programmes de sélection participative sur le brocoli intégrant les spécificités de l’AB (en Bretagne et en Oregon). Ces types de programmes sont plus à même de prendre en compte l'existence de plus fortes interactions génotype $\times$ environnement $\times$ itinéraires techniques en $A B$.

\section{Une disponibilité très variable de cultivars résistants dans les catalogues variétaux}

Le nombre de variétés résistantes disponibles sur le marché est très différent selon les pathosystèmes : très élevé dans le cas du mildiou de la laitue, il reste très faible dans celui du mildiou de la vigne. Un accroissement significatif de cette offre est toutefois attendu dans la décennie à venir. La diffusion de ces variétés résistantes est généralement limitée, ce qui n'empêche pas d'observer de manière plus ou moins récurrente des contournements au champ. Il reste donc un travail important à mener pour que les variétés résistantes soient adoptées par les agriculteurs, valorisées par les distributeurs et appréciées 
des consommateurs. Des outils dédiés se mettent progressivement en place, tel l'observatoire national OsCar qui organise en France, depuis 2017, le partage d'expérience sur le comportement des cépages résistants dans différents systèmes de culture pour aider les viticulteurs à construire des itinéraires techniques minimisant le recours au cuivre.

\section{Gérer la durabilité, enjeu majeur mais entreprise difficile}

L'enjeu majeur pour un emploi plus systématique des variétés résistantes reste la gestion de leur durabilité. Celle-ci passe par le choix des types et sources de résistance (résistances non-hôtes a priori très durables mais difficiles à introduire dans des fonds génétiques « étrangers », résistances hôtes spécifiques ou non), par les choix de construction des génotypes eux-mêmes (pyramidage, diversification, multi-lignées), et enfin par des stratégies de déploiement adaptées du matériel végétal ainsi créé (diversification spatiale et temporelle) et pensées dès la conception de ces variétés nouvelles.

Les résistances qualitatives comme quantitatives doivent idéalement être utilisées en combinaison avec d'autres moyens de lutte qui permettent de réduire la taille des populations pathogènes et donc leurs capacités d'adaptation. L'utilisation seule d'une résistance peut certainement permettre de limiter l'utilisation du cuivre, mais seules des combinaisons de solutions (des résistances totale et partielle dans une même variété traitée avec un produit de biocontrôle efficace, par exemple) permettront peut-être, dans certains cas, de se passer totalement du cuivre. Le gain de durabilité des résistances à attendre d'une articulation des combinaisons génétiques avec le déploiement des solutions d'ordre agronomique, voire phytosanitaire, a encore fait l'objet de trop peu de travaux, alors même que le principe de la protection intégrée des cultures (Integrated Pest Management) travaillé à l'échelle mondiale depuis plus de trente ans en fait l'un de ses fers de lance.

Enfin, un élément potentiellement important à considérer pour identifier des stratégies de déploiement des variétés résistantes, mais pour lequel peu de connaissances sont actuellement disponibles, est l'interaction entre les plantes résistantes et les communautés microbiennes, pathogènes et non pathogènes. Il serait notamment nécessaire de déterminer comment les plantes résistantes influencent les communautés microbiennes, et en retour comment les communautés microbiennes influencent la durabilité des résistances. Il s'agit là d'un front de recherche entièrement nouveau, et dont l'exploration débute à peine.

\section{Les stimulateurs des défenses naturelles des plantes}

Le CoRPuS bibliographique analysé a ÉtÉ obTENU en deux temps. Un premier corpus est constitué de 30 articles sélectionnés à partir d'une interrogation du WoS portant sur les articles de synthèse (reviews) traitant d'induction de résistance par les éliciteurs et les mécanismes de défense des plantes (toutes interactions plante-pathogène confondues). Un second corpus est constitué d'environ 600 articles primaires obtenus par une interrogation du WoS ciblant l'induction de résistance par éliciteurs contre des maladies traitées 
par le cuivre. Ce second corpus s'est avéré beaucoup plus riche. Le flux d'articles paraît constant depuis 2000. Ils traitent en majorité des maladies économiquement importantes: mildiou de la pomme de terre, de la tomate et de la vigne, tavelure des arbres fruitiers à pépin, et bactérioses de la tomate. D’autres maladies, qualifiées de secondaires, sont également considérées : les bactérioses du kiwi, l'œil de paon de l'olivier, par exemple.

\section{L’induction de résistance par les éliciteurs}

\section{Bref historique}

La découverte des stimulateurs de défense des plantes (SDP), ou stimulateurs des défenses naturelles (SDN), ou éliciteurs, est liée à celle des mécanismes de défense des plantes contre les bioagresseurs, considérés depuis comme les composantes de l'immunité végétale. L'existence de cette dernière a été pressentie au début du xx siècle par des chercheurs qui étudiaient le phénomène de résistance des plantes aux maladies.

L'étude de ces mécanismes avec des méthodes biochimiques, dans les années 1970, a permis de mettre en évidence des molécules d'origine microbienne ou issues de champignon phytopathogène capables de déclencher chez la plante la production de métabolites antimicrobiens. Ces molécules furent alors nommées « éliciteurs » (de l'anglais to elicit, déclencher).

Aujourd'hui, le terme «éliciteur » désigne plus largement tout produit qui déclenche des réactions de défense. Il est synonyme du terme " inducteur de résistance ", souvent utilisé en anglais (resistance inducer). En France, c'est le sigle «SDP » qui s'est imposé, notamment chez les acteurs de la protection des cultures.

L'utilisation d'éliciteurs pour la protection des plantes a été proposée dès les années 1980. Dans les années 1990, un premier SDP (de synthèse, le Bion ${ }^{\circledR}$ de la firme Ciba-Geigy) est homologué comme produit phytosanitaire, et de nombreuses publications font état d'autres éliciteurs, de diverses natures chimiques (saccharides, protéines...) et origines (paroi végétale ou microbienne, oomycètes phytopathogènes...), et de leur mode d'action dans la plante. La fin des années 1990 et le début des années 2000 voient le développement des travaux visant à accroître l'efficacité de SDP en conditions de production, ainsi que la commercialisation de plusieurs SDP naturels (à base de laminarine, de chitosanes, de harpine ou d'extraits végétaux), d'efficacité variable.

Aujourd'hui, de nombreuses publications scientifiques sur les SDP et leurs effets continuent de paraître ; l'offre de SDP commerciaux reste cependant restreinte, et les applications pratiques encore limitées.

\section{Les défenses des plantes et l'action des SDP}

L'application exogène d'éliciteurs vise à mimer une attaque par un bioagresseur et à déclencher préventivement, de façon artificielle, les défenses de la plante. La plupart des éliciteurs non hormonaux sont considérés comme des PAMP et sont donc censés éliciter la PTI. On admet qu'un PAMPest reconnu par de nombreuses espèces de plantes, malgré de nombreuses 
exceptions. Les éliciteurs hormonaux sont susceptibles d'activer une réponse similaire à celle mobilisée lors de l'ETI, et donc puissante, mais cela n'est vérifié que dans certains cas. Notons que les micro-organismes utilisés en lutte biologique contre les maladies possèdent souvent un mode d'action impliquant l'induction de résistance par la production d'éliciteurs (voir section « Les agents microbiologiques de biocontrôle »).

\section{Les éliciteurs étudiés et leurs applications}

La plupart des SDP étudiés sont des produits expérimentaux ou non encore homologués en France (en tant que produits phytosanitaires). Bénéficient à ce jour d'une AMM en France les SDP suivants : Bion ${ }^{\circledR}$ (benzothiadiazole, Syngenta), Vacciplant ${ }^{\circledR}$ (laminarine, Arysta Goëmar), Régalis ${ }^{\circledR}$ (prohexadione, BASF), Stifénia (poudre de fenugrec, SOFT) et depuis peu un produit à base d'oligosaccharides (COS-OGA) distribué par Syngenta. Stifénia ne concerne pas les maladies visées par l'étude.

Le tableau 2.5 récapitule les principaux SDP examinés dans la littérature, essentiellement scientifique, et précise les efficacités observées contre les principales maladies ciblées par le cuivre.

\section{Les SDP de synthèse}

Ces produits ne sont pas compatibles avec l'AB, mais ils sont intéressants à considérer à titre de comparaison ou en tant que produits de référence, parce que ce sont les plus étudiés et qu'ils font parfois preuve de niveaux d'efficacité élevés.

\section{Les analogues de phytohormones naturelles}

Le benzothiadiazole (BTH), molécule de loin la plus étudiée, est un analogue de synthèse fonctionnel de l'acide salicylique (AS), inventé par la société Ciba-Geigy et homologué en France sous le nom de Bion ${ }^{\circledR}$. Son efficacité est très variable selon les pathosystèmes et les conditions environnementales ; le BTH semble spécifiquement actif contre les maladies mobilisant chez la plante essentiellement la voie de l'AS. Il possède une efficacité partielle contre diverses maladies fongiques et bactériennes (tableau 2.5). Il permet de réduire les doses de cuivre contre les Xanthomonas sur tomate, et peut être utilisé contre les souches de ces bactéries résistantes au cuivre.

L'acide $\beta$-aminobutyrique (BABA) est un acide aminé non protéique, rare dans la nature, produit à de faibles concentrations par la plante en réponse à une agression parasitaire. Il est assez efficace contre les mildious, et possède une forte action synergique avec le mancozèbe. Il permettrait ainsi de réduire les doses de fongicides, par exemple sur pomme de terre contre le mildiou. Son efficacité varierait cependant selon la variété de pomme de terre et serait moindre, sur vigne, lorsque les conditions climatiques sont plus favorables au mildiou. Malgré son intérêt certain, le BABA n’a pas connu de développement commercial. Il est impossible de le breveter, et son profil écotoxicologique n'est pas connu ; de plus, il est légèrement phytotoxique. 
Les anti-gibbérelliques (régulateurs de croissance), notamment le prohexadione-Ca utilisé pour réduire la croissance des arbres à pépin, se sont aussi révélés inducteurs de résistance contre le feu bactérien. Cette molécule est homologuée en France sous le nom de Régalis ${ }^{\circledR}$.

\section{Les phosphites (sels de l'acide phosphoreux)}

De nombreux produits comportant ces sels (le plus souvent sous forme de sels de potassium) sont disponibles sur le marché. Ils sont surtout actifs contre les mildious. Les essais de terrain montrent qu'en général ils présentent une efficacité quasi totale en cas de pression de maladie moyenne, mais sont insuffisants en cas de forte infection et doivent alors être associés à un fongicide à dose réduite. Si les phosphites sont bien des éliciteurs, aux doses employées ils sont surtout fongicides. Leur profil écotoxicologique favorable en fait des produits très intéressants pour limiter le recours aux fongicides de synthèse ou au cuivre. Ils ne sont pas autorisés en $A B$, bien qu'il s'agisse, comme le sulfate de cuivre, de produits minéraux.

\section{Les SDP naturels}

\section{Les phytohormones purifiées}

L'acide salicylique (AS), hormone clé de diverses voies de la défense des plantes, est peu utilisé en pratique. Il existe cependant quelques cas d'application probante, par exemple sur olivier contre la maladie de l'œil de paon. Sa phytotoxicité rend l'AS difficile d'emploi ; le BTH, moins toxique, lui est largement préféré. L'ester méthylique de l'acide salicylique, composé majoritaire de l'huile essentielle de gaulthérie, qui est aussi un SDP, est peut-être amené à se développer.

L'acide jasmonique (AJ) et le jasmonate de méthyle sont également globalement peu utilisés en pratique. Ces deux phytohormones sont susceptibles de perturber le développement de la plante, et sont plutôt appliquées contre les ravageurs. L'AJ protège partiellement les résineux contre des maladies cryptogamiques et la vigne contre l'oïdium.

\section{Les oligosaccharides et polysaccharides}

Ce sont des polymères d'oses (sucres) constituants structuraux des parois des microorganismes, des arthropodes (chitine) et des végétaux (pectine).

Divers travaux montrent une certaine efficacité de sucres simples (oses) pour activer les défenses générales des plantes. Ces activités sont d'ailleurs sans doute mobilisées lors de la dégradation des parois végétales intervenant durant les agressions biologiques. Toutefois, ces molécules ne sont que difficilement protégeables, ce qui limite leur potentiel de développement en phytoprotection.

Le chitosane, un dérivé de la chitine, a fait l'objet de très nombreuses études. C'est un éliciteur, mais il possède aussi un effet fongicide assez puissant, vraisemblablement prépondérant dans les utilisations à forte dose. Expérimenté contre de nombreuses maladies, il présente des efficacités variables (tableau 2.5), mais parmi les plus significatives 
de celles obtenues avec des produits naturels. La comparaison des nombreux résultats obtenus est compliquée par la multiplicité des préparations commerciales, dont le type de chitosane utilisé n'est pas précisé. Ce produit reste peu expérimenté en France. Comestible, le chitosane possède de multiples applications agroalimentaires et cosmétiques, bien qu'il soit potentiellement allergène chez certaines personnes.

Le COS-OGA (oligochitosane et acide oligogalacturonique) est un mélange formulé, mis au point par une start-up belge et récemment homologué et distribué par Syngenta en France. Il a une efficacité de 40-50 \% contre l'oïdium au vignoble, et possède aussi un effet antimildiou. D’après des données Syngenta d'essais au vignoble en 2016, le COS-OGA permet de réduire la dose de cuivre nécessaire à la protection anti-mildiou ; cela reste à confirmer sur plusieurs années et dans différentes conditions géographiques et environnementales.

Les glucanes sont des polymères de glucose, sucres de réserve de certaines algues ou constituants structuraux de la paroi de certains champignons. La laminarine, glucane extrait d'algue, est la matière active de plusieurs produits commercialisés par Goëmar en France et homologués contre diverses maladies (tableau 2.5). Son efficacité sur pommier et sur grandes cultures reste toutefois controversée. Un article récent suggère que l'association de laminarine et de cuivre à dose réduite présente un intérêt contre le mildiou de la vigne en cas d'infestation modérée.

\section{Extraits de micro-organismes, protéines et métabolites issus de micro-organismes}

Extraits ou fractions de micro-organismes. Les filtrats de culture de champignons, d'oomycètes et de bactéries phytopathogènes ou bénéfiques, ainsi que des extraits pariétaux contenant des éliciteurs, ont fait l'objet de diverses publications rapportant leur potentiel en tant que SDP, mais le plus souvent en laboratoire. Ainsi, un extrait de Penicillium sp. (Pen) s'est avéré posséder une activité SDP contre diverses maladies bactériennes ou fongiques (tableau 2.5), mais ce produit prometteur n'a apparemment pas connu de développement commercial. Les extraits de paroi de la levure Saccharomyces cerevisiae sont également des SDP ; la société Agrauxine a obtenu l'autorisation de mise sur le marché d'un tel extrait, sous-produit de la production industrielle de levure, contre le mildiou de la vigne, et sa distribution devrait être assurée par la société BASF.

Protéines issues de micro-organismes. De nombreux MAMP (Microbe Associated Molecular Pattern, c'est-à-dire des molécules provenant de n'importe quel type de micro-organisme, pathogène ou non) sont protéiques : flagelline bactérienne, élicitines d'oomycètes (cryptogéine, oligandrine, par exemple), harpine bactérienne... Toutefois, pour le moment du moins, la plupart restent des objets d'études fondamentales. Plusieurs travaux ont démontré que l'oligandrine était inductrice de résistance dans différents modèles de laboratoire. D'autres ont montré que des elicitin-like de paroi d'oomycète ont une efficacité partielle, mais très significative contre la cercosporiose de la betterave au champ. Une société espagnole (Plant Response) travaille à valoriser des MAMP protéiques issus de champignons phytopathogènes (Sclerotinia sp. par exemple). 


\section{Tableau 2.5. Principaux SDP actifs en conditions de production contre des maladies ciblées par les traitements cupriques.}




La harpine constitue la matière active d'un produit commercial, Messenger ${ }^{\circledR}$, avec diverses applications. Ses effets au champ contre la tavelure du pommier ou le feu bactérien du poirier apparaissent controversés. La harpine est désormais vendue comme biostimulant et non plus comme SDP.

Métabolites microbiens. Les recherches sur les mécanismes par lesquels les microorganismes bénéfiques augmentent la résistance de la plante ont permis d'identifier plusieurs métabolites microbiens jouant un rôle prépondérant dans ce phénomène. Ces travaux confirment que les micro-organismes représentent une source potentiellement importante de SDP pour l'avenir. Notons que l'application de produits bien caractérisés et formulés est souvent plus aisée que celle de micro-organismes vivants.

\section{Autres composés : vitamines, liposaccharides, lipopeptides, acides gras}

Des vitamines comme la riboflavine et la thiamine montrent une activité SDP en conditions de laboratoire contre le mildiou de la vigne, mais leur intérêt en conditions de terrain n'est pas encore documenté. Les rhamnolipides et surfactines (tensioactifs d'origine microbienne) s'avèrent nettement SDP au laboratoire, mais les quelques essais au vignoble de rhamnolipides n'ont pas tous montré d'efficacité contre le mildiou. L'acide hexanoïque (acide gras) présente une certaine efficacité contre des maladies fongiques et bactériennes des agrumes, notamment en application par voie racinaire (arrosage du substrat) ; il a également un effet sur tomate contre le botrytis.

\section{Produits divers}

Des extraits de plantes SDP ont montré une efficacité assez élevée contre diverses maladies : un extrait de lierre contre le feu bactérien du pommier, des extraits de rhubarbe exotique ou de solidage contre le mildiou de la vigne par exemple. Ces préparations activent certes les défenses de la plante, mais agissent souvent aussi directement en bloquant la germination de l'agent pathogène. Il est alors difficile de distinguer nettement la part de chacun des modes d'action dans l'efficacité finalement observée. Ce peut être une source de variabilité des résultats d'efficacité, si les conditions d'expression de chacun (voire de l'un ou de l'autre des mécanismes) ne sont pas constantes.

Certains composts utilisés comme substrat de culture induisent de la résistance contre les maladies, de même que des extraits aqueux de ces composts. Les déterminants de cette induction ne sont pas clairement élucidés, et sont d'ailleurs vraisemblablement différents d'un compost à un autre.

Plusieurs produits commerciaux fertilisants, à base de sels minéraux (azote, phosphore, potasse, oligoéléments) additionnés ou non de composés organiques, ont montré des efficacités partielles significatives contre le mildiou de la vigne ou la tavelure du pommier (d'après le RMT Elicitra). Toutefois, la composition précise de ces produits n'est pas connue, et leur mode d'action SDP reste à confirmer. Jusqu'à présent, les informations 
sur ces produits se trouvent plus dans la littérature grise que dans la littérature scientifique. Leur usage pourrait se développer s'ils permettent de réduire les doses de fongicide à un coût acceptable.

\section{Conclusions}

\section{Les SDP : des produits à effets partiels, moins efficaces que le cuivre}

L'analyse de la littérature scientifique montre qu'il n'existe pas aujourd'hui de SDP aussi efficace que le cuivre pour contrôler les principaux agents pathogènes cibles des traitements cupriques. Certains SDP synthétiques (éliciteurs de la voie de l'acide salicylique notamment, comme le BTH) peuvent être aussi efficaces que les meilleurs fongicides contre certaines maladies non ciblées par le cuivre. Dans les cas où le BTH possède une efficacité contre des maladies ciblées par le cuivre, elle est souvent supérieure à celle des SDP naturels; dans le cas de bactérioses par exemple, certains rapports estiment que le BTH serait presque aussi efficace que le cuivre.

Tous les SDP d'origine naturelle présentent une efficacité toujours partielle, située dans une fourchette de 20 à $70 \%$, très souvent bien inférieure à $50 \%$ en conditions de production ; ils sont donc beaucoup moins efficaces que le cuivre. En outre, il existe bien moins de résultats publiés d'essais au champ avec ces produits qu'avec les substances synthétiques. Les chitosanes se classent souvent parmi les plus efficaces dans les essais publiés, mais ce sont aussi des biofongicides.

\section{Les phosphites (sels de l'acide phosphoreux) : des SDP à part ?}

Ces produits possèdent une efficacité remarquable contre les oomycètes, d'au moins $70-80 \%$. Leur classification comme SDP fait l'objet de controverses : si leur pouvoir éliciteur est prouvé, aux doses utilisées leur effet fongicide est certainement prépondérant. Un autre débat concerne leur nature synthétique ou naturelle : sont-ils vraiment plus synthétiques que les sels de cuivre utilisés en $A B$ ? Les phosphites, qui étaient autorisés en $A B$ dans divers pays européens (Allemagne, Grèce, Autriche, Espagne, Hongrie, République tchèque) jusqu'en septembre 2013, ont perdu cette autorisation avec leur classification en tant que produit de protection des plantes, et non plus fertilisant ou biostimulant comme précédemment. Ils sont actuellement interdits en $A B$ dans l'ensemble de l'Union européenne. Enfin, signalons que ces produits peuvent s'accumuler dans les produits récoltés.

\section{Efficacité : des résultats contradictoires, et des variations importantes}

Les SDP sont réputés avoir des efficacités variables, ce que confirment l'examen de la littérature et les avis d'experts. Mais il existe assez peu de données d'essais de terrain disponibles pour affiner ce point. Par ailleurs, les nombreux facteurs biotiques et abiotiques susceptibles d'affecter la réponse de la plante aux SDP, et par conséquent leur efficacité, 
sont encore mal connus. De rares études montrent que le génotype végétal, la pression de maladie, la nutrition minérale ou le stade de développement des organes peuvent affecter la réponse de la plante, mais ces données restent parcellaires. Les recherches sur le mode d'action des SDP en conditions de production sont encore insuffisantes, ce qui bride certainement l'optimisation des traitements SDP.

Certains articles rapportent des efficacités significatives de SDP, alors que des experts (tels ceux du réseau Elicitra) les jugent sans effet sur les mêmes maladies. Ces contradictions concernent par exemple les effets de la laminarine et de la harpine contre le feu bactérien et la tavelure du pommier. On peut raisonnablement supposer que les efficacités publiées correspondent en fait à des tests réalisés en conditions " optimisées ", du point de vue des conditions expérimentales ou de l'état physiologique des plantes sur les effets obtenus.

\section{La recherche de nouveaux SDP est active}

De nouveaux SDP d'origines variées sont régulièrement révélés dans les publications scientifiques : des métabolites ou des extraits de micro-organismes bénéfiques ou alimentaires, des acides gras « simples » (comme l'acide hexanoïque, prometteur sur les agrumes), des métabolites secondaires de végétaux (salicylate de méthyle), des extraits de plantes plus ou moins caractérisés... Mais la période assez longue couverte par l'analyse bibliographique (2000-2016) permet de constater que des SDP a priori intéressants et éprouvés sur le terrain il y a une dizaine d'années semblent aujourd'hui abandonnés, à l'instar du « Pen ». Ce fait met en évidence l'existence de freins au développement des SDP, qui requiert la maîtrise de nombreux facteurs tels que : l'influence des conditions environnementales, la rémanence, la capacité de la plante à répondre, l'impact de la pression de maladie, la biodisponibilité au sein de la plante, l'influence de la formulation, la rentabilité commerciale.

Notons que la présente expertise repose principalement sur la littérature scientifique publiée ; elle n'a par conséquent qu'une vision réduite de la recherche privée (surtout effectuée par des PME), qui ne donne pour ainsi dire pas accès à ses résultats, alors qu'elle est active et devrait aboutir à la mise sur marché de nouveaux SDP.

Comme pour les autres produits de biocontrôle, la pression sociétale croissante pour la réduction de l'usage des pesticides et l'arrivée récente des grandes firmes phytopharmaceutiques dans le domaine des SDP ne peuvent que favoriser leur intégration dans les pratiques de protection des plantes. Le COS-OGA, inventé par une start-up et commercialisé par une grande firme, en donne un exemple récent. On peut penser que des incitations politiques (du type Écophyto) et la poursuite de la réévaluation des pesticides, amenant nombre de molécules à être retirées du marché, peuvent constituer deux raisons majeures à un maintien de l'intérêt pour les SDP. Cependant, la nécessité de stimuler les défenses de la plante en amont des attaques devrait pousser à un meilleur couplage avec des outils de diagnostic précoce utilisables localement - domaine dans lequel il existe très peu de recherche publiée aujourd'hui. 


\section{Les SDP ne remplaceront pas le cuivre mais peuvent en réduire les doses}

L'intérêt d'associations de SDP et de fongicides (plutôt en mélange) à dose réduite est connu depuis au moins quinze ans (association entre le BTH et des fongicides de synthèse, synergie entre le BABA et le mancozèbe notamment). Certains essais d'associations de SDP et de produits cupriques sont encourageants contre le mildiou de la vigne, et il importe aujourd'hui de développer une base rationnelle pour identifier a priori les meilleures associations, y compris SDP-SDP et SDP-agent de lutte biologique. Cette recommandation va dans le sens des conclusions de l'étude de grande ampleur de Dagostin et al. (2011), qui a identifié des produits naturels, SDP ou biocides, ayant des efficacités partielles contre le mildiou de la vigne, candidats à des essais de réduction des doses de cuivre.

\section{Lisothérapie, les préparations homéopathiques et biodynamiques}

\section{Définitions et principes d'action}

L'isothérapie, fondée sur le principe consistant à « traiter le mal par le mal », est fréquemment employée, sous diverses formes, en médecine humaine et vétérinaire (vaccination par exemple), et parfois en santé végétale. Sa déclinaison principale en santé des plantes consiste à employer des préparations hautement diluées et « dynamisées » (c'està-dire assez longuement agitées) de l'agent pathogène ou de plantes/organes infectés. Ces préparations, à base d'organismes vivants ou morts (cendres issues de l'incinération de ravageurs par exemple), sont ensuite pulvérisées sur les plantes à traiter. D'autres formes d'isothérapie ont également été employées, parfois avec un certain succès, en santé végétale. C'est le cas des protocoles de prémunition par des souches atténuées de virus ou d'inoculation de plants avec des souches «hypovirulentes » de champignons.

L'homéopathie repose sur un principe voisin, mais un peu différent par la nature des principes actifs. Elle emploie de hautes dilutions d'extraits naturels (de plantes, de sols, par exemple) dynamisés, dont certains peuvent être fortement toxiques à dose plus forte, et exploite la " mémoire de l'eau ». En effet, certaines préparations homéopathiques sont tellement diluées qu'elles ne peuvent statistiquement plus contenir une seule molécule de la substance d'origine ; les tenants de cette méthode prétendent que l'activité de ces préparations proviendrait alors de la capacité de l'eau à conserver l'empreinte moléculaire de ces substances. Comme l'isothérapie, il s'agit d'une forme assez répandue de médecine « douce » en santé humaine et animale.

La biodynamie utilise un ensemble de neuf préparations (nommées 500 à 508) dont les recettes ont été décrites par le fondateur du mouvement biodynamique, R. Steiner. Il s'agit 
de fumier de vache ou de quartz finement broyé incubés dans une corne (500 et 501) ou d'extraits de plantes (502 à 508). Ces préparations, elles aussi fortement diluées, sont censées favoriser la croissance, le développement et la capacité des plantes à résister à leurs ennemis. Elles peuvent être préparées par l'agriculteur lui-même ou achetées auprès de fournisseurs spécialisés.

Signalons enfin l'usage de "protéodies », séquences musicales censées interférer avec la séquence des acides aminés des protéines, approche fortement médiatisée auprès du grand public mais dont les fondements scientifiques ne sont en rien avérés. Une recherche dans le Web of Science sur les mots clés « genodics » (proposé par son concepteur J. Sternheimer) ou « proteod* » ne fournit ainsi aucune référence.

\section{Effets phytosanitaires}

Ces différentes pratiques ont fait l'objet de très peu de publications académiques. L'analyse qui en est faite dans ce rapport repose donc pour l'essentiel sur les quelques articles techniques et ouvrages dédiés à ce mode de protection des plantes.

\section{Isothérapie}

Les quelques références publiées sur l'efficacité des préparations fortement diluées et dynamisées de tissus malades ou de l'agent pathogène lui-même sont toutes des sources « grises » de littérature (revues techniques, rapports sommaires, pages Web grand public). La plupart ne différencient d'ailleurs pas clairement les procédés relevant de l'isothérapie ou de l'homéopathie proprement dite.

Concernant les maladies visées par les traitements cupriques :

- divers essais, répétés et concordants, menés sur moniliose des fleurs d'abricotier montrent que les préparations isothérapiques à 2, 4, 8 et $12 \mathrm{DH}$ s'avèrent nocives, puisqu'elles augmentent la gravité de la maladie ;

- un rapport d'expérimentations ponctuelles en productions maraîchères d'un homéopathe et jardinier amateur montre un effet neutre ou délétère du traitement isothérapique en application curative sur mildiou et bactériose à Corynebacterium de la tomate. L'auteur considère toutefois que les traitements ont un effet, mais reconnaît que la plupart des essais ne sont pas analysables statistiquement, faute de témoin ou d'effectif de plantes suffisant. Ces expérimentations n'ont pas testé les traitements en application préventive ;

- un « retour d'expérience » sur céréales d'un agriculteur belge utilisant des préparations décrites comme isothérapiques, mais contenant également « des oligo-éléments et des extraits hydro-alcooliques » non précisés, rapporte des résultats prometteurs. Toutefois, les imprécisions concernant la nature des préparations elles-mêmes interdisent d'attribuer les effets observés à leur composante « isothérapique ». Par ailleurs, l'article signale qu'un recours à une protection chimique additionnelle se révèle parfois nécessaire. 


\section{Homéopathie}

Concernant l'homéopathie (hautes dilutions d'extraits végétaux ou minéraux), la seule référence trouvée dans le Web of Science ne rapporte aucun effet positif statistiquement significatif de telles préparations pour lutter contre les ravageurs de la tomate au champ, et signale des effets parfois délétères pour la gestion de maladies parasitaires (en particulier la septoriose des feuilles). Des résultats plus encourageants ont été obtenus dans un essai sous serre, mais l'expérimentation n'a pas été répétée et les résultats nécessitent donc une validation plus solide.

Un ouvrage récent répertorie les principaux remèdes homéopathiques utilisés contre les maladies les plus communes des arbres fruitiers et des cultures maraîchères et florales. Collection d'expériences et d'observations ponctuelles, il ne fournit pas de données analysables permettant d'évaluer scientifiquement l'efficacité réelle des « recettes » proposées.

\section{Biodynamie}

Une méta-analyse des divers essais publiés sur l'effet individuel de chacune des préparations biodynamiques montre qu'aucune d'entre elles n'a d'activité biologiquement démontrable en expérimentation factorielle classique (Chalker-Scott, 2013). L'auteur souligne que ces résultats globalement négatifs ne disqualifient pas l'ensemble des pratiques biodynamiques : ils montrent seulement que l'emploi de chacune des neuf préparations n'apporte pas de bénéfice mesurable sur la santé des cultures. On peut noter que Steiner lui-même n'invoquait pas une démarche scientifique, mais plutôt spirituelle, à l'appui de ses pratiques ; il estimait donc qu'elles n'avaient pas besoin d'être confirmées par des essais scientifiques.

Plusieurs préparations, comme les purins d'ortie (504) ou de prêle (508), sont parfois employées seules dans des contextes non biodynamiques. Toutefois, comme montré plus haut (voir section « Les préparations naturelles biocides »), il est difficile d'avérer de leur part une efficacité phytosanitaire répétable dans des essais factoriels classiques. Une analyse approfondie de la composition de plusieurs sources de préparation 500 a montré que celle-ci contient une population microbienne élevée, très riche en Bacillus spp. et responsable d'une activité fermentaire importante, et qu'elle présente une activité auxinique importante en conditions contrôlées vis-à-vis de plantes tests, compatible avec celle pouvant être attendue au champ aux concentrations de préparations utilisées en biodynamie. Il est donc possible que cette préparation ait une action promotrice de croissance, sans effet phytosanitaire ni impact sur la structure physique des sols.

\section{IConclusions}

\section{Des méthodes globalement très peu efficaces, voire délétères}

Au vu des rares publications traitant de l'emploi phytosanitaire de préparations hautement diluées et dynamisées d'origines diverses (tissus malades, préparations homéopathiques 
ou biodynamiques), il est possible de conclure qu'aucune de celles testées jusqu'à présent ne semble posséder une efficacité quelconque ; pire, certaines seraient plutôt nocives, l'application de ces préparations (en particulier celles utilisant des agents pathogènes vivants) s'apparentant à une inoculation. Ce type de préparations recèle donc un potentiel fort limité en protection phytosanitaire.

\section{Des conditions d'expérimentation à repenser}

Il faut noter également que, à l'exception peut-être des préparations biodynamiques, la plupart des essais rapportés concernent des applications curatives, et non préventives, des infections. Il est donc possible que de meilleurs résultats puissent être obtenus avec des positionnements différents. Il est aussi possible (voire vraisemblable) que les quelques succès rapportés après application de ces préparations tiennent soit à des conditions météorologiques post-traitement défavorables au pathogène, soit aux autres pratiques (observation précoce des symptômes, intervention immédiate...) mises en œuvre. Ces dernières étant mal ou non documentées dans les références disponibles, il n'est pas possible d'examiner cette hypothèse, ni de statuer sur l'éventuelle activité élicitrice de réactions de défense de certaines des préparations. 



\section{La gestion agronomique des risques phytosanitaires}

À CôtÉ des MÉTHOdes ALTERNATIVES À L'EMPLOI DE PRÉPARATIONS CUPRIQUES EXaminées dans le chapitre précédent, il existe des méthodes de lutte indirecte, qui jouent soit sur la disponibilité de l'inoculum (méthodes prophylactiques), soit sur la réceptivité de la culture.

Le corpus bibliographique retenu comporte une centaine de références, majoritairement des articles scientifiques issus de l'interrogation du WoS sur des critères de gestion agronomique des maladies contrôlées par des traitements à base de cuivre, complétés par des articles techniques et rapports de projets de recherche identifiés par les experts.

\section{Les méthodes prophylactiques}

LA PROPHYLAXIE VISE À RÉDUIRE LES CONTAMINATIONS PRIMAIRES, en jouant essentiellement sur la survie et la disponibilité de l'inoculum primaire d'un agent pathogène. Elle repose sur trois grands objectifs : éliminer les réservoirs d'inoculum dans ou à proximité des parcelles, limiter la survie de l'inoculum néanmoins présent, et éviter les apports exogènes d'inoculum. Elle mobilise des méthodes très diverses, dont l'efficacité est souvent bonne du fait de leur effet préventif (en amont des épidémies) plutôt que curatif. Son action via un «non-effet » rend toutefois la prophylaxie plus difficile à évaluer que les options curatives, et son intérêt est sans doute sous-évalué.

L'analyse bibliographique a porté sur les méthodes de prophylaxie utilisables en $A B$; celles recourant à des produits non autorisés en $A B$, comme l'urée, ne sont donc pas présentées. Elle a privilégié les essais réalisés in situ et qui ont évalué l'efficacité de la prophylaxie sur la réduction des dégâts.

\section{I Éliminer de la parcelle les sources d'inoculum primaires actives}

Élimination, broyage ou enfouissement des résidus de culture infectés

Le cas le plus étudié concerne la tavelure du pommier. Dans les régions tempérées, Venturia inaequalis se conserve en hiver essentiellement dans les feuilles mortes tombées au sol. Au printemps suivant, des ascospores formées dans ces feuilles sont projetées lors des épisodes pluvieux et causent les contaminations primaires sur feuilles et fruits. Diverses études ont donc exploré les possibilités de réduire ce stock d'ascospores en agissant sur la litière de feuilles au sol. 
Des essais conduits en vergers conventionnels ou biologiques, dans plusieurs pays, ont ainsi testé l'efficacité du ramassage et du retrait des feuilles mortes, et celle de différentes modalités de broyage et/ou d'enfouissement visant à accélérer la décomposition des feuilles pour diminuer la formation des ascospores. Tous ces essais (tableau 3.1) ont confirmé l'intérêt d'une gestion automnale de la litière. L'élimination complète des feuilles est l'option la plus efficace. Un broyage " grossier » des feuilles, réalisé avec le broyeur à marteaux dont sont déjà équipés les producteurs de pommes (pour le broyage des branches après la taille), s'avère moins efficace qu'un broyage « fin » (nécessitant l'achat d'un broyeur spécifique et donc un investissement supplémentaire).

L'enfouissement des feuilles situées sur le rang de plantation est également une méthode très efficace qui vient en complément des opérations de retrait ou de broyage des feuilles situées sur l'inter-rang enherbé. Elle implique un travail du sol sur le rang (enfouissement par buttage) qui doit être couplé avec les opérations de gestion mécanique des adventices. Les essais ont montré l'importance de la gestion de ces feuilles tombées sur le rang de plantation, qui ne peuvent être facilement andainées pour être broyées. Leur enfouissement peut être réalisé avec des outils à disques. Il est facilité par le creusement d'une rigole au pied les arbres (débuttage), les feuilles qui y tombent étant ensuite enfouies à l'automne par un buttage. Ainsi, des stratégies associant le broyage ou l'élimination de la litière entre les rangs et le travail du sol sur le rang ont été développées et validées en AB. Dans un essai conduit dans la Drôme, retirer les feuilles présentes sur l'inter-rang (avec une ramasseuse à feuilles) et enfouir celles tombées sur le rang (par buttage avec des outils à disques) permet ainsi de réduire la concentration aérienne en ascopores de $95 \%$ par rapport à la modalité sans prophylaxie. Associée à une protection fongicide $A B$ (une application de $2,5 \mathrm{~kg} \mathrm{Cu} / \mathrm{ha}$ au débourrement puis des applications de soufre), cette prophylaxie permet de réduire le nombre de taches par fruit à la récolte d'environ $70 \%$, quelle que soit la pression de maladie.

Une stratégie similaire d'enfouissement ou de broyage des feuilles mortes est fortement conseillée pour contrôler l'anthracnose du noyer (due à l'ascomycète Gnomonia leptostyla), qui hiverne dans les feuilles contaminées tombées au sol.

En revanche, et assez curieusement, cette prophylaxie par ramassage des feuilles au sol ne semble pas préconisée contre le mildiou de la vigne, alors que les oospores présentes dans cette litière de feuilles sont reconnues comme étant les principales sources d'inoculum primaire initiant les épidémies. Cette méthode ne fait en tout cas pas l'objet d'évaluations scientifiques : une recherche dans le WoS n'a fourni aucun article concernant l'évaluation de l'élimination des feuilles de litière en prévention des infections, y compris dans les synthèses les plus récentes. L'essentiel des travaux dans ce domaine porte actuellement sur la prédiction de la germination des oospores, afin de positionner les premiers traitements aux périodes adéquates. 







\section{Élimination des organes ou plantes infectés}

Les résidus de culture sur ou dans le sol ne sont pas les seules sources possibles d'inoculum primaire. Pour beaucoup d'espèces pérennes, les lésions sur rameaux ou les organes infectés restant sur la plante durant l'hiver sont également des réservoirs majeurs. Ainsi, l'agent des monilioses sur cerisier (Monilinia spp.) se conserve en hiver sous forme de mycélium à l'intérieur des fruits momifiés, restés accrochés sur l'arbre ou tombés au sol, et au niveau de petits chancres sur rameaux. La prophylaxie consiste donc à enlever les momies et à éliminer par la taille les rameaux moniliés. En Hongrie, des essais en $A B$ ont montré que ces opérations (réalisées en août) permettent une réduction significative du taux de rameaux infectés l'année suivante, y compris dans les modalités avec protection fongicide.

La forme la plus extrême de ce type de prophylaxie est l'élimination complète des plantes infectées ou mortes de la parcelle. Ces pratiques d'arrachage sont répandues dans certaines productions fruitières, comme le pêcher aux États-Unis, mais elles font aussi partie des mesures obligatoires de lutte contre certains parasites bactériens ou viraux réglementés, et sont une méthode majeure de sélection sanitaire en production de semences ou de plants. L'efficacité dépend de plusieurs facteurs : le taux de plantes infectées, la facilité d'observation des symptômes et leur caractère systématique (absence de porteurs sains), les caractéristiques de dispersion de l'agent pathogène, mais aussi la surface concernée. Pour les maladies dont l'inoculum provient chaque année essentiellement de l'extérieur de la parcelle (comme l'enroulement chlorotique de l'abricotier, transmis par un insecte vecteur), cette mesure de prophylaxie au sein de la parcelle n'a qu'un effet limité, insuffisant pour réduire efficacement les nouvelles contaminations ; la nécessité de la mettre en œuvre sur de grandes surfaces la rend difficilement applicable, car l'agent pathogène se conserve également dans les Prunus sauvages.

\section{Limiter la survie des parasites}

\section{Par application d'antagonistes}

La réduction de l'inoculum peut aussi passer par une diminution de son taux de survie. Dans le cas de formes de conservation présentes sur des résidus de culture (feuilles par exemple), une réduction de la survie peut être favorisée par l'application d'agents antagonistes. Contre la tavelure, l'antagoniste qui a montré le plus de potentiel pour réduire la production d'ascospores en verger est le champignon Microsphaeropsis ochracea. Un essai canadien (tableau 3.1) avait montré que sa pulvérisation sur la canopée, à $10 \%$ de chute des feuilles, diminuait significativement la quantité d'ascospores au printemps suivant. Des essais ultérieurs, conduits en Europe et en France, avec un produit précommercial à base de $M$. ochracea n'ont en revanche pas montré d'efficacité satisfaisante en verger. Aucune homologation permettant d'utiliser cet antagoniste en verger n'existe actuellement en France. 


\section{Par accélération de la décomposition des litières infectées}

Les feuilles de litière constituant souvent le support nutritif des formes de conservation des parasites, accélérer leur décomposition par l'apport de matières riches en azote peut permettre de limiter la formation de l'inoculum primaire pour la saison suivante. Dans un essai de quatre années en Allemagne (tableau 3.1), la pulvérisation sur le feuillage d'un produit de vinasse de betterave a ainsi permis de réduire de près de $40 \%$ en moyenne l'incidence de la tavelure sur feuilles et sur fruits.

\section{Par la rotation culturale}

En cultures annuelles, les rotations sont l'un des piliers de la gestion prophylactique des maladies, en particulier celles causées par des parasites du sol. En grandes cultures comme en productions maraîchères, elles permettent d'éviter qu'un agent pathogène présent sur les résidus de culture ou des repousses ne se retrouve en présence d'un hôte sensible sur la même parcelle lors de la culture suivante. Les risques sanitaires sont donc accrus par les systèmes de culture simplifiés et les rotations courtes, ainsi que par les modifications de pratiques qui y sont fréquemment associées (en particulier la suppression du labour) qui réduisent les interventions prophylactiques (pas d'enfouissement des résidus infectés, notamment).

En dépit de son efficacité, ce levier est donc peu mobilisé dans les systèmes de production actuels, les considérations économiques prévalant dans le choix des successions culturales. De ce point de vue, la période d'interculture est sans doute insuffisamment exploitée pour son potentiel d'amélioration de l'état sanitaire, et des travaux scientifiques en ce sens sont encore trop rares. Le principe de cultures nettoyantes entre deux cultures sous serre est en revanche assez travaillé et appliqué.

\section{I Éviter les apports exogènes d'inoculum}

Cet objectif repose principalement sur la sélection sanitaire et la certification du matériel végétal destiné à la plantation. Cette prophylaxie est essentielle, en particulier vis-à-vis d'affections chroniques (viroses, certaines bactérioses) et pour des plantes multipliées par voie végétative (plantes à tubercules, arbres fruitiers, vigne, notamment). Appliquée en routine dans le cadre de la certification du matériel végétal vendu pour replantation, elle permet par exemple de prévenir la dégénérescence virale des plants de pomme de terre. La sélection sanitaire repose sur l'inspection visuelle des parcelles semencières et l'arrachage des plantes visiblement atteintes - qui ne doivent pas être laissées sur place pour éviter les possibles contaminations d'insectes vecteurs. Cette procédure, si elle s'avère globalement efficace contre de nombreux parasites, notamment viraux et bactériens, ne permet toutefois pas d'assurer l'absence d'infection latente (présence asymptomatique du parasite). Il est donc important de compléter l'examen visuel par des tests post-récolte, en particulier avec les outils modernes de détection moléculaire, pour gérer ces infections latentes. 
Établir des filières et des systèmes de production et de distribution de semences certifiées est donc crucial pour le développement de systèmes intégrés de protection sanitaire. C'est également une mesure majeure dans les plans de lutte obligatoire contre les parasites réglementés de quarantaine. Or l'AB tend à favoriser des marchés informels des semences, fondés non sur le commerce de semences certifiées selon les règles adoptées en agriculture conventionnelle, mais plutôt sur des modes de certification « participatifs » ou « cooptatifs ». Il reste à établir dans quelle mesure ces pratiques alternatives permettent, ou non, de maintenir une haute qualité sanitaire des semences diffusées, ce qui requiert des actions de recherche associant les sciences biologiques et agronomiques (étude de l'état des lots au cours des générations, analyse des voies de contamination ou d'assainissement) et les sciences humaines et sociales (circuits de diffusion, valeur économique, organisation des filières et des producteurs).

\section{La protection physique contre les infections}

L'objectif des mÉtHOdes de PROTECTION PHYSIQUe contre les maladies est d'induire un microclimat au niveau de la plante défavorable aux infections par l'agent pathogène, et/ou d'empêcher l'accès du parasite aux organes sensibles de la plante par la mise en place d'un obstacle infranchissable. Ces méthodes reposent essentiellement sur le déploiement de bâches (anti-pluie ou anti-grêle), visant soit à limiter l'humidité (couvertures anti-pluie) et plus généralement à modifier le microclimat (serres et abris froids), soit à empêcher l'intrusion de parasites (limitation des plaies) ou à bloquer leur dispersion dans l'environnement (bâchage des tas de déchets).

L'effet de protection de la culture par les serres et abris est bien connu. L'expertise s'est donc surtout intéressée à des techniques plus récentes : les bâches installées au champ pour protéger les plantes pérennes de la pluie, ou pour recouvrir des sources d'inoculum potentielles (tas de déchets de récolte ou de tri stockés à proximité immédiate des parcelles). Il existe assez peu d'articles scientifiques dans des revues à comité de lecture traitant spécifiquement de ces méthodes. La plupart concernent des cultures pérennes (arbres fruitiers). Ce corpus a donc été enrichi par des rapports techniques et des publications destinées aux producteurs, qui contiennent souvent des indications utiles concernant l'efficacité ou la mise en œuvre.

\section{Les couvertures anti-pluie en cultures pérennes}

Le principe de ces couvertures est de créer une barrière mécanique contre la pluie audessus des arbres ou de la vigne, permettant d'éviter le ruissellement au sein de la frondaison et de réduire les durées d'humectation des fleurs, feuilles et fruits. L'absence de pluie tombant directement sur le végétal peut de plus diminuer la dispersion de l'inoculum due à l'effet splashing (éclaboussement). Il s'agit de bâches en polyéthylène ou 
autre matériau imperméable laissant passer la lumière, tendues au-dessus des rangées d'arbres, et qui laissent l'eau s'écouler au sol sur l'inter-rang. Ce dispositif est souvent prolongé sur les côtés par des filets anti-insectes et/ou couplé à des filets anti-grêle. Dans les essais, les systèmes de protection anti-pluie peuvent être des prototypes réalisés par les producteurs ou les expérimentateurs, ou bien des systèmes commercialisés par des sociétés comme Voen ou Filpack. La qualité de la protection anti-pluie, le microclimat et l'intensité lumineuse sous la bâche, de même que sa résistance au vent, varient certainement d'un système à l'autre.

D’abord développée, dans les années 1990, pour protéger les cerises contre l'éclatement avant récolte dû à la pluie, la technique a été étendue à d'autres productions fruitières. Son efficacité sur le développement des maladies a notamment été testée sur pommiers, en particulier contre la tavelure : les essais conduits en Europe (France, Allemagne, Danemark) ont montré des efficacités de 90 à $100 \%$ contre la tavelure sur fruits (vergers bâchés sans protection phytosanitaire).

Les systèmes de couverture anti-pluie ont montré une très bonne efficacité pour réduire l'incidence de nombreuses maladies dont le développement nécessite une certaine durée d'humectation du végétal. Beaucoup de ces maladies font l'objet de traitements au cuivre en $A B$ : la tavelure du pommier, le mildiou de la vigne, la bactériose du kiwi. Dans de nombreux cas, ces protections physiques permettent une production de très bonne qualité commerciale sans traitements pesticides. Cependant, elles ne contrôlent pas, voire peuvent favoriser, d'autres maladies moins dépendantes des conditions d'humectation du végétal, par exemple l'oïdium sur fraisier, sur pommier ou sur vigne, mais aussi des pullulations de ravageurs rendus peu accessibles à leurs prédateurs. Des études complémentaires restent donc nécessaires pour identifier tous les couples plantes-pathogènes pouvant être concernés par l'usage des couvertures anti-pluie. Nous n'avons ainsi trouvé aucune référence sur le pêcher, traité au cuivre en $A B$, en particulier contre la cloque.

Malgré leur efficacité, ces systèmes connaissent une diffusion encore assez limitée chez les producteurs. Ils sont assez coûteux, mais peuvent être couplés à des dispositifs supplémentaires de protection contre d'autres aléas (grêle, insectes notamment).

\section{Le bâchage de sources extérieures d'inoculum}

L’accumulation de matériel végétal blessé ou infecté (écarts de tri, plantes malades) à proximité des parcelles est fréquente pour des plantes racines comme la pomme de terre. Ces tas de déchets constituent une des sources principales d’inoculum primaire pour les cultures suivantes, en particulier pour des parasites à dispersion aérienne comme le mildiou. La destruction complète de tas de gros volume étant difficile, la recommandation est de les recouvrir d'une bâche noire pour accélérer leur décomposition (solarisation) et éviter toute dispersion de spores. Malgré son efficacité et son coût modeste, et en dépit de l'existence de dispositions réglementaires locales exposant les producteurs négligents à des sanctions, cette prescription reste trop peu suivie, en culture conventionnelle comme en $A B$. 


\section{La Gonduite des plantes et des couverts}

\section{Architecture des plantes et des couverts}

L'architecture des plantes et des couverts est un facteur significatif, mais globalement négligé, de la réceptivité d'une culture aux maladies. Elle joue essentiellement en modifiant le microclimat au sein de la végétation (notamment l'humidité, paramètre important pour le développement de nombreuses maladies), mais aussi la diffusion de l'inoculum, sa répartition et son dépôt sur les plantes. Elle influe également sur le dépôt des produits de protection des plantes. Un ensemble de travaux, souvent assez anciens désormais, montre un impact parfois important de l'architecture des plantes sur le développement épidémique. Elle peut expliquer des variations de quelques dizaines de pourcent dans les vitesses de développement épidémiques entre couverts favorables et couverts défavorables.

La forme des plantes dépend à la fois des caractéristiques génétiques de chaque variété, mais aussi des modalités de conduite de la plante (taille, type de porte-greffe...) ou du couvert (densité de plantation, fertilisation...).

\section{Génétique et architecture des plantes}

Les travaux de cartographie génétique mettent en évidence des colocalisations souvent fortes entre loci gouvernant des caractères architecturaux ou développementaux (date de floraison, précocité, ramification...) et QTL de résistance partielle. Les caractères architecturaux créant des conditions microclimatiques défavorables aux maladies (tiges hautes et peu nombreuses, faible surface foliaire) ont souvent été contre-sélectionnés en création variétale, au profit de couverts bas et denses fournissant une grande efficacité photosynthétique et des potentiels de rendement élevés, mais présentant des sensibilités fortes aux maladies.

\section{Gestion de l'architecture via la conduite}

Pour les cultures pérennes ligneuses (arbres fruitiers, vigne), la densité de plantation, la vigueur obtenue par le choix du porte-greffe, l'intensité de la taille et son type vont influencer la structure végétale au sein de la parcelle et donc le microclimat au sein de la frondaison. La conduite de la plante peut aussi influer sur sa phénologie, sa physiologie et les rythmes de croissance des pousses, qui peuvent aussi favoriser ou défavoriser le développement d'un agent pathogène.

Sur pommier, une taille plus forte permet de réduire le développement de la tavelure, en améliorant le dépôt des traitements fongicides. La taille dite " centrifuge », qui crée un puits de lumière au centre de l'arbre, est supposée produire une frondaison plus aérée, séchant plus vite, et donc moins favorable à la tavelure. Une diminution significative des attaques est effectivement observée durant la phase des contaminations primaires au printemps. Toutefois, parce qu'elle induit une croissance prolongée des pousses en été, 
et donc la présence de jeunes feuilles sensibles à la tavelure, cette taille peut aussi favoriser les infections secondaires.

Sur abricotier, c'est le choix du porte-greffe et de la hauteur de greffage qui s'est avéré déterminant pour préserver les arbres de la bactériose due à Pseudomonas syringae, maladie difficile à contrôler même avec des applications de cuivre, et responsable du dépérissement et de la mort de nombreux arbres.

Des pratiques d'effeuillage précoce et de taille en vert (vigne, houblon) permettent également de réduire la sévérité de maladies foliaires majeures, comme le mildiou et l'oïdium.

\section{Associations variétales et végétales}

Comme cela a été exposé dans la section traitant des résistances végétales, la monoculture de plantes génétiquement identiques, de règle dans les systèmes de culture actuels, favorise l'adaptation des agents pathogènes, et donc le développement des maladies. Augmenter la diversité spatiale des résistances des plantes aux pathogènes, via la culture de mélanges variétaux ou spécifiques, et/ou la diversité temporelle des cultures, est donc l'une des voies proposées pour limiter les pullulations épidémiques et renforcer la robustesse des systèmes.

Les mélanges variétaux présentent le double intérêt de réduire, en général, la vitesse de contournement des résistances spécifiques, mais aussi, notamment via les effets de barrière (une forme d'architecture de couvert défavorable), de limiter plus ou moins fortement le développement épidémique. Ce type de couvert peut ainsi permettre de continuer à cultiver une variété d'intérêt commercial assez sensible à une maladie en l'associant à des variétés résistantes. La question de la récolte séparée des variétés pour une valorisation séparée est importante (faisabilité, surcoûts...). L'un des principaux freins à une utilisation plus large de mélanges variétaux est la difficulté à conduire des couverts très hétérogènes sur le plan des caractères agronomiques, comme la date de maturité ou la qualité de la récolte.

Les résultats concernant l'efficacité des mélanges variétaux, exposés au chapitre précédent, montrent aussi que cette efficacité est augmentée lorsque l'on réduit la pression locale de maladie. Il serait donc intéressant d'évaluer les mélanges variétaux en AB dans des systèmes mobilisant par ailleurs la prophylaxie, la sélection sanitaire et/ou l'utilisation de méthodes de biocontrôle.

Les cultures associées (mélanges interspécifiques) au sein d'une parcelle sont également efficaces, mais sont très peu utilisées dans les formes actuelles d'agriculture (à l'exception notable des productions fourragères, peu traitées au cuivre). Elles trouvent cependant un regain d'intérêt dans des systèmes d'agriculture valorisant la biodiversité (agroforesterie, permaculture), mais font encore l'objet de très peu de travaux quant à leurs capacités à réduire l'emploi de cuivre. 


\section{Éléments de conclusion}

\section{La prophylaxie, mesure négligée mais efficace}

Les méthodes visant à éliminer - ou tout au moins à diminuer fortement - l'inoculum des parcelles (arrachage des plantes infectées, broyage ou enfouissement des résidus de culture, taille des organes infectés) sont mises en œuvre avec succès en cultures fruitières. Elles sont en revanche peu utilisées dans d'autres productions pérennes, comme la viticulture, sans que la raison en soit évidente.

D'autres techniques permettent de réduire la survie de l'inoculum : l'apport d'éléments organiques favorisant la décomposition des litières infectées, l'application d'antagonistes en amont de la formation des structures de survie des parasites, la rotation dans le cas de cultures annuelles. Si ces méthodes ont globalement fait la preuve de leur efficacité, elles sont cependant peu mobilisées en pratique. Les systèmes de production biologiques $\mathrm{y}$ ont toutefois plus volontiers recours que les systèmes conventionnels.

\section{La sélection sanitaire, base de la production de matériel de plantation sain}

La sélection sanitaire des semences est un élément capital pour une prophylaxie réussie, en particulier contre les viroses et bactérioses transmises par le matériel végétal destiné à la plantation (graines, tubercules, boutures). Son efficacité est encore accrue en adjoignant aux contrôles visuels des tests moléculaires ou sérologiques de détection des infections latentes. En AB, ce levier reste toutefois discuté ou peu mobilisé, au nom de la promotion de modèles alternatifs de diffusion et de production du matériel de plantation et des ressources génétiques.

\section{La lutte physique, une option efficace en cultures pérennes ligneuses}

Les systèmes de protection anti-pluie ont montré une forte efficacité pour réduire l'incidence de nombre de maladies ciblées par les traitements au cuivre en $A B$, notamment la tavelure du pommier et le mildiou de la vigne. Ces dispositifs permettent souvent une production commerciale de très bonne qualité sans protection fongicide. Toutefois, ils sont sans effet contre d'autres maladies telles que l'oïdium, voire peuvent les favoriser. Les couples cultures-pathogènes et les situations pouvant tirer bénéfice de ces couvertures anti-pluie restent donc à identifier.

Malgré leur efficacité, et la possibilité de les coupler à des dispositifs supplémentaires de protection contre d'autres aléas (grêle, insectes), ces systèmes connaissent une diffusion encore assez limitée chez les producteurs. Ils peuvent par ailleurs être confrontés à une faible acceptabilité sociale, en raison du caractère « artificiel » qu'ils confèrent aux surfaces agricoles.

Le déploiement des bâches anti-pluie, et plus généralement des méthodes de lutte physique, est en effet relativement coûteux, et nécessite un ajustement des modes de conduite 
de la culture, mais aussi du choix variétal. C'est donc un élément qui doit nécessairement être raisonné dans une optique de système intégré de protection, voire de production.

\section{Exploiter l'architecture des plantes et des couverts pour restreindre les épidémies}

L'architecture des plantes et des couverts, en régulant à la fois le microclimat (température, durées d'humectation des organes) et la disposition spatiale des surfaces sensibles, a un impact important sur les infections microbiennes et, partant, sur le développement des épidémies. Les caractères architecturaux défavorables aux parasites, qui colocalisent souvent sur les cartes génériques avec des QTL de résistance quantitative, ont toutefois souvent été contre-sélectionnés dans les variétés modernes, car ils sont associés à des traits a priori défavorables à une forte productivité (faible surface foliaire, plantes hautes, grands entrenœuds).

Il est possible de retrouver des génotypes architecturalement défavorables aux infections, et de les exploiter à nouveau en création variétale. De plus, dans le cas d'espèces ligneuses pérennes, les types de taille permettent de restaurer des architectures défavorables aux parasites. C'est le cas par exemple de la conduite centrifuge du pommier vis-à-vis de la tavelure, ou des techniques d'effeuillage partiel précoce contre le mildiou ou l'oïdium chez la vigne ou le houblon.

\section{Associations variétales et végétales : des bénéfices multiples}

Cultiver simultanément dans la même parcelle plusieurs variétés d'une même plante, voire plusieurs espèces végétales, réduit souvent la vulnérabilité de chaque composant de l'association aux attaques parasitaires. Lorsque ces associations comportent des génotypes résistants, la culture associée peut freiner en outre la dynamique d'adaptation des parasites aux résistances (effet de dilution et de prémunition), et prolonge donc la durabilité de celles-ci. La performance des associations dépendant étroitement de la pression locale d'inoculum, elle devrait croître sensiblement si l'on mène ces cultures associées en conjonction avec des interventions prophylactiques et/ou l'utilisation de méthodes de biocontrôle.

Toutefois, et même si certains acteurs (y compris des meuniers ou des malteurs) commencent à les développer, l'emploi d'associations variétales ou végétales reste très limité dans les formes contemporaines d'agriculture (à l'exception des productions fourragères), du fait de difficultés dans la conduite de couverts très hétérogènes (mécanisation, date de récolte), et/ou de contraintes sur l'utilisation des produits récoltés. Les associations sont au cœur de systèmes de culture tels que l'agroforesterie ou la permaculture, mais leur performance en matière de régulation des bioagresseurs reste à évaluer. 



\section{L'insertion des leviers alternatifs dans des systèmes intégrés de protection}

DÉVELOPPER DES SYSTÈMES DE PROTECTION ÉCONOMES ou sans cuivre suppose a minima deux conditions : disposer de solutions techniques (méthodes préventives ou curatives, pratiques agronomiques) alternatives, de variétés résistantes ou peu sensibles aux maladies, accessibles et si possible intégrables au sein de systèmes dont la démonstration d'efficacité peut être faite; et rendre ces nouveaux systèmes acceptables par les agriculteurs et les filières.

Les analyses précédentes montrent qu'à l'évidence, il sera difficile de remplacer les produits cupriques par une seule technique alternative, tout en gardant la même efficacité et la même persistance d'action sur de longues périodes et pour un prix d'intervention similaire. Dès lors, il convient de s'interroger sur la possibilité de combiner ces efficacités partielles (dans le temps ou dans l'espace) pour parvenir à concevoir non plus des solutions individuelles alternatives (logique de substitution), mais des itinéraires de protection, voire des systèmes intégrés de production (logique de reconception plus ou moins poussée) permettant d'assurer un niveau d'efficacité et une durabilité au moins équivalents à ceux des systèmes actuels à base de cuivre, mais sans recours (ou avec un recours minime) aux produits cupriques. Pour cette entrée " système ", nous avons choisi de traiter les trois cas correspondant aux usages majeurs du cuivre déjà mentionnés, qui sont d'ailleurs les seuls sur lesquels existe un minimum de littérature dans le domaine. Le tableau 4.1 récapitule les différentes méthodes alternatives identifiées dans les chapitres précédents pour ces trois cas. La figure 4.1 illustre la complémentarité des méthodes, qui agissent sur des phases différentes du cycle de l'agent pathogène.

Nous nous intéresserons dans un second temps aux déterminants et verrous à la conception et/ou à l'adoption de tels systèmes intégrés, et en particulier au rôle de la stratégie des acteurs de l'agrofourniture dans la diffusion des innovations clés pour la construction de ces systèmes. C'est en effet une dimension essentielle pour comprendre dans quelle mesure des résultats expérimentaux souvent probants peuvent, ou non, passer rapidement dans la pratique agricole, et pour imaginer le type de mesures d'accompagnement susceptibles de favoriser ces transitions. 
Figure 4.1. Les méthodes alternatives aux traitements cupriques, et leur action sur le cycle de vie des agents pathogènes de type ascomycètes ou oomycètes.



\section{Les évaluations et comparaisons de systèmes de culture}

Les tRaVauX D'Évaluation de SYStèmes de PRotection en tant que tels, et non de leurs composants individuels, sont remarquablement rares. Ceux qui ont donné lieu à publication proviennent, dans le domaine couvert par cette ESCo, essentiellement de deux types de projets de recherche ou d'expérimentation-démonstration, spécialisés ou pluri-filières : - trois projets de recherche européens consacrés aux alternatives au cuivre - Blight $M o p$, dédié à la pomme de terre, RepCo, focalisé sur la lutte contre le mildiou de la vigne et la tavelure du pommier, et Co-Free, qui visait le développement de stratégies de protection sans cuivre en $A B$ sur pommier, vigne, tomate et pomme de terre - annonçaient des expérimentations "systèmes ». Certaines ont été effectivement conduites dans Blight Mop et Co-Free, mais n'ont toutefois été mises en place que tardivement dans le déroulement de ces projets et n'ont donc en général pas été répétées. De plus, ou de ce fait, les résultats n'en ont pas été diffusés autrement que via les rapports des projets, rapports non encore accessibles dans le cas de Co-Free ; 
- en France, près de 400 systèmes de culture Dephy réduisant l'usage des produits phytosanitaires, couvrant la diversité des filières végétales, sont testés dans le réseau Dephy EXPE du plan Écophyto, avec l'objectif de favoriser progressivement leur transfert auprès des agriculteurs. Certains de ces systèmes, en arboriculture, viticulture, grande culture et productions légumières, sont conduits en $A B$. D'une durée de 5 ou 6 ans, les projets ont démarré en 2012 ou 2013 et ne sont donc pas encore arrivés à terme. Des « synthèses des résultats à mi-parcours à l'échelle nationale » ne sont disponibles actuellement que pour les filières Viticulture et Grandes cultures.

\section{Viticulture}

Il existe une littérature assez abondante sur des solutions visant une meilleure efficacité des moyens de lutte (protéger mieux avec moins de cuivre) en viticulture bio, ainsi que sur la substitution du cuivre par des méthodes alternatives (voir chapitre 2 et tableau 4.1). On ne trouve en revanche pas vraiment de publications sur la reconception de systèmes de culture visant à supprimer totalement l'usage du cuivre, en assemblant des leviers génétiques, de prophylaxie et de substitution.

\section{Les essais agronomiques visant une meilleure efficacité du cuivre ou des méthodes alternatives}

L'utilisation d'un modèle de prévision du démarrage et du développement des infections par le mildiou (à partir de données climatiques, agronomiques et pathologiques) permet de réduire le nombre d'applications de cuivre. Des essais, conduits en Italie en 2009 et 2010, montrent que cette approche permet de réduire de $50 \%$ la consommation de cuivre sans augmenter significativement l'incidence et la sévérité des attaques sur feuilles et grappes. Des réductions d'utilisation du cuivre du même ordre ont été obtenues avec les $\mathrm{OAD}$ Coptimizer (en $\mathrm{AB}$ ) et Mildium (travaux non spécifiques à l'AB). Un meilleur raisonnement des applications permet donc d'envisager une réduction significative du recours au cuivre, mais reste loin de l'objectif de son abandon.

Les nombreux essais de produits alternatifs au cuivre, conduits un peu partout en Europe ou ailleurs, montrent en général une efficacité quelquefois égale, mais le plus souvent inférieure, à celle du cuivre. L'efficacité de ces produits de substitution semble améliorée quand ils sont associés à des doses réduites de cuivre, mais les publications ne précisent pas le niveau de réduction obtenu sur l'ensemble du cycle de croissance de la vigne.

L'essai le plus ambitieux sur les alternatives au cuivre contre le mildiou de la vigne est celui réalisé dans le cadre du projet RepCo (rapporté par Dagostin et al., 2011), qui a évalué 112 préparations, sur deux sites en Italie et en Suisse et pendant quatre années. Toutefois, cet essai ne mobilisait pas de levier agronomique à caractère préventif ou curatif, et la nécessaire intégration des produits alternatifs à effet partiel étudiés dans une stratégie de protection intégrée n'est évoquée qu'en conclusion. De même, la revue 


\section{Tableau 4.1. Méthodes alternatives aux traitements cupriques, disponibles ou potentielles, pour les trois usages majeurs du cuivre.}

\begin{tabular}{|c|c|c|c|c|}
\hline Méthodes & Disponibilité & Tavelure du pommier & Mildiou de la vigne & $\begin{array}{l}\text { Mildiou de la pomme } \\
\text { de terre }\end{array}$ \\
\hline \multirow[t]{2}{*}{$\begin{array}{l}\text { Substances } \\
\text { biocides }\end{array}$} & Disponible & 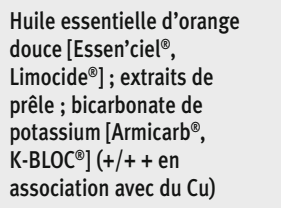 & $\begin{array}{l}\text { Extraits de prêle, ortie ; } \\
\text { lécithine (?) }\end{array}$ & Ortie (--) \\
\hline & Potentiel & $\begin{array}{l}\text { Huile essentielle de thym } \\
\text { et de sarriette ; extraits de } \\
\text { peuplier noir }(++) \text {, de yucca } \\
(++)\end{array}$ & $\begin{array}{l}\text { Huile essentielle de thym, } \\
\text { d’arbre à thé (in vitro } \\
+++) \text {; extraits de sauge } \\
\text { officinale }(++) \text {, réglisse } \\
(++) \text {, yucca, ail, } \\
\text { margousier; huile végétale; } \\
\text { lipopeptides bactériens }\end{array}$ & \\
\hline \multirow[t]{3}{*}{ Substances SDP } & Disponible & Laminarine [Vacciplant $\left.{ }^{\circledast}\right]$ (!) & & \\
\hline & & $\begin{array}{l}\text { Hors AB : BTH }\left[\text { Bion }^{\oplus}\right](+/++) \\
\text { phosphites }(+/++)[\text { Kendal] }\end{array}$ & $\begin{array}{l}\text { Hors AB : COS-OGA, } \\
\text { phosphites (SDP } \\
\text { et biocide) }\end{array}$ & $\begin{array}{l}\text { Hors AB : BABA (+/-) ; } \\
\text { phosphites }(++)\end{array}$ \\
\hline & Potentiel & & & \\
\hline \multirow{2}{*}{$\begin{array}{l}\text { Agents } \\
\text { microbiologiques } \\
\text { de biocontrôle }\end{array}$} & Disponible & $\begin{array}{l}\text { Bacillus subtilis QST } 713 \\
\text { [Serenade }{ }^{\oplus} \text { (SDP) }\end{array}$ & & Aucun \\
\hline & Potentiel & & & Serenade ${ }^{\circledast}$ (?) \\
\hline \multirow[t]{2}{*}{$\begin{array}{l}\text { Résistance } \\
\text { génétique }\end{array}$} & Disponible & $\begin{array}{l}\text { Des variétés dotées de la } \\
\text { résistance totale } V f(+++ \\
\text { mais rapidement contournée) } \\
\text { et/ou de résistances } \\
\text { partielles (++ mais } \\
\text { durables) }\end{array}$ & $\begin{array}{l}\text { Regent, Bronner (mais } \\
\text { durabilité apparemment } \\
\text { faible) } \\
\text { Variétés « ResDur » } \\
\text { inscrites en 2017: } \\
\text { Artaban, Vidoc, Floreal, } \\
\text { Voltis }\end{array}$ & $\begin{array}{l}\text { Passion, Makhai (+++) } \\
\text { Allians, Eden, Coquine } \\
(++) \\
\text { Désirée et nombreuses } \\
\text { autres variétés à } \\
\text { résistance partielle } \\
(+/++)\end{array}$ \\
\hline & Potentiel & $\begin{array}{l}\text { Des gènes ou QTL identifiés } \\
\text { non exploités }\end{array}$ & $\begin{array}{l}\text { Des variétés Inra } \\
\text { résistantes en phase } \\
\text { de test }\end{array}$ & $\begin{array}{l}\text { Pyramidage de gènes de } \\
\text { résistance }(+++ \text { mais } \\
\text { durabilité discutable) }\end{array}$ \\
\hline \multirow[t]{2}{*}{$\begin{array}{l}\text { Prophylaxie } \\
\text { agronomique } \\
\text { et protection } \\
\text { physique }\end{array}$} & Disponible & $\begin{array}{l}\text { Retrait ou enfouissement } \\
\text { des feuilles mortes infectées } \\
(++) \\
\text { Protection (bâches) anti- } \\
\text { pluie }(+++)\end{array}$ & & $\begin{array}{l}\text { Rotations culturales } \\
\text { plus longues et } \\
\text { diversifiées (+++) } \\
\text { Qualité sanitaire des } \\
\text { plants (+++) } \\
\text { Bâchage des tas de } \\
\text { déchets infectés }\end{array}$ \\
\hline & Potentiel & & $\begin{array}{l}\text { Retrait des feuilles mortes } \\
\text { infecttées, mais pas de } \\
\text { référence en Europe } \\
\text { Bâches anti-pluie, mais } \\
\text { pas testées en Europe }\end{array}$ & \\
\hline
\end{tabular}


Tableau 4.1. Suite.

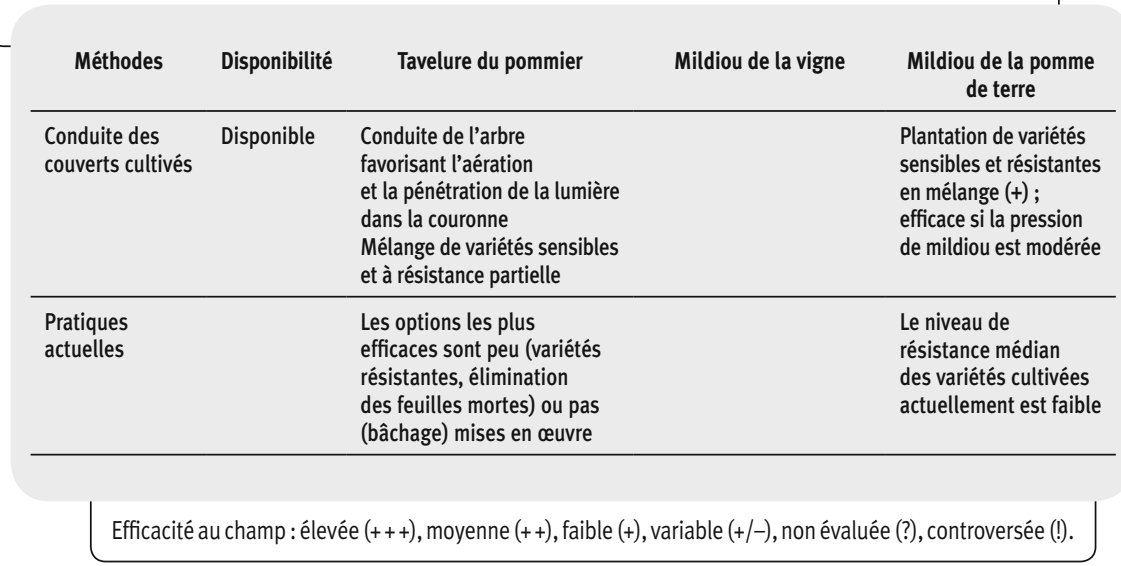

très détaillée sur le mildiou de la vigne et les méthodes de lutte de Gessler et al. (2011) examine les différents recours au cuivre, aux fongicides de synthèse et au biocontrôle, mais n'évoque pas de levier agronomique de prévention ou de protection contre le mildiou, ni l'intégration de méthodes de lutte à effet partiel dans une stratégie intégrée.

\section{Les essais agronomiques visant la reconception de systèmes de culture}

Dans le cadre du projet Co-Free, des systèmes construits autour de variétés résistantes au mildiou ont été testés, mais les résultats n'en ont pas encore été rendus publics. Par ailleurs, différents traitements contre le mildiou ont été comparés sur différents sites et durant 2-3 années : $100 \%$ cuivre, produits alternatifs associés à de faibles doses de cuivre, produits alternatifs seuls. Les produits alternatifs seuls semblent ne pas avoir assuré une protection suffisante. En revanche, leur combinaison avec une dose réduite de cuivre (o,6 à 1,5 kg/ha/an) semble avoir apporté une protection satisfaisante de la vigne, au moins durant les années où la pression de mildiou était modérée.

L'expérience la plus aboutie de reconception de systèmes de culture viticoles à bas niveaux d'intrants phytosanitaires est celle conduite en France depuis 2013 par le réseau Dephy EXPE viticulture. Sur un total de 48 systèmes de culture mis en œuvre dans six régions viticoles, 13 répondent au cahier des charges de l'AB et visent donc, entre autres, la réduction des applications de cuivre. En Alsace, des applications de cuivre très raisonnées (fondées sur de nombreuses observations), associées à une gestion stricte du développement végétatif (enherbement, effeuillage pneumatique) et à l'application d'huiles essentielles et de propolis, ont permis de limiter les doses de cuivre entre 466 et $745 \mathrm{~g} / \mathrm{ha} / \mathrm{an}$ de 2013 à 2015, avec un bon contrôle du mildiou. À Gaillac (Tarn), la maîtrise du 
développement végétatif et l'application de règles de décision ont permis de limiter les doses de cuivre entre 350 et $600 \mathrm{~g} / \mathrm{ha} /$ an de 2013 à 2015, avec un bon contrôle du mildiou mais de faibles rendements.

Par ailleurs, deux systèmes de culture (non $A B$ ) du réseau sont construits autour de cépages résistants au mildiou et à l'oïdium sélectionnés par l'Inra et en phase de test. À Bordeaux, aucun fongicide n'a été appliqué en 2013 et 2014, mais cette absence de traitement a permis l'expression de maladies secondaires, telles que le black rot, auxquelles ces variétés ne sont pas résistantes ; c'est pourquoi en 2015 et 2016, une à deux applications de fongicide de synthèse ont été réalisées. En Alsace, les variétés résistantes ont également permis une très bonne maîtrise du mildiou en 2015 et 2016 ; jusqu'à deux traitements fongicides par an restent toutefois autorisés, pour limiter le risque de contournement de la résistance au mildiou et lutter contre le black rot. Ainsi le recours à des variétés résistantes au mildiou permettrait la réduction la plus significative, mais pas la suppression totale, du recours au cuivre en viticulture biologique.

\section{Arboriculture fruitière}

En production de pommes, il existe quelques travaux ayant associé et intégré différents leviers de gestion des bioagresseurs au sein de systèmes de culture. Ces essais « systèmes » en vergers, implantés à partir de la fin des années 1990, ont généralement comparé des systèmes en $A B$ à des systèmes en production fruitière intégrée (PFI) et/ou conventionnels, mais la réduction de l'usage du cuivre n'était pas toujours affichée comme un objectif prioritaire, y compris dans la conduite en $A B$. Les quatre essais conduits en Europe faisant l'objet de publications scientifiques ont principalement exploité la résistance variétale, en particulier contre la tavelure.

En Suisse, un essai a comparé des systèmes en PFI et en AB implantés avec des variétés de pommiers peu sensibles à la tavelure (Boskoop, Idared) ou résistantes (gène $V f$ ). Dans la modalité $A B$, la protection annuelle contre les maladies a consisté, en moyenne de 1995 à 2002, en au maximum une application fongicide cuprique, 6 à 11 applications de soufre et 9 à 11 applications d'argile. Un bon contrôle de la tavelure a été observé, excepté sur /dared.

En Hongrie, dans une étude sur sept ans (1999-2005) incluant 27 cultivars de pommier ( 9 résistants à la tavelure, 9 commerciaux et 9 anciens), la fréquence finale moyenne de la tavelure est apparue considérablement plus élevée dans le système en $A B$ que dans celui en PFI, sauf pour les variétés résistantes, qui ne présentaient aucun symptôme de tavelure sur les fruits. Dans le même pays, la variété résistante Prima a montré (sur deux saisons de culture) son intérêt dans un système en $A B$ par rapport à la variété modérément résistante Jonathan : Prima a notamment permis de réduire la période de couverture phytosanitaire à base de cuivre.

Dans l'ouest de la France, où le climat est très favorable à la tavelure, une étude (publiée en 2016) a comparé des stratégies de protection intégrée associant à la fois des variétés 
résistantes (Reine des Reinettes, partiellement résistante, et Ariane, porteuse du gène majeur $V f$ ), des pratiques culturales prophylactiques (broyage de la litière foliaire) et des traitements fongicides en cas de risques importants de contamination par la tavelure seulement (les risques légers n'étant pas protégés). Une réduction de $50 \%$ des traitements fongicides a été obtenue, tout en préservant l'efficacité des résistances partielles de Reine des Reinettes et en retardant de deux ans le contournement du gène $V f$. L'intérêt de Reine des Reinettes avait déjà été montré dans la même région, notamment les années à faible pression de tavelure, où cette variété ne présentait, en l'absence de protection fongicide, presque aucun fruit atteint (contre $22 \%$ de fruits tavelés pour la variété Gala).

Dans la Drôme, le dispositif pommiers BioREco, implanté en 2005 à l'Inra de Gotheron, intègre plusieurs leviers dans le raisonnement de la protection phytosanitaire, avec un objectif de réduction du nombre de traitements, y compris dans la modalité AB. Pour la gestion des maladies, les leviers mobilisés sont la résistance variétale, la réduction de l'inoculum primaire de tavelure par retrait/enfouissement de la litière de feuilles automnale, le raisonnement du positionnement des fongicides grâce à l'utilisation d'OAD et de contrôles en verger. Les trois variétés testées sont : Golden Smoothee, sensible aux maladies, Melrose, peu sensible, et Ariane, résistante à la tavelure par le gène $V f$. En AB, c'est sur Golden Smoothee, recevant le plus d'applications fongicides, que les dégâts dus aux maladies ont été les plus importants. Cet essai a montré l'importance de la sensibilité/résistance variétale (tableau 4.2) associée aux autres leviers pour réduire les applications fongicides (dont cupriques) en AB.

Tableau 4.2. Nombre annuel de traitements fongicides en AB (moyenne sur la période 2006 à 2009), pour les trois variétés testées dans le dispositif pommiers BioREco.

\begin{tabular}{lccc}
\multicolumn{1}{c}{ Variété } & $\begin{array}{c}\text { Golden Smoothee } \\
\text { (sensible aux } \\
\text { maladies) }\end{array}$ & $\begin{array}{c}\text { Melrose } \\
\text { (peu sensible } \\
\text { aux maladies) }\end{array}$ & $\begin{array}{c}\text { Ariane } \\
\text { (résistante à la tavelure } \\
\text { par le gène } V f \text { ) }\end{array}$ \\
\hline $\begin{array}{l}\text { Nombre annuel de traitements } \\
\text { fongicides } \\
\text { dont fongicides cupriques }\end{array}$ & 18 & 8 & 6,25 \\
\hline & 1,75 & 1 & 0,75 \\
\hline & *En l'absence de souches de Venturia inaequalis virulentes vis-à-vis de $V f$. \\
\hline
\end{tabular}

\section{Mildiou de la pomme de terre}

Les travaux les plus ambitieux ont été menés dans le cadre des projets européens Blight Mop et Co-Free, visant tous les deux à construire et tester des systèmes de protection des cultures sans recours au cuivre. Dans les deux cas, les essais 
" systèmes » n'ont été mis en place que vers la fin du projet, et leurs résultats n'ont pas été publiés autrement que dans les rapports finaux des projets (ceux de Co-Free étant encore non diffusés).

Les essais conduits dans le cadre de Blight Mop montrent que les leviers les plus prometteurs à intégrer dans des stratégies «zéro cuivre » contre le mildiou de la pomme de terre sont l'emploi de variétés résistantes, leur utilisation en associations variétales (rangs alternés ou mélanges variétaux classiques), voire en associations d'espèces, et dans une faible mesure quelques pratiques agronomiques telles que des dates de plantation plus précoces et un niveau modéré de fertilisation azotée. Ils révèlent également des possibilités de synergies entre certains leviers. Ainsi, l'efficacité des associations variétales (de cultivars résistants et sensibles) augmente lorsque la pression d'inoculum est diminuée, par l'application de doses réduites de cuivre par exemple.

Il semble dès lors possible d'envisager des stratégies alternatives avec un bon niveau d'efficacité et sans emploi de cuivre. Diverses combinaisons de leviers au sein de systèmes ont donc été testées au champ, dans les sept pays participant au projet Blight $M o p$, en conditions de production agricole (parcelles d'au moins un demi-hectare, pratiques mises en œuvre par des agriculteurs) et en comparaison avec les itinéraires normalement utilisés sur ces exploitations. Ces expérimentations ont généralement montré une amélioration significative des performances techniques (réduction de la sévérité de mildiou) et économiques (marge brute) par rapport au système standard initial, y compris dans des systèmes sans cuivre ou avec des doses fortement réduites de cuivre. C'est en particulier le cas pour les systèmes reposant sur l'utilisation, seule ou combinée avec d'autres leviers (densité de plantation, associations variétales, fertilisation adaptée), de variétés à bon niveau de résistance au mildiou du feuillage.

Toutefois, cette performance est très hétérogène selon les stratégies et/ou les lieux, effets indissociables ici : elle semble globalement meilleure dans les zones océaniques et tempérées (France, Grande-Bretagne, Norvège, Danemark) que dans les régions plus continentales (Suisse, Allemagne). Par ailleurs, la gestion du mildiou n'est manifestement pas le seul facteur de performance de certaines de ces stratégies de conduite : le choix variétal influe aussi sur le potentiel de rendement, voire sur la valeur commerciale du produit ; certaines interventions inefficaces contre le mildiou dans ces essais ont pu procurer un bénéfice contre d'autres maladies (Alternaria), voire d'autres stress (état nutritionnel des plantes), se traduisant par un gain de rendement sans contrôle amélioré du mildiou.

La mise en œuvre de ces stratégies s'avère souvent contraignante en matière de travail (lors de la plantation et de la récolte en particulier), d'équipements et de suivi (par exemple concernant la mise en place et la récolte d'associations variétales, le choix variétal ou la gestion agronomique), et entraîne une augmentation significative des coûts de production. Enfin, ces stratégies ciblées sur une seule maladie (le mildiou en l'occurrence) peuvent s'avérer complexes à gérer dans des modes de protection intégrée 
visant l'ensemble du complexe parasitaire de la pomme de terre. Elles se heurtent aussi à des problèmes d'acceptabilité commerciale de certaines innovations, notamment variétales (voir ci-dessous).

\section{Les stratégies d'acteurs, la mise à disposition et l'acceptabilité des innovations}

LE CONSTAT QUE LES INNOVATIONS D'ORES ET DÉJÀ DISPONIBLES SUR LE MARCHÉ, dans leS domaines de la création variétale ou du biocontrôle, restent peu mises en œuvre par les producteurs agricoles conduit à s'intéresser aux conditions dans lesquelles les innovations peuvent arriver sur le marché, puis être éventuellement adoptées par leurs destinataires.

\section{Mise à disposition de solutions innovantes et stratégies commerciales des industriels}

Une innovation étant « une invention qui a trouvé un marché », la mise à disposition des produits ou services par les entreprises qui les commercialisent est une phase cruciale dans le processus d'innovation. Dès lors, la question des stratégies d'acteurs industriels dans la mise sur le marché de ces supports d'innovation est essentielle, d'autant plus quand il s'agit de marchés nouveaux, émergents ou de niche, comme c'est le cas aujourd'hui du biocontrôle.

Une enquête réalisée en 2016 auprès des adhérents d'IBMA France (l'association française des entreprises de produits de biocontrôle) indique que 60 projets de recherche et développement sont en cours, avec comme objectif principal la mise sur le marché de 50 nouveaux produits d’ici 2018 (17 pour la vigne, 14 pour les légumes, 9 pour les fruits, 7 pour les céréales, 3 pour les fleurs et 2 pour la betterave). Si elle ne précise pas la nature des produits ou solutions concernées, et moins encore leur efficacité observable, ni même l'état actuel d'avancement de ces projets, cette étude révèle un portefeuille important de " candidats », et donc un potentiel fort de développement de ce marché. La nature même des produits et les coûts liés aux travaux de recherche et aux obligations réglementaires (protection de la propriété intellectuelle) font que la littérature scientifique disponible aujourd'hui ne peut couvrir les travaux confidentiels (souvent les plus prometteurs) réalisés dans l'industrie du biocontrôle.

L'industrie actuelle du biocontrôle est essentiellement constituée de deux groupes d'acteurs : des entreprises spécialisées, souvent de petite taille (chiffre d'affaires annuel inférieur à 1-2 ME) et développant un ou quelques produits, et des grands groupes du domaine phytosanitaire, dont le biocontrôle est une des voies de diversification, et qui investissent ce marché le plus souvent par concentration du secteur (rachat des petites entreprises les plus prometteuses). Ce panorama évolue assez rapidement, le marché étant en croissance rapide. 
Il est plausible que les stratégies des différents types d'acteurs industriels concernant la mise sur le marché de produits de biocontrôle soient sensiblement différentes selon le degré de spécialisation de ces acteurs, mais aussi selon leur structure et leur surface financière, et qu'elles conditionnent fortement le flux de produits innovants arrivant sur le marché. Il est ainsi possible que ce flux soit fortement dépendant de leurs capacités de R\&D et donc de leurs disponibilités financières, en particulier au vu des coûts nécessaires à l'homologation. Deux cas de figure sont alors envisageables :

- soit les petites entreprises présentes sur ce marché cherchent à se positionner sur de nouveaux produits, y compris sur des marchés de niche, mais elles sont, pour ce faire, limitées financièrement dans leur capacité à développer ces nouveaux produits. Se crée alors un hiatus avec les grands groupes de l'agrochimie dont les stratégies reposent sur des valeurs sûres visant des marchés larges, alors qu'ils auraient plus de capacités financières pour soutenir la R\&D sur des candidats prometteurs mais risqués ;

- soit les petites entreprises ont des profils de start-up, et leur fonction est alors d'explorer intensément de nouveaux produits en lien fort avec les secteurs de la recherche d'amont, puis, une fois les innovations stabilisées, ces start-up cherchent à se faire absorber par de plus grands groupes pour la phase de développement du marché.

La littérature scientifique consultée ne propose pas d'études spécifiques au secteur du biocontrôle, et ne permet pas l'analyse détaillée des stratégies industrielles des acteurs concernés et de leurs conséquences sur la mise sur le marché de produits nouveaux. Dans ce contexte, il serait intéressant d'examiner la possibilité d'une transposition, au cas particulier du biocontrôle, des travaux portant sur d'autres secteurs de la santé (par exemple le cas des biotechs et medtechs), pour éclairer cette question encore mal documentée et qui mériterait sans doute une étude plus spécifique.

Notons l'absence d'information sur les prix auxquels les alternatives au cuivre sont, ou seront, accessibles sur le marché. Il y a peu de probabilité qu'aucune d'entre elles ne ressorte comme moins chère qu'un ou plusieurs traitements cupriques. Tant qu'elles relèvent d'un marché de niche, la situation a peu de raison intrinsèque de changer, sauf si les procédés industriels s'améliorent significativement. Les orientations réglementaires ou politiques sont alors des éléments déclencheurs de premier ordre pour favoriser l'adoption de telles alternatives.

\section{Acceptabilité en pratique de solutions ou de systèmes innovants}

Un changement plus ou moins profond de pratiques, d’itinéraires culturaux, voire de systèmes de production (allongement et diversification des rotations, exploitation de couverts associés...), quelle que soit la qualité de la preuve de son efficacité phytosanitaire, suppose un risque technique, mais aussi économique, que tous les acteurs peuvent ne pas être prêts à courir. Cependant, des études montrent que la production biologique recèle de nombreux éléments favorables à la diffusion de tels systèmes innovants : les agriculteurs qui se convertissent à l'AB sont majoritairement des innovateurs, prêts à prendre des risques 
et à expérimenter, même en l'absence d'un corpus fourni de références techniques. Par ailleurs, l'AB peut être considérée comme une software innovation, fondée sur l'information et sa diffusion. Dès lors, la disponibilité de l'information est cruciale pour son processus de diffusion, et les difficultés liées à l'accès à l'information, donc à la formation et au conseil, sont très souvent citées comme des barrières à la conversion.

Au-delà des critères de personnalité (aversion plus ou moins grande au risque, attrait ou non pour les développements technologiques récents, par exemple) influençant le comportement individuel des agriculteurs, les choix d'adoption ou non d'une innovation dépendent de l'environnement économique, structurel et institutionnel de l'activité agricole. Cela a été bien étudié dans le cas des variétés résistantes, dont les bénéfices sanitaires sont reconnus mais qui restent peu cultivées en pratique, et plus récemment dans celui des principes agroécologiques. De nouvelles approches méthodologiques, comme la construction et la mise en réseaux de " cartes mentales », permettent maintenant d'analyser sous un jour différent les relations et l'interdépendance des acteurs dans les processus d'innovation.

Le cas des cultivars résistants est assez démonstratif des différents points possibles de blocage à la diffusion des innovations, contribuant à une situation de verrouillage sociotechnique (lock-in) qui s'oppose à l'adoption de toute modification majeure. Ces points sont d'au moins quatre natures différentes, jouant parfois de manière concomitante. Ce sont :

- des réserves techniques de la part des utilisateurs sur l'efficacité ou la durabilité des solutions proposées. Le fait que de nombreux utilisateurs de variétés résistantes les conduisent comme des génotypes sensibles en termes de protection phytosanitaire peut être interprété comme révélateur d'un manque de confiance des producteurs dans la capacité de ces variétés à contrôler durablement les attaques parasitaires. Ces réserves peuvent être levées ou réduites par la manière dont les utilisateurs peuvent se saisir des modalités de création et d'évaluation des variétés, que ce soit lors de la définition d'idéotypes variétaux ou via des opérations de sélection participative ou collaborative ;

- des réserves sur les compromis pour l'ensemble des caractères agronomiques et d'utilisation imposés par la résistance. Beaucoup de variétés résistantes souffrent en effet d'une productivité ou d'une qualité nutritionnelle (ou de présentation) plus faible que les cultivars sensibles de référence. II n'y a donc pas d'incitation forte à les utiliser tant que des solutions pesticides chimiques (dont le cuivre) sont disponibles, en particulier pour des marchés fortement structurés autour de standards variétaux bien établis (fruits et légumes ou viticulture par exemple). Dans ce cas, la réticence à adopter de nouvelles variétés peut également provenir des marchés eux-mêmes, qui éprouvent parfois des difficultés à valoriser la résistance comme un argument de promotion des produits agricoles correspondants. Une étude de cas portant sur deux coopératives engagées dans les démarches agroécologiques montre bien l'écart qui peut exister entre l'affirmation de l'adoption d'une telle démarche et leur mise en pratique effective... Là encore, il 
existe cependant des moyens efficaces pour surmonter ce type de blocage par un travail de fond avec chacun des acteurs de la filière, comme le démontre un très bel exemple récent, étudié en détail dans le cadre du projet Co-Free, et concernant la valorisation de variétés de pomme de terre résistantes au mildiou et pouvant être cultivées en $A B$ sans apport de cuivre. Ces travaux soulignent le rôle essentiel de l'information des consommateurs pour orienter leurs pratiques d'achat vers des variétés plus résistantes mais qu'ils ne connaissent pas, et la nécessité d'associer étroitement les distributeurs à la mise en place de ces systèmes innovants ;

- des conflits de valeurs amenant à récuser non les produits eux-mêmes mais leurs procédés d'obtention. C'est notamment le cas en $A B$ pour les produits issus de synthèse (ce qui conduit le mouvement biologique à refuser l'emploi de phosphites comme alternative au cuivre), mais aussi pour les principes de respect de l'intégrité des plantes, qui fonde le refus des techniques de génie génétique (y compris d’édition de génome) en création variétale et limite ainsi le recours aux génotypes résistants dérivant, ou même soupçonnés de provenir, de telles techniques. Cette situation de blocage ne peut être levée, et dans certains cas seulement, que par une transparence complète sur les procédés employés et l'origine des variétés proposées ;

- enfin, des blocages issus des systèmes de recherche et de promotion de l'innovation eux-mêmes. Comme le montre par exemple une étude de cas sur blé, les choix d'activités des chercheurs sont très souvent orientés vers des démarches d’ingénierie technologique au sein des modes de production existants. De ce fait, de nombreuses innovations techniques produites ne font chacune que renforcer les lock-in des systèmes. Cette propension à seulement améliorer l'efficacité de systèmes existants montre rapidement ses limites, en particulier dans le domaine phytosanitaire.

Il en va de même de tous les programmes de développement agricole fondés sur une « recette » unique imposée d'en haut. L'analyse des situations sur le terrain montre que ce mode de promotion des innovations, de type top-down, nie souvent les savoirs et savoir-faire locaux, et les réalités économiques et sociales locales et sectorielles plutôt que d'en tirer profit. II se heurte donc souvent à une réticence forte de la part des populations ou des producteurs qu'il est censé appuyer.

\section{Élêments de conclusion}

\section{Un déficit majeur d'expérimentations systèmes pour valider des itinéraires sans cuivre}

S'il existe un grand nombre d'essais factoriels testant individuellement des solutions alternatives au cuivre, la littérature ne recèle que très peu d'expérimentations « systèmes " permettant d'évaluer l'efficacité, mais aussi les performances vis-à-vis d'autres critères (temps de travail, bilan d'énergie, retour économique par exemple) d’itinéraires complets de protection phytosanitaire sans cuivre. Ce déficit d'approches systémiques 
est dommageable, car le remplacement complet du cuivre impose, comme l'ont montré les études de leviers individuels, une intégration poussée de méthodes chacune à effets partiels, et une optimisation des combinaisons retenues.

Les quelques tentatives répertoriées pour expérimenter des approches plus systémiques et des stratégies intégrées de lutte montrent toutefois un potentiel important de suppression totale ou partielle des applications de cuivre, en particulier dans les systèmes employant des variétés avec un niveau assez élevé de résistance.

Par ailleurs, il est intéressant de constater que des applications réduites de cuivre (ou d'autres fongicides en systèmes conventionnels) sont compatibles avec plusieurs des leviers alternatifs (la résistance génétique bien sûr, mais aussi certains SDP ou agents de biocontrôle), dont ils renforcent l'efficacité en limitant la pression parasitaire. Les études publiées évaluent cependant rarement les effets secondaires, bénéfiques (contrôle d'autres espèces du complexe parasitaire que celle principalement visée) ou non, de ces stratégies intégrées. A minima, recenser et valoriser les situations de synergie entre pratiques à effet partiel permettraient de les gérer conjointement.

De ce fait, un développement des travaux de conception de systèmes innovants de protection sans cuivre et d'évaluation multicritères de ces systèmes, travaux encore très rarement entrepris aujourd'hui, est fortement souhaitable.

\section{Des potentiels de développement important d'innovations...}

L'examen de la littérature scientifique comme les enquêtes menées auprès des industriels montrent qu'un grand nombre de produits ou préparations candidates pour des applications dans le secteur du biocontrôle sont actuellement à l'étude ou en cours de développement. L'information sur ces travaux de R\&D est toutefois trop partielle (confidentialité et protection de la propriété intellectuelle obligent) pour pouvoir disposer d'une vision consolidée du flux effectif de nouveautés (nouveaux principes actifs et nouvelles cibles) que l'on peut espérer voir arriver sur le marché dans les cinq prochaines années.

\section{... Mais des champs de recherche à explorer sur les modèles économiques sous-jacents...}

Le développement espéré du marché du biocontrôle repose sur des acteurs industriels de taille et de structure variées, mais dont une majorité est constituée d'entreprises de petite taille et aux moyens financiers limités. Cela pose donc la question de la prise en charge du développement technologique et des stratégies d'acteurs pour la mise sur le marché de produits innovants. Nous n'avons pas trouvé dans la littérature étudiée de travail économique spécifique au secteur du biocontrôle, et avons donc mobilisé des éléments d'analyse plus génériques, issus de travaux dans d'autres secteurs de l'agriculture ou de la santé. Il serait néanmoins pertinent de conduire des études plus spécifiques, en particulier concernant les modèles économiques des petits industriels du biocontrôle, pour mieux comprendre les freins et leviers à l'innovation dans ce secteur 
en développement rapide. Le rôle que pourraient jouer les interprofessions pour porter et partager le risque mériterait sans doute aussi des explorations.

\section{... Et donc sur les modes de diffusion de l'innovation technologique dans ce secteur}

Une fois mises sur le marché, les solutions nouvelles ne deviennent des innovations qu'une fois adoptées. Le cas des variétés résistantes montre que cette acceptabilité se heurte à de nombreuses difficultés, agronomiques (efficacité et durabilité de la résistance), économiques (lock-in sociotechnique lié à la disponibilité de pesticides, compromis entre résistance et qualité alimentaire ou technologique des produits végétaux ; coût de revient de solutions initialement « de niche »), voire liées aux processus de recherche pour l'innovation eux-mêmes (en particulier dans des modèles top-down prenant mal en compte les attentes et les savoir-faire locaux). Dès lors, une coconception des modes et procédés innovants avec les destinataires, actuellement peu pratiquée, est sans doute une voie importante à explorer pour un changement plus rapide et plus profond des systèmes de protection des plantes. 


\section{Conclusions générales}

Ce travail d'Analyse APPRofondie des aCquis SCIEntifiques, mais aussi des manques actuels dans certains domaines, permet de dégager plusieurs conclusions importantes dans une perspective de réduction ou d'abandon des usages phytosanitaires du cuivre. Si les études disponibles privilégient l'agriculture biologique, plus affectée par les restrictions d'utilisation du cuivre et qui recherche donc plus activement des solutions alternatives, les enseignements tirés de cette expertise concernent également les autres formes d'agriculture ou modes de production agricole. La logique du plan national Écophyto constitue notamment un cadre favorable à de tels déploiements appliqués à l'agriculture conventionnelle. Ainsi, dans certains cas, les alternatives peuvent bénéficier du système des Certificats d'économie de produits phytosanitaires comme incitation financière et comme source accrue de visibilité.

\section{Une masse considérable d'information disponible...}

LES RECHERCHES INITIALES dans le Web of Science ont mis en évidence l'existence de milliers de références scientifiques concernant les méthodes alternatives à l'emploi des traitements cupriques. Des requêtes plus affinées et ciblées ont permis de retenir un corpus de près de 900 références scientifiques et documents techniques. Cette abondance des publications scientifiques et techniques montre que la recherche, tant académique qu'appliquée, est active pour l'identification et l'évaluation de solutions phytosanitaires alternatives à l'emploi massif de cuivre, les résultats étant potentiellement transposables ou élargis à d'autres pesticides ciblant les mêmes pathogènes.

...Mais très inégalement répartie entre les champs de recherche et de développement

IL EST SIGNIFICATIF DE NOTER QUE L'ESSENTIEL DES EFFORTS porte sur la caractérisation de leviers ou pratiques individuels (c'est-à-dire non intégrés ou combinés dans un système de production). Ces leviers sont ainsi pensés comme des moyens de substitution aux applications chimiques, alors que les travaux de conception, de validation ou d'évaluation multicritère de systèmes de protection intégrée restent très (et certainement trop) peu nombreux. Les travaux se placent donc actuellement beaucoup plus dans une optique de substitution (remplacer du cuivre par un produit alternatif ou une pratique alternative) que dans une perspective de reconception des systèmes de production ou de protection des cultures. 


\section{Des solutions individuelles à effets partiels...}

Cette expertise a Permis de RÉaliser un InVentaire complet des alternatives disponibles dans des stratégies de substitution au cuivre, et de rassembler les données existantes concernant leur niveau d'efficacité observé. Elle souligne le potentiel, mais aussi les limites actuelles de ces alternatives, qui peuvent être regroupées en trois grands types.

\section{Les méthodes à action directe sur l'organisme pathogène}

La recherche d'agents microbiens de biocontrôle fait l'objet de nombreux travaux. Ces micro-organismes peuvent agir directement sur les agents pathogènes, par antagonisme, hyperparasitisme ou compétition écologique. Outre leur effet direct, certains ont également la propriété de stimuler les défenses des plantes. Du fait de leurs caractéristiques particulières (organismes vivants), leur déploiement est plus complexe que l'application de molécules chimiques, ce qui peut entraver leur adoption et favoriser la variabilité de leur efficacité au champ. Les travaux récents s'attachent donc à déterminer les conditions optimales d'utilisation de ces produits, et à identifier des souches à fort potentiel par une exploration des microbiotes complets présents au voisinage des plantes ou organes à protéger.

L'utilisation phytosanitaire de ces produits à base de micro-organismes nécessite par ailleurs un processus long et coûteux de mise sur le marché. Il existe actuellement peu de produits homologués contre les agents pathogènes ciblés par le cuivre, et les souches ou espèces encore au stade de la recherche d'amont sont très loin de couvrir les manques et les besoins. Il y a donc encore peu de pistes réellement sérieuses et avérées pour remplacer le cuivre par des agents microbiens de biocontrôle.

L'utilisation de préparations ou d'extraits naturels à activité biocide fait également l'objet de nombreux travaux. De composition souvent complexe, ces préparations ont fréquemment, outre leur activité biocide, une action de stimulation des défenses des plantes (cas de beaucoup d'huiles essentielles). Leur forte activité antimicrobienne en conditions contrôlées en fait des candidats sérieux pour se substituer au cuivre, mais leur formulation reste difficile. De même, certains effets indésirables sur les produits récoltés, et des interrogations sur le statut de certaines préparations vis-à-vis des cahiers des charges de l’AB, rendent leur emploi parfois problématique.

\section{L'utilisation des capacités de résistance des plantes}

Ces résistances peuvent être constitutives ou induites après infection ou stimulation exogène. Des variétés résistantes, issues de programmes de création variétale ciblés et exploitant les ressources génétiques de l'espèce cultivée ou d'espèces apparentées, sont disponibles et efficaces vis-à-vis de beaucoup des maladies ciblées par le cuivre, y compris celles qui représentent actuellement une forte proportion des emplois de pesticides cupriques (mildiou de la pomme de terre, mildiou de la vigne, tavelure du pommier par exemple). Ces variétés présentent soit des résistances complètes, à déterminisme génétique souvent simple et se traduisant par une absence complète de symptômes ou par 
de petites nécroses localisées aux points d’infection (réactions hypersensibles), soit des résistances partielles, à déterminisme génétique le plus souvent complexe (nombreux loci ou QTL) et causant un ralentissement ou une diminution plutôt qu'une absence de développement épidémique.

Malgré cette disponibilité de matériel végétal résistant, son usage en pratique reste souvent marginal. Cette situation apparemment paradoxale s'explique par plusieurs réserves des utilisateurs, concernant : 1) des incertitudes sur le niveau d'efficacité et de durabilité de ces résistances au champ, en particulier pour les résistances quantitatives, même si ces caractéristiques peuvent être renforcées par une complexification des constructions génétiques à l'échelle des plantes (pyramidage de gènes ou de QTL dans un même génotype) ou des peuplements végétaux (associations de variétés ou d'espèces dans une même parcelle) ; 2) des préoccupations sur l'effet délétère de la sélection des résistances sur d'autres critères agronomiques (rendement, précocité) ou d'utilisation (qualité gustative, valeur alimentaire) des variétés ; 3) de possibles conflits de valeurs sur l'origine et les modes de sélection des génotypes résistants, notamment (mais pas uniquement) en $A B$ concernant l'emploi des outils du génie génétique (transformation génétique, édition du génome), qui limitent de fait l'utilisation de variétés dérivant, ou même soupçonnées de dériver, de la mobilisation de ces technologies dans le processus d'obtention ; et 4) des interrogations sur l'opportunité de changer de types variétaux alors que des solutions autres que la résistance variétale (en particulier les pesticides, y compris le cuivre) permettent de gérer l'état sanitaire des cultures, en particulier dans le cas où le choix variétal est imposé par des systèmes de qualité (type AOP). Ce lock-in (verrouillage sociotechnique) est observable non seulement dans les systèmes productifs de nos pays, mais aussi dans les agricultures des pays émergents et en développement.

Les stimulateurs de défense des plantes font actuellement l'objet de recherches très actives. De nombreux produits ou molécules possédant une activité biologique avérée en conditions de laboratoire ont ainsi été identifiés. Beaucoup d'entre eux (phosphites, extraits de microorganismes...) semblent avoir un mode d'action multiple, avec à la fois des effets d'induction de défense et des effets biocides (cas en particulier des phosphites) ou perturbateurs directs. Si ces molécules semblent souvent actives en conditions confinées et contrôlées de laboratoire, le transfert de cette activité au champ s'avère en général problématique, avec des protections conférées faibles ou très aléatoires/irrégulières. Cela peut provenir de difficultés de formulation (les produits doivent pouvoir pénétrer la plante pour y être biodisponibles et perçus), de positionnement du traitement (un stimulateur de défense doit forcément être appliqué en amont de l'infection, alors que beaucoup de biocides sont plus efficaces lorsqu'ils sont appliqués en présence du parasite visé), de perception du signal par la plante, de persistance d'action, voire de méthodes d'évaluation. Or ces problématiques restent peu étudiées, l'essentiel des travaux étant actuellement dédié à la recherche de molécules ou de produits à efficacité démontrable au laboratoire. Notons enfin que, comme pour d'autres produits de biocontrôle, tous les SDP ne sont pas utilisables en $A B$ : c'est en particulier le cas des phosphites. 
Les méthodes fondées sur l'homéopathie ou l'isothérapie semblent d'une efficacité très discutable, et ne constituent sans doute pas une alternative crédible aux autres possibilités. Elles ne font d'ailleurs l'objet que de très rares publications académiques et techniques ; très peu de données scientifiquement évaluables les concernant sont actuellement disponibles.

\section{La mise en œuvre de pratiques agronomiques}

Diverses pratiques peuvent être mises en œuvre pour lutter contre les infections primaires et les contaminations secondaires, et limiter le développement épidémique.

Plusieurs techniques physiques permettent de limiter la survie de l'inoculum résiduel dans les parcelles (élimination des résidus de culture infectés, gestion des repousses...) ou d'empêcher son accès aux organes productifs (enfouissement, bâchage, sélection sanitaire des semences et plants). Elles s'avèrent très efficaces, mais sont souvent contraignantes et peu valorisantes pour le producteur. Ainsi, par exemple, les bâches de protection des arbres fruitiers contre la pluie sont assez coûteuses (moins si elles sont couplées à des filets anti-grêle et/ou anti-insectes, déjà largement utilisés).

La diversification spatiale et temporelle des variétés dans les parcelles (variétéspopulations, associations de variétés ou d'espèces pour freiner les infections secondaires) et l'organisation des cultures à l'échelle des paysages (mosaïques paysagères, successions culturales) visent la gestion des infections secondaires. Elles sont importantes pour beaucoup de maladies épidémiques à grand rayon de dispersion.

\section{... Mais encore insuffisamment insérées au sein de systèmes intégrés de protection des plantes}

Si les ÉVAluations de nouveaux PRoduits ou PRÉPARATIONS foisonnent actuellement, force est de constater que très peu d'outils d'accompagnement et de pilotage spécifiques sont aujourd'hui développés ou en cours de développement. C'est le cas pour la mise au point d'OAD spécifiquement dédiés au biocontrôle, mais aussi pour l'évaluation de la réponse des génotypes végétaux à ces nouvelles préparations. Parmi ces outils, une place particulière devrait revenir à la détection précoce des premiers stades d'infestation directement dans les parcelles (capteurs, dispositifs d'épidémiosurveillance) qui conditionnement très souvent l'efficacité des modèles de prévision des risques, voire l'efficacité de certains leviers de lutte (résistance partielle, mélanges variétaux...).

Par ailleurs, le niveau très partiel d'efficacité de la plupart de ces leviers impose de les insérer dans des stratégies intégrées de protection phytosanitaire, et non de les utiliser comme éléments isolés, individuellement substituables aux applications cupriques. Or il n'existe encore aujourd'hui que très peu de références et de données scientifiquement évaluables sur des systèmes intégrés (y compris à dimension 
paysagère, comme l'agroforesterie). Enfin, faute de disposer de modèles paramétrés de manière adéquate et suffisamment précise, la conception et l'évaluation de tels systèmes restent difficiles.

\section{Se passer du cuivre : des marges de manœuvre considérables}

\section{Une forte réduction des dosages de cuivre est possible, sans autre ajustement des systèmes de culture}

Un grand nombre d'études sur des pathosystèmes très variés (mildious de la pomme de terre ou de la vigne, tavelure du pommier...) montrent qu'une diminution de moitié, voire plus, des quantités appliquées, le plus souvent en conservant une cadence d'application identique mais en réduisant fortement les doses à chaque passage, permet dans la plupart des cas une efficacité identique ou très comparable à celle obtenue avec une utilisation à pleines doses. Ainsi, une protection très satisfaisante vis-à-vis de ces parasites peut être fournie par l'emploi de $1,5 \mathrm{~kg}$ de cuivre métal par hectare et par an, contre 3 dans les programmes standard, et 6 dans les dispositions réglementaires. De ce fait, une réduction significative de la quantité de cuivre autorisée ne se traduirait en général pas par une impasse phytosanitaire ou une mise en péril des productions, sauf en cas de très forte pression de maladie.

\section{Des systèmes expérimentaux sans cuivre sont efficaces...}

Quelques expérimentations pilotes, en particulier dans le cadre de projets européens comme Blight Mop, RepCo ou Co-Free, ont permis de montrer que des systèmes complexes, associant plusieurs leviers (résistance variétale, SDP, pratiques agronomiques comme les associations végétales, prophylaxie...) peuvent présenter, en conditions de station expérimentale, voire (beaucoup plus rarement) d'exploitations agricoles, des efficacités de contrôle des maladies équivalentes à celle d'un programme de protection classique fondé sur le cuivre. Le succès de ces conduites alternatives semble toutefois moins difficile à atteindre et à répéter en cultures annuelles qu'en productions pérennes (arbres fruitiers, vigne), ainsi que lorsqu'il existe peu d'obstacles à l'emploi de résistances variétales (donc hors AOP par exemple). Il faut néanmoins noter que les efficacités observées sont très variables, et que les conclusions ci-dessus restent préliminaires, du fait du petit nombre de cas étudiés.

\section{... Mais leur efficacité dépend fortement des composantes de ces systèmes...}

Ces expérimentations montrent que la résistance variétale est indispensable à l'efficacité de tout système de protection sans cuivre. Elle peut d'ailleurs s'accompagner de stratégies d'utilisations permettant de renforcer son efficacité ou de protéger sa durabilité (associations variétales et associations d'espèces, mosaïques paysagères...). Elle se 
trouve utilement renforcée par des mesures prophylactiques visant soit à éliminer l'inoculum résidant dans les parcelles (ramassage ou broyage des débris végétaux infectés), soit à empêcher l'accès de cet inoculum aux organes sensibles (bâches). En revanche, la gestion de la fertilisation (forme ou quantité) ainsi que le recours à des préparations biodynamiques ou isothérapiques se sont montrés généralement peu efficaces.

\section{... Et leur généralisation ou extension suppose des efforts tout au long des filières}

Pour être adoptés, de tels systèmes, qui introduisent potentiellement des ruptures majeures, requièrent un ajustement important tout au long des filières de production (débouchés pour des cultures de diversification introduites pour allonger les successions ; réseaux d'approvisionnement ; valorisation des produits issus d'itinéraires techniques sans cuivre...). Certaines démarches intéressantes, comme le développement de « clubs variétaux » de producteurs pour promouvoir des variétés résistantes, mériteraient sans doute une attention plus soutenue. Il en est de même de l'évolution du cahier des charges des AOC (autorisant par exemple des cépages résistants).

\section{Des prototypes à imaginer... et à tester ?}

Les éléments collectés par l'expertise permettent de se livrer à un exercice, purement intellectuel à ce stade, de construction de prototypes de systèmes de protection, en regard d'objectifs spécifiques à atteindre : remplacer les produits cupriques sans modifier les autres éléments du système, rechercher une protection maximale ou surtout durable... L'exercice a été tenté pour les trois pathosystèmes sur lesquels le plus de références sont disponibles, en se fondant sur le cadre conceptuel dit «ESR », pour efficacité des intrants (optimisation de leur emploi dans une logique d'agriculture raisonnée ou de précision), substitution par des intrants « naturels » ou des méthodes ponctuelles telles que la résistance variétale, et reconception du système de culture dans une logique de protection intégrée.

Pour construire ces prototypes, nous avons adopté la démarche suivante :

- disposer le long d'un gradient de rupture par rapport aux pratiques actuelles les leviers disponibles en culture (efficacité ou substitution) ou potentiellement utilisables sur la base de travaux de laboratoire ou d'expérimentations préliminaires (reconception), en indiquant pour chacun leur efficacité individuelle attendue par rapport à une absence totale d'intervention (témoin non traité) ;

- spécifier les objectifs visés, en dessinant pour chaque pathosystème trois scénarios d'ambition croissante par rapport à l'élimination du cuivre ;

- identifier les combinaisons intégrables pour approcher au mieux les exigences de ces objectifs. Faute d'éléments concrets, nous n'avons pris en compte ni les coûts qu'engendrerait la mise en œuvre de chacun de ces prototypes, ni leurs conséquences pour la gestion des autres éléments du complexe parasitaire. 


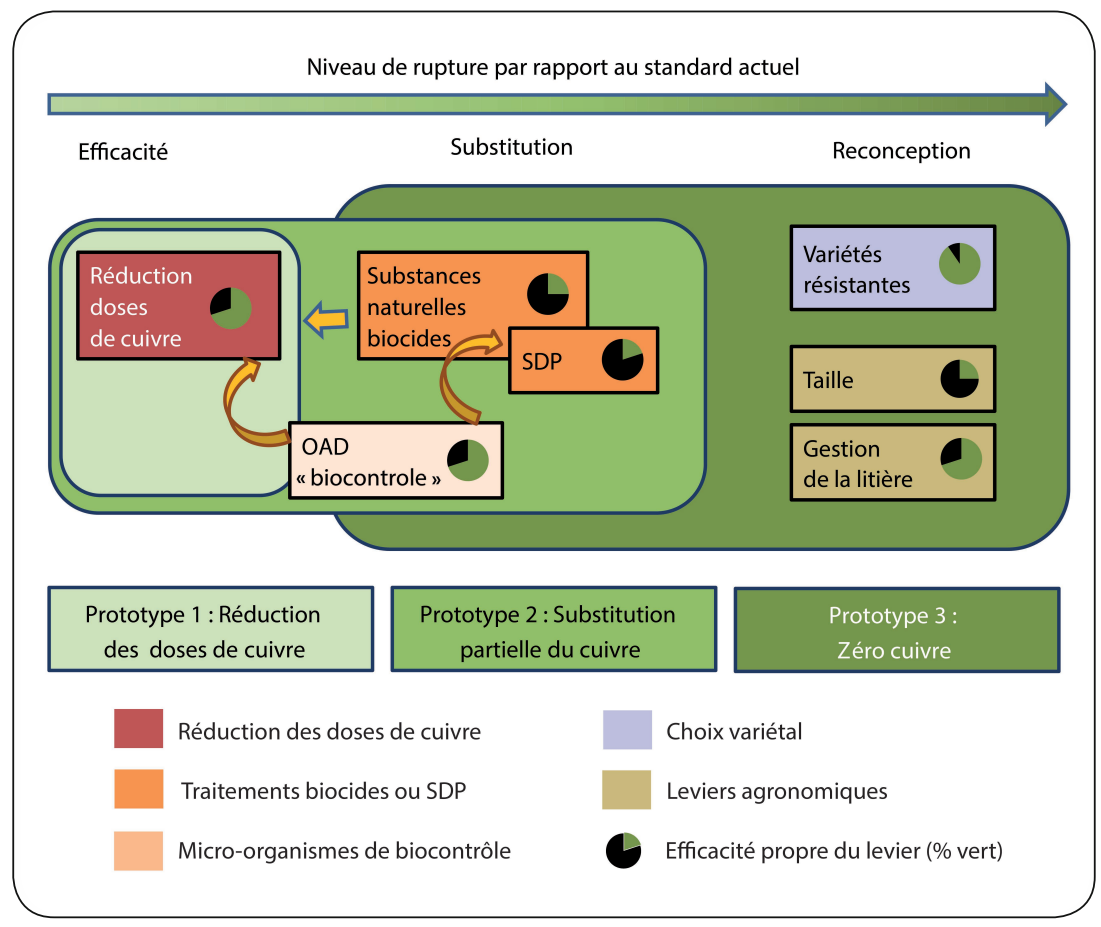

Il s'agit sans doute de la situation la plus délicate des trois envisagées, du fait de la disponibilité d'un assez faible nombre de leviers alternatifs, et dont certains (cépages résistants par exemple) sont difficiles à introduire rapidement dans les systèmes.

Le prototype 1 vise donc une protection à faible ou très faible utilisation de cuivre. II repose pour l'essentiel sur une réduction directe des doses de cuivre, avec l'appui d'OAD (type Mildium) pour choisir au mieux les doses et dates d'intervention et de systèmes de pulvérisation performants. La réduction d'emploi du cuivre pourra être renforcée par l'apport de SDP ou de préparations biocides, qui pourront se substituer à certains des traitements au cuivre (prototype 2, substitution partielle). Enfin, l'objectif d'une protection «zéro cuivre " (prototype 3) devra impérativement mobiliser, outre les solutions de biocontrôle du prototype 2, l'emploi de cépages résistants, mais aussi des interventions à visée prophylactique, comme la gestion du microclimat grâce à la taille et l'élimination des litières infectées par ramassage. 
Cas 2. Tavelure du pommier

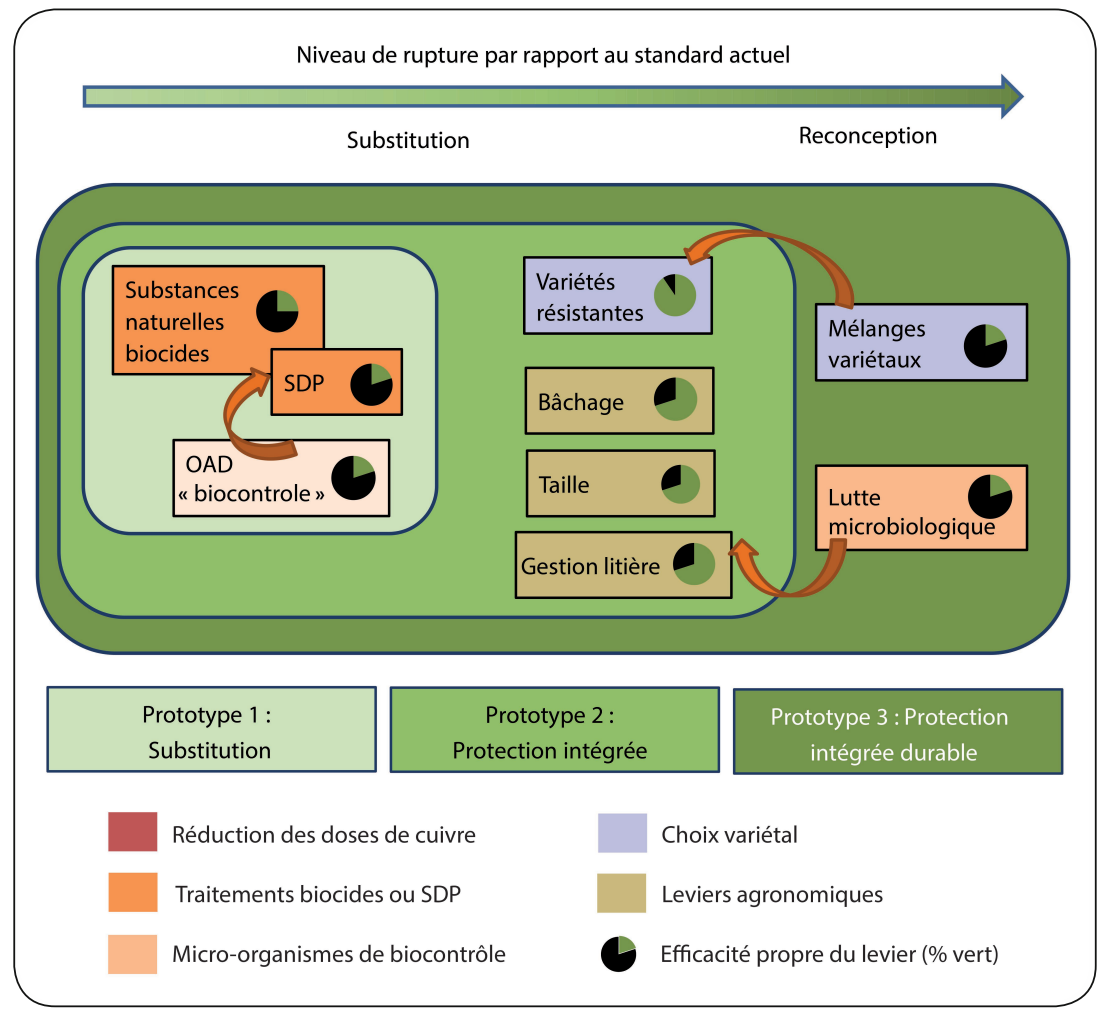

Il s'agit là, a contrario, du cas pour lequel le plus grand nombre de leviers sont disponibles. C'est pourquoi tous les prototypes ont été construits en excluant tout recours au cuivre.

Dans le prototype 1, l'objectif est simplement de substituer ces traitements cupriques avec des produits de type biocontrôle (SDP ou biocides) positionnés à l'aide d'un OAD spécifique. Chacun de ces leviers n'ayant qu'une efficacité individuelle limitée, il est probable qu'un tel système n'atteindrait pas une efficacité de protection satisfaisante, sauf en situation récurrente de très faible pression de maladie. Un prototype $\mathbf{2}$, visant une protection intégrée sans cuivre, associerait donc à ces solutions de biocontrôle, d'une part, l'emploi de méthodes prophylactiques destinées à limiter fortement la pression d'inoculum dans la parcelle (bâchage, conduite centrifuge des arbres, élimination ou enfouissement des litières infectées) et, d'autre part, l'emploi de variétés résistantes. Enfin, un prototype 3 (protection intégrée durable) vise à renforcer les points potentiellement critiques du prototype 2, à savoir le risque de contournement des résistances variétales (via des mélanges variétaux sur le rang) et celui d'apports exogènes d'inoculum (via une lutte microbiologique par hyperparasitisme). 
Cas 3. Mildiou de la pomme de terre



Comme dans le cas précédent, tous les prototypes ont été construits en excluant tout recours au cuivre.

Dans le prototype 1, l'objectif est simplement de substituer ces traitements cupriques avec des produits de type biocontrôle (SDP ou biocides) positionnés à l'aide d'un OAD spécifique. Comme vis-à-vis de la tavelure, l'efficacité individuelle limitée de chaque solution individuelle rendra probablement un tel prototype insuffisant en matière d'efficacité, en particulier dans des environnements climatiquement très favorables au parasite. Un niveau plus important de substitution (prototype 2), faisant notamment appel aux variétés les plus résistantes du catalogue variétal et à une sélection sanitaire rigoureuse, en particulier des plants autoproduits sans certification, devrait pallier ce manque d'efficacité, mais reste vulnérable à la fragilité de la plupart des résistances variétales très efficaces. Dès lors, un prototype 3 " zéro cuivre durable » renforçant cette résistance par d'autres mécanismes (architecture défavorable à l'infection, mélanges variétaux, réduction supplémentaire de la pression parasitaire par une gestion efficace des tas de déchets à proximité des parcelles) devrait idéalement être mis en place. 


\section{Plusieurs domaines insuffisamment explorés en recherche, mais cruciaux dans une perspective d'élimination complète du cuivre}

COMME EXPLICITÉ CI-DESSUS, VISER UNE PROTECTION PHYTOSANITAIRE sans cuivre supposera le plus souvent un réaménagement de fond des systèmes de protection, et plus largement de production végétale. Or l'analyse fournie par la présente expertise montre que trois grands champs de recherche, indispensables à cette reconception des systèmes, sont aujourd'hui très insuffisamment investis par les communautés scientifiques spécialisées.

Le premier est d'ordre phytopathologique. Il concerne : le développement d'outils de pilotage spécifiques aux méthodes alternatives (par exemple des OAD adaptés aux spécificités d'action des stimulateurs de défense des plantes ou des agents de lutte microbiologique), mais aussi à la prévision du risque (capteurs et dispositifs d'épidémiosurveillance pour détecter les infections primaires par exemple) ; la prise en compte non plus de bioagresseurs uniques, mais de complexes de bioagresseurs d'une même culture dans des stratégies de protection intégrée ; et l'évaluation de la durabilité des leviers alternatifs et/ou des stratégies les incluant.

Le deuxième domaine de recherche méritant un investissement supplémentaire relève de l'agronomie des systèmes. Il inclut en particulier le développement de méthodes et outils de conception de systèmes de protection innovants avec peu ou pas de recours aux pesticides de synthèse et cupriques (règles d'assemblage des leviers techniques pour les choix stratégiques, règles de décision pour les interventions tactiques), mais aussi d'évaluation de long terme de tels systèmes intégrés. Quelques travaux pionniers ont commencé à travailler ces questions, par exemple au sein des réseaux Dephy, mais ils restent rares et cantonnés à des cas relativement spécifiques (essentiellement des cultures pérennes ou des plantes industrielles de grande culture, très peu les cultures maraîchères ou spécialisées). L'application de ces démarches aux cas de systèmes sans cuivre reste donc largement à entreprendre.

Enfin, le troisième domaine encore insuffisamment exploré se situe dans le champ des sciences économiques. Il serait ainsi nécessaire d'analyser les conséquences économiques pour les exploitations agricoles de l'adoption de méthodes alternatives de protection des cultures (évolution des charges, du temps de travail par exemple). Serait également à effectuer l'étude des stratégies industrielles déployées en amont de l'agriculture, de leurs impacts sur la disponibilité et la diffusion des innovations, et de leur variabilité en fonction des structures de marché (marché de masse ou marché de niche) et du poids des acteurs industriels concernés (grands groupes de l'agrochimie versus micro-entreprises ou start-up). On peut en effet émettre l'hypothèse que la surface financière très limitée des start-up, qui se lancent sur le marché des produits de biocontrôle en favorisant en général l'exploitation de ressources issues de la recherche publique et donc non protégeables, restreint fortement à la fois leurs capacités de R\&D et de 
marketing, et qu'elle les cantonne à une homologation a minima (par exemple comme " biostimulant », c'est-à-dire «fertilisant » plutôt que comme produits de protection des plantes) et à la distribution essentiellement de produits déjà éprouvés. A contrario, les grands groupes de la chimie phytosanitaire, entrés plus ou moins récemment sur le marché du biocontrôle via le rachat de start-up ou de PME spécialisées, pourraient avoir des stratégies plus globales et des moyens financiers plus étendus pour assurer le développement et la promotion de ces solutions. Il serait donc pertinent que des économistes et des sociologues de l'innovation se penchent activement sur cette question, pour voir si ces hypothèses peuvent être confirmées tant théoriquement qu'empiriquement dans le cas du biocontrôle, ou si d'autres facteurs plus importants sont en action. Le rôle que pourraient jouer les interprofessions, en tant que piliers de l'organisation économique des filières, pour promouvoir l'usage des solutions alternatives mériterait aussi une instruction poussée.

\section{Des enseignements à tirer depuis et vers les systèmes dits " conventionnels "}

LES OPPORTUNITÉS ET LES FREINS AU DÉVELOPPEMENT des méthodes et systèmes alternatifs à l'utilisation du cuivre en $A B$ sont identiques à ceux relatifs aux alternatives aux pesticides de synthèse dans les autres formes d'agriculture. Les solutions envisagées sont le plus souvent les mêmes (variétés résistantes, biocontrôle, utilisation accrue de la prophylaxie sanitaire...). Les questions posées sont également comparables, concernant le niveau de rupture dans les systèmes de protection phytosanitaire, les possibilités et difficultés d'assemblages de leviers à efficacité partielle ou transitoire au sein d'itinéraires intégrés de protection des cultures. Les conséquences sur l'organisation des activités et des filières, l'acceptabilité des innovations ou la capacité à surmonter les verrouillages sociotechniques sont aussi similaires. C'est pourquoi agriculture biologique et autres formes d'agriculture auraient des bénéfices mutuels à tirer d'approches plus concertées de recherche sur ces différentes questions, quitte à en transposer ensuite les résultats génériques aux spécificités de chaque système de production. 



\section{Sélection bibliographique}

\section{Articles scientifiques}

\section{Contexte}

Brun L.A., Maillet J., Richarte J., Herrmann P., Remy J.C., 1998. Relationships between extractable copper, soil properties and copper uptake by wild plants in vineyard soils. Environmental Pollution, 102 (2-3), 151-161. https://doi.org/10.1016/S0269-7491(98)00120-1.

Bunemann E.K., Schwenke G.D., Van Zwieten L., 2006. Impact of agricultural inputs on soil organisms: a review. Australian Journal of Soil Research, 44 (4), 379-406. https://doi.org/10.1071/SRo5125.

Speiser B., Mieves E., Tamm L., 2015. Utilisation de cuivre par les paysans bio suisses dans différentes cultures. Recherche agronomique suisse, 6 (4), 160-165.

Wuana R.A., Okieimen F.E., 2011. Heavy metals in contaminated soils: a review of sources, chemistry, risks and best available strategies for remediation. ISRN Ecology, 20 p. http://dx.doi. org/10.5402/2011/402647.

\section{Références communes à plusieurs leviers}

Barrière V., Lecompte F., Nicot P.C., Maisonneuve B., Tchamitchian M., Lescourret F., 2014. Lettuce cropping with less pesticides. A review. Agronomy for Sustainable Development, 34 (1), 175-198. https://doi.org/10.1007/s13593-013-0158-5\%od.

Dagostin S., Scharer H.J., Pertot I., Tamm L., 2011. Are there alternatives to copper for controlling grapevine downy mildew in organic viticulture? Crop Protection, 30 (7), 776-788. https://doi. org/10.1016/j.cropro.2011.02.031\%od.

Gessler C., Pertot I., Perazzolli M., 2011. Plasmopara viticola: a review of knowledge on downy mildew of grapevine and effective disease management. Phytopathologia Mediterranea, 50 (1), 3-44. https://doi.org/10.14601/Phytopathol_Mediterr-9360\%od.

\section{Substances biocides}

Bengtsson M., Wulff E., Jorgensen H., Pham A., Lubeck M., Hockenhull J., 2009. Comparative studies on the effects of a yucca extract and acibenzolar-S-methyl (ASM) on inhibition of Venturia inaequalis in apple leaves. European Journal of Plant Pathology, 124 (2), 187-198. https://doi. org/10.1007/s10658-008-9405-z\%od.

Dayan F.E., Cantrell C.L., Duke S.O., 2009. Natural products in crop protection. Bioorganic and Medicinal Chemistry, 17 (12), 4022-4034. https://doi.org/10.1016/j.bmc.2009.01.046\%od.

Jamar L., Lefrancq B., Lateur M., 2007. Control of apple scab (Venturia inaequalis) with bicarbonate salts under controlled environment. Journal of Plant Diseases and Protection, 114 (5), 221-227. https://doi.org/10.1007/BF03356221.

La Torre A., Mandala C., Pezza L., Caradonia F., Battaglia V., 2014. Evaluation of essential plant oils for the control of Plasmopara viticola. Journal of Essential Oil Research, 26 (4), 282-291. https:// doi.org/10.1080/10412905.2014.889049\%od. 
Marchand P.A., Isambert C.A., Jonis M., Parveaud C. E., Chovelon M., Gomez C., Lambion J., Ondet S.J., Aveline N., Molot B., Berthier C., Furet A., Clerc F., Rey A., Navarro J.F., Bidault F., Maille E., Bertrand C., Andreu V., Treuvey N., Pierre S.P., Coulon A., Chaput C., Arufat A., Brunet J.L., Belzunces L., Bonafos R., Guillet B., Conseil M., Tournant L., Oste S., Larrieu J.F., 2014. Évaluation des caractéristiques et de l'intérêt agronomique de préparations simples de plantes, pour des productions fruitières, légumières et viticoles économes en intrants. Innovations agronomiques, (34), 83-96. https://www6.inra.fr/ciag/content/download/5226/40868/.../Vol34-6-Marchand.pdf.

Martins N., Barros L., Santos-Buelga C., Henriques M., Silva S., Ferreira I.C.F.R., 2015. Evaluation of bioactive properties and phenolic compounds in different extracts prepared from Salvia officinalis L. Food Chemistry, 170, 378-385. https://doi.org/10.1016/j.foodchem.2014.08.096\%od.

Ongena M., Jacques P., 2008. Bacillus lipopeptides: versatile weapons for plant disease biocontrol. Trends in Microbiology, 16 (3), 115-125. https://doi.org/10.1016/j.tim.2007.12.009\%od.

Perina F.J., Amaral D.C., Fernandes R.S., Labory C.R.G., Teixeira G.A., Alves E., 2015. Thymus vulgaris essential oil and thymol against Alternaria alternata (Fr.) Keissler: effects on growth, viability, early infection and cellular mode of action. Pest Management Science, 71 (10), 1371-1378. https:// doi.org/10.1002/ps.3933.

Scherf A., Treutwein J., Kleeberg H., Schmitt A., 2012. Efficacy of leaf extract fractions of Glycyrrhiza glabra L. against downy mildew of cucumber (Pseudoperonospora cubensis). European Journal of Plant Pathology, 134 (4), 755-762. https://doi.org/10.1007/s10658-012-0051-0\%od.

\section{Agents microbiologiques de biocontrôle}

Adrees M., Ali S., Rizwan M., Ibrahim M., Abbas F., Farid M., Zia-ur-Rehman M., Irshad M.K., Bharwana S.A., 2015. The effect of excess copper on growth and physiology of important food crops: a review. Environmental Science and Pollution Research, 22 (11), 8148-8162. https://doi. org/10.1007/s11356-015-4496-5\%od.

Anjum N.A., Adam V., Kizek R., Duarte A.C., Pereira E., Iqbal M., Lukatkin A.S., Ahmad I., 2015. Nanoscale copper in the soil-plant system: toxicity and underlying potential mechanisms. Environmental Research, 138, 306-325. https://doi.org/10.1016/j.envres.2015.02.019\%od.

Fousia S., Paplomatas E.J., Tjamos S.E., 2016. Bacillus subtilis QST 713 confers protection to tomato plants against Pseudomonas syringae pv. tomato and induces plant defence-related genes. Journal of Phytopathology, 164 (4), 264-270. https://doi.org/10.1111/jph.12455\%od.

Gachango E., Kirk W.W., Schafer R., 2012. Effects of in-season crop-protection combined with postharvest applied fungicide on suppression of potato storage diseases caused by oomycete pathogens. Crop Protection, 41, 42-48. https://doi.org/10.1016/j.cropro.2012.04.010\%od.

Gent D.H., Schwartz H.F., 2005. Management of Xanthomonas leaf blight of onion with a plant activator, biological control agents, and copper bactericides. Plant Disease, 89 (6), 631-639. https:// doi.org/10.1094/pd-89-0631\%od.

Gwynn R.L., 2014. The Manual of Biocontrol Agents: A World Compendium. Fifth Edition, Brithish Crop Production Council, Alton, UK, 278 p.

Legler S.E., Pintye A., Caffi T., Gulyas S., Bohar G., Rossi V., Kiss L., 2016. Sporulation rate in culture and mycoparasitic activity, but not mycohost specificity, are the key factors for selecting Ampelomyces strains for biocontrol of grapevine powdery mildew (Erysiphe necator). European Journal of Plant Pathology, 144 (4), 723-736. https://doi.org/10.1007/s10658-015-0834-1\%od.

Mackie K.A., Muller T., Kandeler E., 2012. Remediation of copper in vineyards: a mini review. Environmental Pollution, 167, 16-26. https://doi.org/10.1016/j.envpol.2012.03.023\%od. 
Wilson M., Campbell H.L., Ji P., Jones J.B., Cuppels, D.A., 2002. Biological control of bacterial speck of tomato under field conditions at several locations in North America. Phytopathology, 92 (12), 1284-1292. https://doi.org/10.1094/phyto.2002.92.12.1284\%od.

\section{Résistances variétales}

Brown J.K.M., 2015. Durable resistance of crops to disease: a darwinian perspective (VanAlfen N.K., ed.). Annual Review of Phytopathology, 53, 513-539. https://doi.org/10.1146/ annurev-phyto-102313-045914\%od.

Bus V.G.M., Rikkerink E.H.A., Caffier V., Durel C.-E., Plummer K.M., 2011. Revision of the nomenclature of the differential host-pathogen interactions of Venturia inaequalis and Malus. Annual Review of Phytopathology, 49 (1), 391-413. https://doi.org/10.1146/annurev-phyto-072910-095339\%od.

Foolad M.R., Merk H.L., Ashrafi H., 2008. Genetics, genomics and breeding of late blight and early blight resistance in tomato. Critical Reviews in Plant Sciences, 27 (2), 75-107. https://doi.org/ 10.1080/07352680802147353\%od.

Leach J.E., Cruz C.M.V., Bai J.F., Leung H., 2001. Pathogen fitness penalty as a predictor of durability of disease resistance genes. Annual Review of Phytopathology, 39, 187-224. https://doi.org/10.1146/ annurev.phyto.39.1.187\%od.

Mundt C.C., 2014. Durable resistance: a key to sustainable management of pathogens and pests. Infection Genetics and Evolution, 27, 446-455. https://doi.org/10.1016/j.meegid.2014.01.011\%od.

Rodewald J., Trognitz B., 2013. Solanum resistance genes against Phytophthora infestans and their corresponding avirulence genes. Molecular Plant Pathology, 14 (7), 740-757. https://doi.org/10.1111/ mpp.12036.

Spoel S.H., Johnson J.S., Dong X., 2007. Regulation of tradeoffs between plant defenses against pathogens with different lifestyles. Proceedings of the National Academy of Sciences of the United States of America, 104 (47), 18842-18847. https://doi.org/10.1073/pnas.0708139104\%od.

Stall R.E., Jones J.B., Minsavage G.V., 2009. Durability of resistance in tomato and pepper to Xanthomonads causing bacterial spot. Annual Review of Phytopathology, 47, 265-284. https:// doi.org/10.1146/annurev-phyto-080508-081752\%od.

\section{Substances SDP}

Harm A., Kassemeyer H.H., Seibicke T., Regner F., 2011. Evaluation of chemical and natural resistance inducers against downy mildew (Plasmopara viticola) in grapevine. American Journal of Enology and Viticulture, 62 (2), 184-192. https://doi.org/10.5344/ajev.2011.09054\%od.

Lachhab N., Sanzani S.M., Adrian M., Chiltz A., Balacey S., Boselli M., Ippolito A., Poinssot B., 2014. Soybean and casein hydrolysates induce grapevine immune responses and resistance against Plasmopara viticola. Frontiers in Plant Science, 5, 10. https://doi.org/10.3389/fpls.2014.00716\%od.

Narusaka M., Minami T., Iwabuchi C., Hamasaki T., Takasaki S., Kawamura K., Narusaka Y., 2015. Yeast cell wall extract induces disease resistance against bacterial and fungal pathogens in Arabidopsis thaliana and Brassica crop. Plos One, 10 (1), 14. https://doi.org/10.1371/journal.pone.0115864\%od.

Nechwatal J., Zellner M., 2015. Potential suitability of various leaf treatment products as copper substitutes for the control of late blight (Phytophthora infestans) in organic potato farming. Potato Research, 58 (3), 261-276. https://doi.org/10.1007/s11540-015-9302-8\%od.

Perazzolli M., Roatti B., Bozza E., Pertot I., 2011. Trichoderma harzianum T39 induces resistance against downy mildew by priming for defense without costs for grapevine. Biological Control, 58 (1), 74-82. https://doi.org/10.1016/j.biocontrol.2011.04.006\%od. 
Pinto K.M.S., do Nascimento L.C., Gomes E.C.D., da Silva H.F., Miranda J.D., 2012. Efficiency of resistance elicitors in the management of grapevine downy mildew Plasmopara viticola: epidemiological, biochemical and economic aspects. European Journal of Plant Pathology, 134 (4), 745-754. https://doi.org/10.1007/s10658-012-0050-1\%od.

Roberts P.D., Momol M.T., Ritchie L., Olson S.M., Jones J.B., Balogh B., 2008. Evaluation of spray programs containing famoxadone plus cymoxanil, acibenzolar-S-methyl, and Bacillus subtilis compared to copper sprays for management of bacterial spot on tomato. Crop Protection, 27 (12), 1519-1526. https://doi.org/10.1016/j.cropro.2008.06.007\%od.

Thuerig B., Binder A., Boller T., Guyer U., Jimenez S., Rentsch C., Tamm L., 2006. An aqueous extract of the dry mycelium of Penicillium chrysogenum induces resistance in several crops under controlled and field conditions. European Journal of Plant Pathology, 114 (2), 185-197. https://doi.org/10.1007/ S10658-005-4512-6\%od.

Walters D.R., Ratsep J., Havis N.D., 2013. Controlling crop diseases using induced resistance: challenges for the future. Journal of Experimental Botany, 64 (5), 1263-1280. https://doi.org/10.1093/ jxb/erto26.

\section{Homéopathie et isothérapie}

Chalker-Scott L., 2013. The science behind biodynamic preparations: a literature review. Horttechnology, 23 (6), 814-819. http://horttech.ashspublications.org/content/23/6/814.full.

\section{Leviers agronomiques, systèmes de culture}

Andrivon D., Giorgetti C., Baranger A., Calonnec A., Cartolaro P., Faivre R., Guyader S., Lauri P.E., Lescourret F., Parisi L., Ney B., Tivoli B., Sache I., 2013. Defining and designing plant architectural ideotypes to control epidemics? European Journal of Plant Pathology (Special issue Epidemiology and Canopy Architecture), 135 (3), 611-617. https://doi.org/10.1007/s10658-012-0126-y.

Cabus A., Pellini M., Zanzotti R., Devigili L., Maines R., Giovannini O., Mattedi L., Mescalchin E., 2017. Efficacy of reduced copper dosages against Plasmopara viticola in organic agriculture. Crop Protection, 96, 103-108. https://doi.org/10.1016/j.cropro.2017.02.002\%od.

Cook R.J., 2000. Advances in plant health management in the twentieth century. Annual Review of Phytopathology, 38, 95-116. https://doi.org/10.1146/annurev.phyto.38.1.95.

Didelot F., Caffier V., Orain G., Lemarquand A., Parisi L., 2016. Sustainable management of scab control through the integration of apple resistant cultivars in a low-fungicide input system. Agriculture Ecosystems and Environment, 217, 41-48. https://doi.org/10.1016/j.agee.2015.10.023.

Gomez C., Brun L., Chauffour D., Le Vallee D.D., 2007. Effect of leaf litter management on scab development in an organic apple orchard. Agriculture Ecosystems and Environment, 118 (1-4), 249-255. https://doi.org/10.1016/j.agee.2006.05.025\%od.

Holb I.J., 2007. Effect of four non-chemical sanitation treatments on leaf infection by Venturia inaequalis in organic apple orchards. European Journal of Horticultural Science, 72 (2), 60-65. http:// www.pubhort.org/ejhs/2007/file_254544.pdf.

Holb I.J., 2009. Fungal disease management in environmentally friendly apple production: a review. In: Climate change, intercropping, pest control and beneficial microorganisms (Lichtfouse E., ed.), New York, Springer, 219-292. https://doi.org/10.1007/978-90-481-2716-0_10.

McGee D.C., 1995. Epidemiologic approach to disease management through seed technology. Annual Review of Phytopathology, 33, 445-466. https://www.annualreviews.org/doi/pdf/10.1146/annurev. py.33.090195.002305. 
Menesatti P., Antonucci F., Costa C., Mandala C., Battaglia V., La Torre A., 2013. Multivariate forecasting model to optimize management of grape downy mildew control. Vitis, 52 (3), 141-148.

Mundt C.C., 2002. Use of multiline cultivars and cultivar mixtures for disease management. Annual Review of Phytopathology, 40, 381-410. https://doi.org/10.1146/annurev.phyto.40.011402.113723.

Olle M., Tsahkna A., Tahtjarv T., Williams I.H., 2015. Plant protection for organically grown potatoes: a review. Biological Agriculture and Horticulture, 31 (3), 147-157. https://doi.org/10.1080/01448 765.2014.983546.

Pertot I., Caffi T., Rossi V., Mugnai L., Hoffmann C., Grando M.S., Gary C., Lafond D., Duso C., Thiery D., Mazzoni V., Anfora G., 2017. A critical review of plant protection tools for reducing pesticide use on grapevine and new perspectives for the implementation of IPM in viticulture. Crop Protection, 97, 70-84. https://doi.org/10.1016/j.cropro.2016.11.025.

Ratnadass A., Fernandes P., Avelino J., Habib R., 2012. Plant species diversity for sustainable management of crop pests and diseases in agroecosystems: a review. Agronomy for Sustainable Development, 32 (1), 273-303. https://doi.org/10.1007/s13593-011-0022-4.

Reuveni M., Zahavi T., Cohen Y., 2001. Controlling downy mildew (Plasmopara viticola) in field-grown grapevine with beta-aminobutyric acid (BABA). Phytoparasitica, 29 (2), 125-133. https://doi. org/10.1007/bfo2983956\%od.

Romanazzi G., Mancini V., Feliziani E., Servili A., Endeshaw S., Neri D., 2016. Impact of alternative fungicides on grape downy mildew control and vine growth and development. Plant Disease, 100 (4), 739-748. https://doi.org/10.1094/pdis-05-15-0564-re\%od.

Stuthman D.D., Leonard K.J., Miller-Garvin J., 2007. Breeding crops for durable resistance to disease. Advances in Agronomy, 95, 319-367.

Zahavi T., Reuveni M., Scheglov D., Lavee S., 2001. Effect of grapevine training systems on development of powdery mildew. European Journal of Plant Pathology, 107 (5), 495-501. https://doi. org/10.1023/a:1011289018599\%od.

\section{Acceptabilité/innovations}

Estevez B., Domon G., Lucas E., 2000. Le modèle ESR (efficacité-substitution-reconceptualisation), un modèle d'analyse pour l'évaluation de l'agriculture durable applicable à l'évaluation de la stratégie phytosanitaire au Québec. Courrier de l'environnement de l'INRA, 41, 97-104. http://www7. inra.fr/lecourrier/assets/C41Domon.pdf.

Nuijten E., Messmer M.M., van Bueren, E.T.L., 2017. Concepts and strategies of organic plant breeding in light of novel breeding techniques. Sustainability, 9 (1), 19. https://doi.org/10.3390/su9010018.

Padel S., 2001. Conversion to organic farming: a typical example of the diffusion of an innovation? Sociologia Ruralis, 41 (1), 40-61. https://doi.org/10.1111/1467-9523.00169.

Vanloqueren G., Baret P.V., 2008. Why are ecological, low-input, multi-resistant wheat cultivars slow to develop commercially? A Belgian agricultural 'lock-in' case study. Ecological Economics, 66 (2-3), 436-446. https://doi.org/10.1016/j.ecolecon.2007.10.007.

\section{Documents techniques}

Berthier C., Chovelon M., 2013. Argumentaire pour le maintien d'une dose de cuivre efficace en agriculture - dossier technique, 28 p. http://www.itab.asso.fr/downloads/com-intrants/dossiercuivre-en-ab-dec2013.pdf. 
Bertrand C., 2016. Introduction au bio-contrôle : constats, prévisions et exigences réglementaires ; le cas particulier des extraits naturels. Journées techniques PNPP, Substances naturelles en production végétale, Paris, France, 2016/04/26-27, 3 p. https://shareslide.org/journees-techniques-pnpp.

Inra-GRAB (Groupe de recherche en agriculture biologique), 2016. Guide des sensibilités variétales aux bio-agresseurs. L'arboriculture fruitière, 698, supplément, 16 p. https://www.grab.fr/ sensibilites-des-fruitiers-suivez-le-guide- 6728 .

ITAB (Institut technique de l'agriculture biologique), 2017. Guide des produits de protection des cultures utilisables en France en Agriculture biologique. http://www.itab.asso.fr/downloads/comintrants/2017-guide_intrants.pdf.

Jonis M., 2009. Usage du cuivre en agriculture biologique - résultats d'enquêtes. In : Usage du cuivre pour la production de vin, fruits et légumes biologiques, ITAB, 3-25. http://www.itab.asso.fr/downloads/viti/rapport-final-cu-vitiog.pdf.

Köhl J., 2007. Replacement of copper fungicides in organic production of grapevine and apple in Europe (REPCO). Final Activity Report, 70 p. http://cordis.europa.eu/docs/ publications/1248/124857061-6_en.pdf.

Rousseau J., Chanfreau S., 2013. Les cépages résistants aux maladies cryptogamiques. Panorama européen, Groupe Institut coopératif du vin, 228.

Schmitt A., 2016. CO-FREE (Innovative strategies for copper-free low input and organic farming systems). Final Report Summary, 32 p. http://cordis.europa.eu/result/rcn/192500_en.html.

Zavagli F., Verpont F., Giraud M., Favareille J., 2016. Réduction d'emploi des produits phytosanitaires. Couvrir les pommiers avec une bâche anti-pluie. Infos Ctifl, 322, 48-54.

\section{Sites}

Agence nationale de sécurité sanitaire de l'alimentation (Anses). E-Phy : Le catalogue des produits phytopharmaceutiques et de leurs usages, des matières fertilisantes et des supports de culture autorisés en France. https://ephy.anses.fr.

Observatoire national du déploiement des cépages résistants (OsCar) : http://observatoire-cepagesresistants.fr.

Programme de recherche européen Co-Free : http://www.co-free.eu/.

Réseau mixte technologique Elicitra : https://elicitra.org.

Union européenne, 2016. Pesticides database : http://ec.europa.eu/food/plant/pesticides/ eu-pesticides-database/public/?event=homepage $\&$ language $=F R$. 


\section{Annexe. Le corpus bibliographique analysé}

PAR définition de l'EXercice, L'ESCo eSt fondée sur l'analyse critique des publications scientifiques internationales, référencées dans les bases de données mondiales. Elle se distingue donc des exercices «à dire d'experts », fondés sur les connaissances préalables desdits experts. Dans l'ESCo, l'origine des connaissances mobilisées doit être explicitée et vérifiable, et une question ne peut être traitée que si des publications sont disponibles sur le sujet.

L'ESCo fournit donc au collectif d'experts un corpus de références extraites du Web of Science (WoS). Produite par Thomson Scientific, c'est « la » base de référence des milieux scientifiques du monde entier; elle couvre toutes les disciplines en sciences biophysiques et sciences sociales. Les experts sélectionnent dans ce corpus initial les références qu'ils jugent pertinentes. Ils le complètent avec des publications issues de leur propre base bibliographique, et avec les documents plus techniques ou institutionnels qu'ils jugent utiles pour traiter la question posée.

En fin d'exercice, le corpus des références citées dans les contributions des différents experts est analysé. Pour cette ESCo, il comporte 992 références.

\section{Répartition temporelle des références citées}

Les années de publication des références citées s'étendent de 1951 à 2018 (figure A1). Les experts ont cité majoritairement des documents publiés à partir de 2000, qui représentent plus de $93 \%$ des références. Cela est cohérent avec le choix fait, en début d'ESCo, de retenir la période de publication 2000-2016 pour l'interrogation de la base WoS. 
Figure A1. Répartition temporelle des 992 références citées dans le rapport d'expertise (dont 878 articles référencés dans le WoS).



\section{Types de références citées}

Les experts se sont référés principalement à des documents scientifiques, qui représentent $91 \%$ des références citées (figure A2). Il s'agit, à plus de 89\%, d'articles publiés dans des revues à comité de lecture. Les experts ont également utilisé des documents techniques (6\%), ainsi que quatre textes réglementaires et trois bases de données de référence en ligne concernant les produits phytosanitaires autorisés.

Figure A2. Types de documents cités dans le rapport d'expertise.

Documents scientifiques

Documents techniques
Communications à des congrès, séminaires

Réglementation - Database online 


\section{Pays et institutions des auteurs des publications}

L'analyse porte sur les 878 articles référencés dans le WoS. Les auteurs des publications sont majoritairement originaires de pays européens (646 publications), d'Amérique du Nord (225 publications, dont 188 pour les États-Unis), d’Asie (148 publications, dont 69 pour la Chine) et d'Amérique du Sud ( 90 publications, dont 40 pour le Brésil). Au sein de l'Europe, les auteurs affiliés à une adresse française sont prépondérants (149 articles), suivis d'auteurs italiens, hollandais, allemands, anglais et suisses (de 74 à 56 publications pour chacun de ces pays).

Au niveau institutionnel, les organismes européens sont très bien représentés, avec l'Inra (128 publications), l'université de Wageningen (51), le CNRS (27), le BBSRC John Innes Center (20), l'université de Saclay (16)...

\section{Revues de publications}

Le corpus comprend 878 références correspondant à des articles publiés dans des revues avec comité de lecture (245 revues) et dans des revues techniques sans comité de lecture (20 revues telles que Phytoma, Infos Ctifl...). Parmi les revues à comité de lecture les plus représentées (tableau $\mathrm{A} 1$ ), la première est Acta Horticulturae, qui publie des communications à des congrès organisés par l'ISHS (International Society for Horticultural Science). Les autres sont des revues généralistes en phytopathologie (Phytopathology, European Journal of Plant Pathology, Plant Disease, Plant Pathology...) ou plus spécialisées, par exemple sur la protection des cultures (Biological Control, Crop Protection, Pest Management Science...) ou sur une espèce végétale (Potato Research, American Journal of Potato Research).

\section{Tableau A1. Principales revues de publication des articles parus dans des revues à comité de lecture.}

\begin{tabular}{lc|lc}
\multicolumn{1}{c|}{ Revue } & $\begin{array}{r}\text { Nombre } \\
\text { d'articles }\end{array}$ & \multicolumn{1}{|c}{ Revue } & $\begin{array}{c}\text { Nombre } \\
\text { d'articles }\end{array}$ \\
\hline Acta Horticulturae & 68 & Molecular Plant-Microbe Interactions & 14 \\
Phytopathology & 47 & Euphytica & 14 \\
European Journal of Plant Pathology & 37 & Annual Review of Phytopathology & 13 \\
Plant Disease & 32 & Plos One & 12 \\
Plant Pathology & 29 & Molecular Plant Pathology & 12 \\
Biological Control & 26 & Potato Research & 11 \\
Crop Protection & 25 & American Journal of Potato Research & 11 \\
Theoretical and Applied Genetics & 21 & Pest Management Science & 10 \\
Molecular Breeding & 15 & New Phytologist & 10 \\
\hline
\end{tabular}




\section{Répartition des références selon les thématiques}

L'analyse porte sur les 992 références citées dans les différents chapitres de l'ESCo. Trois chapitres sont majoritairement représentés en termes de références : Résistances variétales, Agents microbiologiques de biocontrôle, Stimulateurs de défense des plantes (figure $A_{3}$ ).

Figure A3. Nombre de références citées par les différents chapitres de l'expertise.

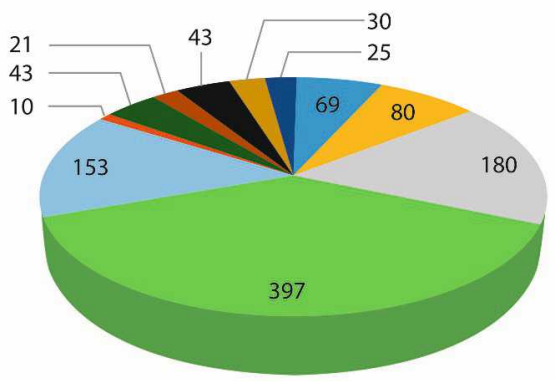

- Contexte-réglementation

- Biocides

Agents de biocontrôle

- Résistances variétales

- SDP

n Isothérapie...

- Prophylaxie

- Protection physique

- Conduite des couverts

- Systèmes de culture

- Innovations 


\section{Auteurs et éditeurs}

de l'expertise

\section{Experts scientifiques}

\section{Responsable scientifique}

\section{Didier ANDRIVON}

Inra, département Santé des plantes et environnement, Rennes, UMR1349 Institut de génétique, environnement et protection des plantes (IGEPP). Directeur de recherche en biologie des populations, épidémiologie des maladies des plantes et protection intégrée de la pomme de terre ; membre du Comité interne en agriculture biologique (CIAB) de l'Inra. Coordination scientifique générale de l'étude et rédaction des parties du rapport sur le contexte, la réglementation, l'innovation.

\section{Contributeurs}

\section{MARC BARDIN}

Inra, département Santé des plantes et environnement, Avignon, URo407 Pathologie végétale. Pathologiste et microbiologiste, spécialisé dans la lutte microbiologique contre les champignons pathogènes des cultures. Corédacteur (avec P. Nicot) de la section du rapport consacrée aux agents de lutte biologique.

\section{CÉdRIC BertRAnd}

Université de Perpignan, USR3278 Centre de recherches insulaires et observatoire de l'environnement (CRIOBE). Président du Groupe francophone d'étude des pesticides organiques d'origine naturelle, président de l'Académie du biocontrôle et de la protection biologique intégrée, directeur scientifique de la société AkiNaO. Phytochimiste, expert en métabolomique environnementale. Rédacteur de la section du rapport consacrée aux substances naturelles biocides.

\section{LAURENT BRUN}

Inra, département Santé des plantes et environnement, PACA, UE0695 Unité expérimentale Recherches intégrées-Gotheron. Agronomie et pathologie des arbres fruitiers ; un des initiateurs de l'essai système BioREco. Rédacteur ou corédacteur des sections consacrées aux arbres fruitiers en matière d'emploi du cuivre, de lutte physique et agronomique, et de systèmes intégrés de lutte.

\section{XAVIER DAIRE}

Inra, département Santé des plantes et environnement, Dijon, UMR1347 Agroécologie. Coanimateur scientifique du RMT Elicitra. Spécialiste de l'étude des SDP en conditions pratiques d'utilisation, et de leurs modes d'action. Phytopathologie, induction de résistance par les éliciteurs chez la vigne. Corédacteur (avec P. Reignault) de la section consacrée aux SDP.

\section{FrÉDÉRIC FABRE}

Inra, département Santé des plantes et environnement, Bordeaux, UMR1065 Santé et agroécologie du vignoble (SAVE). Epidémiologiste et modélisateur, spécialisé dans la gestion durable des résistances végétales. Corédacteur (avec). Montarry) des parties du rapport dédiées aux résistances végétales et à leur utilisation. 


\section{Christian Gary}

Inra, département Environnement et agronomie, Montpellier, UMR1230 Fonctionnement et conduite des Systèmes de culture tropicaux et méditerranéens (SYSTEM). Agronomie, conception de systèmes de culture peu dépendants des pesticides. Corédacteur des sections du rapport consacrées aux méthodes agronomiques de lutte et aux essais d'intégration systémique.

Josselin Montarry

Inra, département Santé des plantes et environnement, Rennes, UMR1349 Institut de génétique, environnement et protection des plantes (IGEPP). Biologiste et généticien des populations ; étude de l'adaptation des agents pathogènes aux résistances végétales. Corédacteur (avec F. Fabre) des parties du rapport dédiées aux résistances végétales et à leur utilisation.

\section{PhiLIPPE NicOT}

Inra, département Santé des plantes et environnement, Avignon, URo407 Pathologie végétale ; président de l'OILB-SROP (Organisation internationale de lutte biologique et intégrée). Protection intégrée et lutte biologique contre les maladies des cultures maraîchères et fruitières. Corédacteur (avec M. Bardin) de la section du rapport consacrée aux agents de lutte biologique.

\section{Philippe Reignault}

Université du Littoral-Côte-d'Opale, Calais, Unité de chimie environnementale et interactions sur le vivant (UCEIV). Professeur de pathologie végétale, spécialiste de l'étude des interactions plantespathogène et des résistances induites. Corédacteur (avec X. Daire) de la section consacrée aux SDP.

\section{LUCIUS TAMM}

FiBL (Forschungsinstitut für biologischen Landbau, Institut de recherche de l'agriculture biologique), Frick (Suisse). Chef du département Sciences des plantes et directeur adjoint du FiBL. Spécialiste des systèmes de protection intégrée en $\mathrm{AB}$. Contributeur à la section du rapport sur les études systèmes de protection intégrée.

\section{Conduite du projet}

ISABELLE SAVINI

Inra, Délégation à l'expertise, à la prospective et aux études (DEPE), Paris ; membre du CIAB. Suivi du projet, rédaction et coordination éditoriale.

KIM GIRARD

Inra, Délégation à l'expertise, à la prospective et aux études (DEPE), Paris. Logistique.

\section{Documentation}

\section{VÉRONIQUE DECOGNET}

Inra, département Santé des plantes et environnement, Avignon, URo407 Pathologie végétale. Construction et gestion des corpus documentaires, analyse bibliographique.

AnNe-Sophie Grenier

Inra, département Santé des plantes et environnement, Rennes, UMR1349 IGEPP. Construction et gestion des corpus documentaires, analyse bibliographique. 

Édition : Juliette Blanchet Mise en page : Graph'm Impression : IsiPrint 
Le cuivre est utilisé pour contrôler diverses maladies fongiques ou bactériennes, principalement sur vigne, en productions fruitières et en cultures légumières. II constitue la seule substance active à effet fongicide fort et gamme d'action large homologuée en agriculture biologique. Or la mise en évidence d'effets environnementaux négatifs du cuivre, notamment sur les organismes du sol, a conduit à des restrictions réglementaires d'usage (plafonnement des doses autorisées), et même à son interdiction comme pesticide dans certains pays d'Europe du Nord.

De ces restrictions croissantes à l'emploi du cuivre, qui posent des difficultés notamment aux producteurs qui ne peuvent recourir à des fongicides de synthèse, découle une demande récurrente d'« alternatives ». De nombreux travaux expérimentaux ont ainsi été menés pour identifier et tester d'autres techniques: l'emploi de variétés résistantes aux maladies, l'application de substances d'origine naturelle à effet biocide et/ou stimulant les défenses naturelles des plantes, I'utilisation d'agents microbiologiques de lutte, l'adoption de conduites des peuplements cultivés à visée prophylactique, l'installation de protections physiques. Les résultats restent toutefois dispersés et ces méthodes de lutte peu mises en œuvre sur le terrain.

Issu d'une expertise scientifique collective, cet ouvrage est une synthèse pluridisciplinaire et critique des connaissances disponibles sur le sujet. II présente et étudie les différentes techniques potentiellement efficaces contre les agents pathogènes contrôlés par les traitements cupriques, et la nécessité de les combiner dans des systèmes intégrés de protection des cultures.

Didier Andrivon est directeur de recherche à l'Institut de génétique, environnement et protection des plantes (IGEPP, Rennes); il est membre du Comité interne en agriculture biologique (CIAB) de l'Inra.

Isabelle Savini, ingénieure, travaille à la Délégation à l'expertise, à la prospective et aux études (DEPE, Paris) ; elle est également membre du CIAB. 